\title{
EFEITO DOS TRATAMENTOS DESSENSIBILIZANTES NA EVOLUÇÃO DE LESÕES EROSIVAS EM DENTINA
}

Tese apresentada à Faculdade de Odontologia de Ribeirão Preto da Universidade de São Paulo, para obtenção do título de Doutora em Ciências - Programa: Odontologia Restauradora - Área de concentração: Odontologia Restauradora - Opção: Dentística

Orientadora: Profa. Dra. Regina Guenka Palma Dibb 
Autorizo a reprodução e divulgação total ou parcial deste trabalho, por qualquer meio convencional ou eletrônico, para fins de estudo e pesquisa, desde que seja citada a fonte.

Ficha catalográfica preparada pela Seção de Tratamento da Informação do Serviço de Biblioteca

Sanches, Júlia Olien.

Efeito dos tratamentos dessensibilizantes na evolução de lesões erosivas em dentina. Ribeirão Preto, 2017.

104 p.: il.

Tese (Doutorado) - Universidade de São Paulo, 2017.

Orientadora: Profa. Dra. Regina Guenka Palma-Dibb.

1. Dessensibilizantes dentinários. 2. Erosão dentinária. 3. Hipersensibilidade dentinária. 
SANCHES, J. O. Efeito dos tratamentos dessensibilizantes na evolução de lesões erosivas

em dentina. Tese apresentada à Faculdade de Odontologia de Ribeirão Preto da Universidade de São Paulo para obtenção do título de Doutora em Ciências.

BANCA EXAMINADORA

Data da Defesa:

$\operatorname{Prof}(\mathrm{a}) . \operatorname{Dr}(\mathrm{a})$.

Instituição:

Julgamento:

Assinatura:

$\operatorname{Prof}(\mathrm{a}) . \operatorname{Dr}(\mathrm{a})$.

Instituição:

Julgamento:

Assinatura:

Prof(a). Dr(a).

Instituição:

Julgamento:

Assinatura:

Prof(a). Dr(a).

Instituição:

Julgamento:

Assinatura:

Prof(a). Dr(a).

Instituição:

Julgamento:

Assinatura: 

Aos meus pais, Valentim e Lili, pela dedicação na minha educação, pelo incentivo constante e pelo esforço em me proporcionar sempre o melhor.

Sem vocês essa conquista não seria possível!

Aos meus irmãos, Gabriel e Vítor, pelo companheirismo, carinho

e pelos grandes momentos juntos.

Ao meu bisavô, Vô Eurípedes, pelo exemplo de bondade e ternura.

Ás minhas avós, Vó Sirley e Vó Lourdes, que sempre partilharam das alegrias comigo, me incentivando a alcançar meus objetivos e torcendo pelas minhas conquistas.

À memória de minha bisa, Vó Júlia, e meus avôs, Vô Wilson e Vô Vicente. Não imaginei estar sem vocês nesse momento, que falta vocês nos fazem!

Às minhas afilhadas, Eleonora e Valentina, pelos momentos de alegria, prazer

e por alegrarem nossa família.

Ao meu noivo, Luciano, por sempre estar ao meu lado, pela compreensão, dedicação e companheirismo em todos os momentos.

A todos meus familiares, tios e tias, primos e primas, que sempre me desejaram sucesso.

Obrigada por tudo! 



\section{AGRADECIMENTOS ESPECIAIS}

A Deus, por iluminar meu caminho, dando-me serenidade e força para superar as dificuldades de cada dia.

À minha orientadora, Prof. ${ }^{a}$ Dr ${ }^{a}$ Regina Guenka Palma Dibb, exemplo de trabalho, dedicação, inteligência e honestidade. Agradeço por ter aceitado essa orientação me recebendo de braços abertos e também pela oportunidade enorme de conhecimento. Obrigada por tudo!

À minha amiga e colaboradora, Dra. Juliana Jendiroba Faraoni, pela contribuição deste trabalho e pela disponibilidade em todos os momentos. Agradeço a dedicação e, em especial, a grande amizade.

Às minhas amigas da pós-graduação, Carolina Rodrigues, Flávia Cabral, Ana Bárbara Loiola, Laís Matos e da odontopediatria, Marília Lucisano e Lídia Hidalgo. Obrigada pela amizade e pelas palavras motivadoras, pelos momentos que passamos juntas e pela agradável convivência durante o curso.

Às minhas amigas do laboratório, em especial, Renata Scatolin, Késsia Mesquita, Taísa Lepri, e Juliana Derceli. Obrigada pelos ótimos momentos que compartilhamos dentro e fora da faculdade, sempre acompanhados de muitas risadas. E aos amigos César Lepri e Walter Raucci, por me ajudarem sempre que precisei, meu imenso reconhecimento e carinho.

Aos meus amigos da graduação, em especial à minha dupla, Diego Girotto, parceiro de todas as horas. Às meninas Silvia Moreno, Hortência Marçal, Cristina Dupim e Chaiene Zago. Saudade de vocês!

Às minhas amigas de infância, Denise, Camila, Roberta, Deborah e Pamela, que mesmo de longe sempre me deram apoio e não me faltaram nos momentos mais difíceis.

"Não há solidão mais triste do que a do homem sem amizades. A falta de amigos faz com que o mundo pareça um deserto." 

À Faculdade de Odontologia de Ribeirão Preto-USP, representada pela Digníssima Diretora Prof ${ }^{a}$ Dr $^{a}$ Léa Assed Bezerra da Silva e pelo Vice-Diretor Prof. Dr. Arthur Belém Novaes Júnior.

À Comissão de Pós-Graduação da Faculdade de Odontologia de Ribeirão Preto-USP, na pessoa do Prof. Dr. Manuel Damião de Sousa Neto.

À Coordenação do Programa de Pós-Graduação em Odontologia Restauradora da Faculdade de Odontologia de Ribeirão Preto-USP, na pessoa do Prof. Dr. Manoel Damião de Sousa Neto.

Ao Chefe do Departamento de Odontologia Restauradora da Faculdade de Odontologia de Ribeirão Preto-USP, na pessoa do Prof. Dr. Marcelo Oliveira Mazzetto.

À Fundação de Amparo à Pesquisa do Estado de São Paulo (FAPESP, processo no 2013/02450-3) e à Coordenação de Aperfeiçoamento de Pessoal de Nível Superior (CAPES, processo ${ }^{\circ} 140928 / 2013-8$ ) pelo apoio e financiamento do trabalho.

Aos professores e aos funcionários do Departamento de Odontologia Restauradora da Faculdade de Odontologia de Ribeirão Preto-USP pelo conhecimento, atenção e disposição.

Em especial, ao Carlos, secretário do Curso de Pós-Graduação em Odontologia Restauradora da Faculdade de Odontologia de Ribeirão Preto da Universidade de São PauloUSP, por ser sempre tão prestativo, pela paciência e amizade.

Aos funcionários da Seção de Pós-Graduação da Faculdade de Odontologia de Ribeirão Preto-USP, pelo apoio constante e dedicação aos alunos. 

Às funcionárias da Clínica de Pós-Graduação da Faculdade de Odontologia de Ribeirão Preto-USP, Daniela Martins, Sueli Cooke e Joana Leandro e à técnica Patrícia Marchi, do Laboratório de Pesquisa em Dentística pela convivência, paciência, disponibilidade e amizade.

Aos meus professores da Faculdade de Odontologia de Araraquara-UNESP, pela construção do meu conhecimento e amizade, em especial, Drs. Lourdes Aparecida Martins dos Santos Pinto, Rita de Cássia Loiola Cordeiro , Rosemary Adriana Chiérici Marcantonio, Aylton Valsecki Júnior, Oscar Fernando Muñoz Chávez, Luiz Antônio Borelli Barros, Patrícia Petromilli Garcia, Camilla Pinelli, Cinara Maria Camparis, Daniela Aparecida Godoi Gonçalves, Ary dos Santos Pinto, Fábio Cesar Braga de Abreu e Lima, Cyneu Aguiar Pansani, Andréa Gonçalves, Marcelo Gonçalves, Ana Carolina Pero Vizoto, Ticiana Sidorenko de Oliveira Capote, Paulo Sérgio Cerri, Estela Sasso Cerri, Milton Carlos Kuga, Gisele Faria, Mario Tanomaru Filho e Juliane Maria Guerreiro Tanomaru.

Aos meus primos e primas, tios e tias e afilhadas, adoro vocês!

À minha segunda família, Maria Ângela, Mário, Vó Neusa (in memorian), Rodrigo e Mateus, pelos momentos agradáveis que passamos juntos.

Às minhas amigas, Gabriela, Ana Maria, Carolina, Aninha, Gi e Cássia, saudade de vocês!

A todos que, de alguma forma, contribuíram para a realização deste trabalho, seja pela ajuda constante ou por uma palavra de amizade. 

SANCHES, J. O. Efeito dos tratamentos dessensibilizantes na evolução de lesões erosivas em dentina. 2017. 104 p. Tese (Doutorado). Faculdade de Odontologia de Ribeirão Preto, Universidade de São Paulo, 2017.

\section{RESUMO}

O estudo in vitro avaliou os agentes dessensibilizantes sobre a evolução do processo erosivo em dentina radicular e o estudo in vivo avaliou o tratamento dessensibilizante na progressão das lesões erosivas e na hipersensibilidade dentinária (HD). 90 espécimes foram imersos em ácido cítrico 6\% (erosão inicial) e observados através da Microscopia Confocal a Laser (MCL) (avaliação inicial). Os espécimes tiveram metade de sua superfície isolada (área controle) e então divididos aleatoriamente em 6 grupos ( $n=15)$ : G1(sem tratamento); G2(Oxagel); G3(Desensibilize Nano P); G4(MI Paste); G5(pasta experimental); G6(laser de diodo, 970nm0,7W/10Hz, 70mJ). Logo após foram submetidos à ciclagem erosiva (ácido cítrico 0,3\%, 9 dias) e aplicação dos tratamentos (a cada 3 dias). As avaliações do perfil, rugosidade, degrau, perda de volume e morfologia da área tratada foram realizadas pelo MCL em diferentes tempos da ciclagem. Após exposição da área controle, a análise final foi realizada no $9^{\circ}$ dia. O teste de permeabilidade foi realizado ao final do experimento (microscopia óptica). Para análise superficial, os tratamentos foram comparados por ANOVA e o fator tempo foi analisado internamente pelo teste de Friedman $(\alpha=5 \%)$. Para a análise morfológica e da permeabilidade dentinária realizou-se ANOVA e o teste de Tukey $(\alpha=5 \%)$. Para o estudo clínico, 20 pacientes foram selecionados com lesões cervicais erodidas em dois diferentes quadrantes sendo estas divididas aleatoriamente em dois grupos experimentais: grupo controle (agente placebo) e grupo tratado (Desensibilize Nano P). Foram realizadas 4 sessões de tratamento (intervalo de 7 dias) e 3 sessões de acompanhamento pós-tratamento (1, 3 e 6 meses). Para avaliar a progressão das lesões, em cada sessão, foi realizada a moldagem e réplicas, feitas para obtenção de imagens e análise no MCL. A avaliação da HD foi realizada por meio da aplicação de jato de ar na lesão e pela escala de estimativa numérica. Realizou-se ANOVA, os testes de Friedman e KruskallWallis e Tukey $(\alpha=5 \%)$. Para análise da HD, os dados foram submetidos ao teste nãoparamétrico Wilcoxon $(\alpha=5 \%)$. Avaliação in vitro do desgaste: observou-se diferença significante para todas as variáveis de resposta; G3 apresentou os menores valores para degrau de desgaste e volume perdido. Análise morfológica: G5 apresentou o menor número e área de 

túbulos expostos durante toda ciclagem. Permeabilidade dentinária: G3 apresentou os maiores valores e G5 os menores; os demais grupos foram semelhantes entre si e ao G3 e G5. Avaliação clínica do desgaste: não houve diferença significante entre os grupos. Com relação ao tamanho das lesões também não houve diferença, porém, comparando os valores iniciais e finais, houve um aumento similar em ambos os grupos. HD: não houve diferença significante entre os grupos somente entre inicial e final. In vitro, o Desensililize Nano $P$ foi capaz de controlar o processo erosivo na dentina radicular e a pasta experimental demonstrou resultados positivos na oclusão dos túbulos dentinários e na permeabilidade dentinária. Clinicamente o Desensililize Nano P não foi capaz de controlar a progressão das lesões erosivas e demonstrou resultados positivos para o tratamento da HD.

Palavras-chave: Dessensibilizantes dentinários. Erosão dentinária. Hipersensibilidade dentinária. 

SANCHES, J. O. Effect of desensitizing treatments in the evolution of erosive lesions on dentin. 2017. 104 p. Tese (Doutorado). Faculdade de Odontologia de Ribeirão Preto, Universidade de São Paulo, 2017.

\section{ABSTRACT}

The in vitro study evaluated the desensitizing agents in the evolution of the erosive process on root dentin and the in vivo study evaluated the desensitizing treatment in the progression of the erosive lesions and in the dentin hypersensitivity (DH). 90 specimens of root dentin were immersed in 6\% citric acid (initial erosion) and they were observed through the Confocal Laser Scanning Microscopy (CLM) (initial evaluation). The half their buccal surface was covered (control area). The specimens were randomly divided into 6 groups ( $n=15)$ : G1(no treatment); G2(Oxagel); G3(Desensibilize Nano P); G4(MI Paste); G5(experimental paste); G6(970-nm diode laser- $0.7 \mathrm{~W} / 10 \mathrm{~Hz}, 70 \mathrm{~mJ})$. After that, they were cycled through erosive challenge $(0.3 \%$ citric acid, 9-days). The treatments were applied every 3 days. The evaluations of the wear profile, roughness, step and the volume loss of treated area were carried out by the CLM at different times of the erosive challenge. After control area exposure, the final analysis was performed on the $9^{\text {th }}$ day. The permeability test was performed at the end of the experiment (optical microscopy). For superficial analysis, the treatments were compared by ANOVA and the time factor was analyzed by the Friedman and Tukey's Tests $(\alpha=5 \%)$. For the morphological and dentin permeability analysis, ANOVA and Tukey's Test $(\alpha=5 \%)$ were performed. For the clinical study, 20 patients were selected with erosive cervical lesions in two different quadrants and they were randomly divided into two groups: control group (placebo agent) and treated group (Desensibilize Nano P). Four treatment sessions (7 days interval) and 3 post-treatment follow-up sessions (1, 3 and 6 months) were performed. For the progression analysis of the lesions, replicas were obtained by molding them at each session and evaluated by the MCL. The DH evaluation was performed through the application of air jet in the lesion and by the numerical rating scale. The analysis of variance, the Friedman, Kruskall-Wallis and Tukey's Tests was performed $(\alpha=5 \%)$. For DH analysis, data were submitted to the non-parametric Wilcoxon's Test ( $\alpha=5 \%$ ). In vitro evaluation of the wear: significant difference was observed in all response variables; G3 showed the lowest values for step and volume loss. Morphological analysis: G5 showed the lowest number and area of exposed tubules during the cycling. Dentin permeability: G3 showed the highest values and G5 exhibited the lowest values; the other groups were similar to each other and to G3 and G5. Clinical evaluation of the wear: there was 

no significant difference between the groups. Regarding lesion dimension, there was no difference, but comparing the initial and final values, there was a similar increase in both groups. DH: there was no significant difference between the groups, only between the initial and final. In vitro, Desensililize Nano $\mathrm{P}$ was able to control the erosive process and the experimental paste showed positive results on dentin tubule occlusion and dentin permeability. Clinically, Desensililize Nano P was not able to control the progression of erosive lesions and demonstrated positive results for the treatment of $\mathrm{DH}$.

Keywords: Dentin desensitizing. Dentin Erosion. Dentin Hypersensitivity. 

INTRODUÇÃO

OBJETIVO

METODOLOGIA 33

Estudo in vitro. 33

Estudo in vivo

RESULTADOS 59

Estudo in vitro. 59

Estudo in vivo

DISCUSSÃO

CONCLUSÃO

REFERÊNCIAS 95

ANEXO 1 .103 

O aumento na expectativa de vida associado a medidas preventivas reduziu a perda de elementos dentários por cárie e doenças periodontais e concomitantemente vem ocorrendo uma maior incidência de outros problemas na cavidade bucal, como por exemplo, o desgaste dentário e hipersensibilidade dentinária (CHERMONT et al., 2015), se tornando cada vez mais comum na prática clínica. As lesões cervicais não cariosas são caracterizadas pela perda irreversível da estrutura dental na junção cemento-esmalte (JCE) através de processos de desgaste não relacionados à ação bacteriana (NGUYEN et al., 2008). Diferentes fatores etiológicos estão associados a estas lesões incluindo a abrasão (desgaste mecânico causado pela escovação/dentifrícios), abfração (forças biomecânicas de flexão) e/ou erosão (degradação química) (GRIPPO; SIMRING; COLEMAN, 2012; FAHL, 2015).

A erosão dental pode ser definida como a perda de estrutura dentária causada pela dissolução química resultante da ação de ácidos não bacterianos (MEDEIROS et al., 2014) que podem ser de origem intrínseca ou extrínseca, como por exemplo, ácido gástrico ou dietas ácidas (WOOD et al., 2008). A alta prevalência desse processo está intimamente relacionada ao grande consumo de comidas e bebidas ácidas e ao aumento nos casos de doenças crônicas como refluxo gastroesofágico e distúrbios alimentares (CHI et al., 2010; SCHLUETER; JAEGGI; LUSSI, 2012, MOEZIZADEH; ALIMI, 2014).

Dependendo da gravidade das lesões erosivas, essas podem promover alterações tanto no esmalte quanto na dentina coronária e radicular, porém a interação entre os agentes erosivos e cada um deles é diferente. A desmineralização da dentina ocorre mais rapidamente do que no esmalte uma vez que possui um menor teor mineral (DE-MELO et al., 2011; POGGIO et al., 2013) e pH crítico para dissolução de 6,7 contra 5,5 do esmalte (PONDURI; MACDONALD; ADDY, 2005). Nesse caso, a erosão é caracterizada por uma perda mineral centrípeta a partir 
das áreas peritubulares, seguida por uma desmineralização intertubular, resultando na remoção da camada de esfregaço e exposição dos túbulos dentinários (SOARES et al., 2012).

Considerando a natureza irreversível da perda estrutural causada pela erosão, medidas preventivas que visam minimizar a desmineralização ácida são extremamente importantes e devem incluir: aconselhamentos sobre a dieta, orientações sobre possíveis hábitos deletérios durante a escovação (abrasão), uso de fluoretos, estimulação do fluxo salivar e uso de medicamentos com efeito de tamponamento (STEINER-OLIVEIRA et al., 2010). A necessidade de intervenção nos pacientes que apresentam lesões erosivas em dentina é ainda mais importante visto que a sintomatologia dolorosa está presente devido à exposição dos túbulos dentinários (LOPES; ARANHA, 2013). No entanto, o controle dos fatores etiológicos da erosão é altamente dependente da cooperação dos pacientes, o que dificulta o tratamento (DE-MELO et al., 2011).

A hipersensibilidade dentinária é considerada uma consequência direta da erosão (MOEZIZADEH; ALIMI, 2014) e pode ser definida como uma dor aguda temporária, quando há dentina exposta, em resposta a estímulos térmico, tátil, osmótico ou químico (PORTO; ANDRADE; MONTES, 2009). O processo erosivo dissolve a camada de esfregaço e expõe os túbulos dentinários à cavidade oral, resultando em agravamento de sintomas dolorosos (MOEZIZADEH; ALIMI, 2014). Normalmente a hipersensibilidade dentinária causa desconforto diário ao paciente afetando seus hábitos alimentares e mesmo a higiene bucal devido à alta hiperestesia (SHIAU, 2012) tornando-se um problema crônico mais doloroso e com menor chance de sucesso no tratamento comparado às lesões cariosas e doenças periodontais (GOPINATH et al., 2015). Os dentes mais acometidos são os pré-molares e os sintomas estão intimamente relacionados com a recessão gengival (CHRYSANTHAKOPOULOS, 2011; YE; FENG; LI, 2012), ou seja, exposição da dentina radicular e/ou cemento. Uma vez expostos ao meio bucal, esses tecidos estão mais suscetíveis 
à erosão causando exposição e ampliação da embocadura dos túbulos dentinários (KUROIWA et al., 1994; SAURO; WATSON; THOMPSON, 2010). Segundo a teoria hidrodinâmica proposta por Brännström (1986), a sensação dolorosa é resultado da estimulação da dentina exposta através do movimento rápido do fluido para dentro ou para fora dos túbulos dentinários. O deslocamento do fluido no interior dos túbulos determina uma alteração na pressão intrapulpar que estimula as terminações nervosas localizadas na interface dentina-polpa e, assim, resulta na geração de dor (BRÄNNSTRÖM, 1986).

Assim, dentre as possíveis intervenções, o tratamento restaurador pode ser eleito a fim de proteger a dentina exposta e produtos dessensibilizantes podem ser indicados para prevenção e tratamento da sensibilidade (KAMOZAKI et al., 2015). Geralmente o tratamento restaurador é indicado em situações onde as lesões são muito profundas e/ou quando os sintomas dolosos não respondem aos tratamentos dessensibilizantes menos invasivos. Dentre as desvantagens dessa opção está a possível deterioração das propriedades dos materiais na região cervical que compromete, por exemplo, a adaptação marginal (PINNA et al., 2015; LAWSON et al., 2015) e os desafios clínicos, como por exemplo, o acesso à lesão, controle do campo operatório (isolamento), inserção e manuseio do material, acabamento marginal, desconforto do paciente e tempo de cadeira (FAHL, 2015). Outro grande problema ocorre quando o paciente relata sensibilidade mesmo após a restauração da lesão (FEMIANO et al., 2016). Para dificultar ainda mais a escolha do plano de tratamento, não há relação entre a hipersensibilidade dentinária e a extensão da lesão (FEMIANO et al., 2016) e nestes casos, os tratamentos dessensibilizantes podem ser uma solução.

Com o aumento na prevalência da hipersensibilidade dentinária ao longo dos anos (MOEZIZADEH; ALIMI, 2014), diferentes métodos e agentes foram desenvolvidos a fim de reduzir ou eliminar esta condição (GOPINATH et al., 2015). O mecanismo de ação dos agentes dessensibilizantes, embora ainda não seja completamente compreendido, ocorre através de um 
dos seguintes métodos: bloqueio dos túbulos dentinários através de deposição sobre a superfície, alteração do conteúdo tubular através da coagulação, precipitação de proteínas ou formação de complexos de cálcio insolúveis ou interferência direta na atividade neural sensorial (MAHESUTI et al., 2014).

Entre os diferentes produtos utilizados, o oxalato de potássio tem uma história particularmente longa de aceitação e uso por parte dos profissionais (SHARMA; KOHAD; YELTIWAR, 2013). O agente atua no tecido como um ácido fraco, aumentando a concentração do cálcio ionizado para níveis elevados na superfície. Seu resultado é uma rápida formação de cristais de oxalato de cálcio que oblitera os túbulos dentinários expostos, reduzindo assim a sensibilidade da dentina (ARANHA; PIMENTA.; MARCHI, 2009). Diferentes estudos têm demonstrado resultados positivos in vitro (CALABRIA et al., 2014) e in vivo (ANTONIAZZI et al., 2014). O efeito dessensibilizante do oxalato de potássio também está relacionado à despolarização das células nervosas (ASSIS et al., 2011) o que pode explicar a eficácia clínica do tratamento a curto e longo prazo. Em relação ao desgaste erosivo, o agente parece ter um efeito positivo contra a progressão da erosão na dentina, porém a dissolução dos cristais formados pode ocorrer ao longo do tempo (CALABRIA et al., 2014).

Recentemente, o nanofosfato de cálcio organizado na forma cristalina de hidroxiapatita foi desenvolvido como uma pasta dessensibilizante com o nome comercial Desensibilize Nano P (FGM) (DE CARVALHO et al., 2013). Seu efeito dessensibilizante foi comprovado clinicamente considerando também a ação do nitrato de potássio nas fibras nervosas e o fluoreto de sódio presentes em sua formulação (ODEBRECHT; LOGUERCIO; BOTTAN, 2010; WANG et al., 2016). A deposição de cristais pode ocorrer na superfície e/ou dentro dos túbulos dentinários e sua eficácia pode ser atribuída ao tamanho das partículas que obtém uma penetração mais profunda (KUNAM et al., 2016). De acordo com a literatura (B LOW; ALLEN; KONTOGIORGOS, 2015), os produtos com nanohidroxiapatita são capazes de 
reparar micro-defeitos na superfície do esmalte e dentina também devido ao tamanho dos cristais. Em estudo in vitro (MEIER et al., 2010) foi observado que o produto obliterou os túbulos dentinários de forma efetiva sendo este resistente a desafios erosivos e de força mecânica (escovação mecânica). Contudo, poucos trabalhos investigaram a eficácia do nanomaterial na superfície do esmalte e dentina sendo os resultados controversos entre si (COMAR et al., 2013; MEDEIROS et al., 2014).

Uma outra alternativa que vem sendo estudada é a propriedade anticariogênica de produtos lácteos em que se observa efeitos químicos diretos da fosfoproteína de caseína (proteína derivada do leite bovino) no substrato dental (OSHIRO et al., 2007; AZARPAZHOOH e LIMEBACK, 2008). Fosfopeptídeo de caseína (CPPs) são peptídeos fosforilados derivados de caseína que se ligam quimicamente com minerais como cálcio, magnésio e ferro. Na presença de água, o fosfato de cálcio amorfo (ACP) pode ser convertido em hidroxiapatita e precipitar no formato estável na superfície do dente (NONGONIERMA; FITZGERALD, 2012). Na literatura, existem diferentes trabalhos (RAHIOTIS; VOUGIOUKLAKIS，2007; RANJITKAR，2008; TRUSHKOWSKY; OQUENDO，2011; WALKER et al., 2009) que utilizam o CPP-ACP (fosfopeptídeo de caseína - fosfato de cálcio amorfo) como método de remineralização do substrato dental, diminuição no desgaste da dentina e tratamento da hipersensibilidade dentinária.

Quando o CPP-ACP é aplicado à áreas de dentina exposta, ocorre o bloqueio da entrada dos túbulos dentinários através da deposição do componente proteico e da ligação dos íons cálcio e fosfato no interior dos mesmos. O complexo proporciona concentrações supersaturadas de íons cálcio e fosfato que aumentam a formação de cristais de hidroxiapatita em regiões desmineralizadas (TANG; MILLAR, 2010). Além disso, o CPP-ACP incorpora grupos fosfato nas fibrilas de colágeno, o que atrai íons de cálcio resultando também na formação de hidroxiapatita (CAO et al., 2013). Dessa forma, o agente pode prevenir a desmineralização 
enquanto promove a remineralização do tecido duro (MAHESUTI et al., 2014). Quando os túbulos dentinários são bloqueados através da remineralização, a hipersensibilidade dentinária diminui consequentemente, o que pode explicar sua eficácia clínica no tratamento dessensibilizante (MAHESUTI et al., 2014).

Um outro tratamento que vem demonstrando ser eficaz na gestão da hipersensibilidade dentinária é o laser de diodo (DILSIZ; AYDIN; GUNGORMUS, 2010; YILMAZ; KURTULMUS-YILMAZ; CENGIZ, 2011; YILMAZ et al., 2011; SURI et al., 2016; WANG et al., 2016). O mecanismo de ação varia de acordo com os diferentes parâmetros. O laser de diodo com comprimento de onda de 980nm tem sua energia absorvida pelas estruturas minerais da dentina que provoca um aumento de energia na superfície da estrutura dental promovendo a fusão e recristalização podendo selar ou reduzir a embocadura dos túbulos dentinários (LIU et al., 2013; UMANA et al., 2013). Esse equipamento é eficaz para o tratamento da hipersensibilidade dentinária e pode ser utilizado como rotina no consultório (LIU et al., 2013). Além disso, os lasers de baixa potência também têm um efeito analgésico causado pela diminuição na transmissão nervosa ou pela obliteração dos túbulos dentinários através da formação de dentina terciária (YILMAZ et al., 2011). Por estarem suscetíveis a processos físicos e químicos do meio bucal, os túbulos podem ficar expostos novamente com facilidade. Dessa forma, a resistência à erosão seria fundamental para a laserterapia manter sua eficácia a longo prazo.

Devido aos resultados clínicos positivos obtidos pelos tratamentos dessensibilizantes no manejo da hipersensibilidade dentinária, os mesmos poderiam ser utilizados para a redução da sintomatologia dolorosa causada pelo processo erosivo. Entretanto, além do efeito oclusivo nos túbulos dentinários, esses tratamentos necessitam ser resistentes aos desafios ácidos presentes no meio bucal para manter seu efeito a longo prazo. Ademais, o substrato tratado também deve 
ser resistente aos processos erosivos a fim de evitar a progressão da lesão erosiva e, concomitantemente, a hipersensibilidade.

Frente à possibilidade da aplicação dos tratamentos dessensibilizantes como forma de intervenção na sintomatologia da erosão dentinária, determinar um tratamento dessensibilizante eficaz e que controle a progressão das lesões erosivas seria de grande importância para a sua abordagem, principalmente frente a inúmeros agentes disponíveis, tanto in vitro como in vivo. 
Este estudo foi realizado em duas fases, sendo a primeira a avaliação in vitro e a segunda a avaliação in vivo.

O objetivo do estudo in vitro foi avaliar os efeitos dos tratamentos dessensibilizantes sobre a evolução do processo erosivo em dentina radicular por meio da:

1) Rugosidade, perfil de desgaste, perda de volume e degrau de desgaste - microscopia confocal a laser (MCL);

2) Morfologia da superfície - dimensões dos túbulos dentinários - microscopia confocal a laser (MCL);

3) Permeabilidade dentinária - microscopia óptica (MO).

O objetivo do estudo in vivo foi avaliar a eficácia do tratamento dessensibilizante na:

1) Progressão das lesões erosivas (rugosidade, degrau de desgaste e dimensões das lesões) microscopia confocal a laser (MCL);

2) Hipersensibilidade dentinária dos pacientes - Escala de Estimativa Numérica (Numeric Rating Scale - NRS). 
A primeira fase do estudo foi a avaliação in vitro que determinou o tratamento a ser executado na segunda fase, a avaliação in vivo.

\section{ESTUDO IN VITRO}

\section{DELINEAMENTO EXPERIMENTAL DO ESTUDO IN VITRO}

Este estudo teve 2 fatores de estudo: tratamentos dessensibilizantes, em 6 níveis: ausência de tratamento - controle, Oxagel (Kota), Desensibilize Nano P (FGM), Mi Paste ${ }^{\mathrm{TM}}$ $\left(\mathrm{GC}^{\mathrm{TM}}\right)$, agente experimental (a base de caseína) e laser de diodo e tempo em 4 níveis $\left(1^{\circ}, 4^{\circ}\right.$, $7^{\circ}$ e $9^{\circ}$ dia da ciclagem erosiva/tratamentos). As unidades experimentais foram 90 fragmentos de dentina radicular bovina, divididos aleatoriamente em 6 grupos experimentais.

O estudo foi realizado de acordo com um delineamento em blocos completos casualizados. As variáveis de resposta quantitativa foram o perfil de desgaste, rugosidade superficial, degrau e a perda de volume avaliados em 4 tempos da ciclagem erosiva/tratamentos e dimensões dos túbulos dentinários em 13 tempos por meio da microscopia confocal a laser 3D. A análise da permeabilidade foi realizada por meio de microscopia óptica. 
Incisivos bovinos íntegros, visivelmente sem manchas, foram previamente selecionados para obtenção dos espécimes e armazenados em solução de formol a 10\%, com pH 7,0. Após limpeza com taça de borracha, pedra pomes e água, os dentes foram seccionados na junção cemento-esmalte com disco de corte diamantado (\#7015, KG Sorensen, Barueri, Brasil) sob refrigeração e auxílio da máquina de corte de precisão (Minitom, Struers A/S, DK-2610, Copenhagen, Dinamarca) separando a coroa da raiz. Em seguida, as raízes foram fixadas em placa de plexiglass e seccionadas para a obtenção dos espécimes de dentina radicular do terço cervical mais próximo à junção cemento-esmalte. Ao todo foram 90 espécimes com dimensões de 3x3x2mm. As superfícies circundantes dos espécimes foram isoladas com resina composta a fim de protegê-las durante os desafios erosivos (Figura 1).

Após o isolamento, o acabamento da superfície vestibular exposta dos espécimes foi realizado em politriz (Arotec APL-4, Arotec Indústria e Comércio, São Paulo - SP, Brasil) sob refrigeração com lixa de granulação \#1200 (Norton Abrasivos Ltda, São Paulo-SP, Brasil), durante 10 segundos para padronizar a remoção do cemento, e o polimento foi realizado com disco de feltro e suspensão de alumina 0,3 e 0,05 $\mu$ m (Arotec Sj685 /A Ind, e Comércio, São Paulo/SP, Brasil). Dessa forma, a resina composta circundante ficou nivelada com a área de dentina exposta vestibular sendo determinada como área de referência para as análises. Ao final do polimento os espécimes foram imersos sob ação do ultra-som (Ultrasonic Cleaner T - 1449 - D, Odontobrás Indústria e Comércio, Ribeirão Preto - SP, Brasil) por 10 minutos, em água deionizada para lavagem e remoção de resíduos. Após o desafio erosivo inicial os espécimes foram selecionados quanto ao número de túbulos dentinários expostos e a superfície vestibular foi dividida em duas áreas sendo a esquerda a área controle (nenhum tratamento) e a direita a área tratada. Para isso, um terço da superfície foi isolada com resina composta (área controle), como citado anteriormente, com o objetivo de protegê-la durante a ciclagem 
erosiva/tratamentos (Figura 1); na região lateral dos fragmentos foi realizada uma marcação para identificação da mesma. Todos os espécimes foram armazenados em água destilada sob refrigeração $\left(4^{\circ} \mathrm{C}\right)$ até o início do experimento.

\section{DESAFIO EROSIVO INICIAL}

Os espécimes foram individualmente imersos em $5 \mathrm{ml}$ de ácido cítrico a 6\%, durante 90 segundos, sob agitação (HAN et al., 2013; KIM et al., 2013) (Mesa agitadora CT155, Cientec, Piracicaba-SP, Brasil) (Figura 1), para exposição dos túbulos dentinários confirmada através da análise inicial da superfície em microscopia confocal a laser (Microscópio Laser Confocal LEXT OLS4000, Olympus). Esta leitura inicial teve como finalidade a seleção das amostras. A média do número de túbulos dentinários expostos de todos os espécimes foi obtida e aqueles que apresentaram valores $20 \%$ acima e $20 \%$ abaixo da média foram excluídos. Após a seleção, a análise inicial da rugosidade foi realizada.

A área controle do grupo 1 (controle) não recebeu o desafio ácido para que a diferença entre a superfície dentinária íntegra e a superfície com túbulos dentinários expostos fosse observada. 


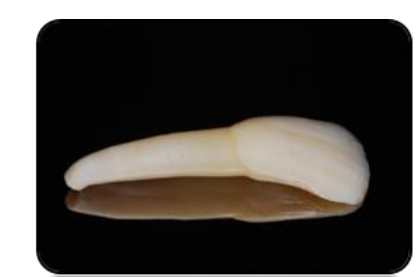

Incisivo bovino íntegro

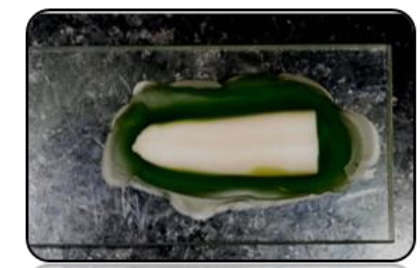

Fixação da raíz em placa de plexiglass

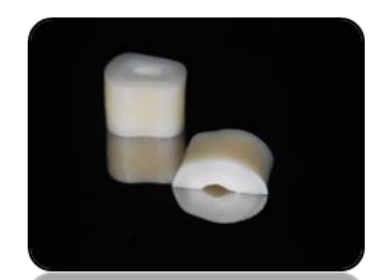

Secção transversal dos discos de dentina radicular

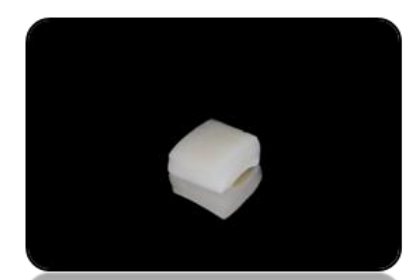

Espécime obtido com $3 \times 3 \times 2 \mathrm{~mm}$ de dimensão

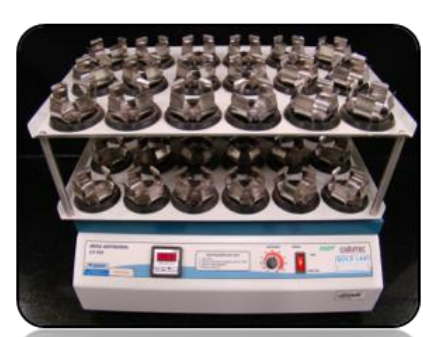

Mesa agitadora (90 seg de agitação)

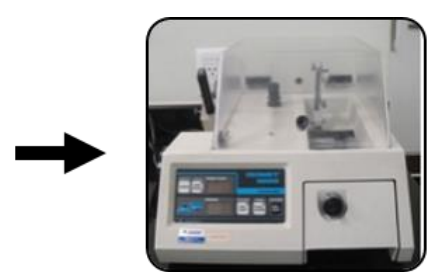

Máquina de corte

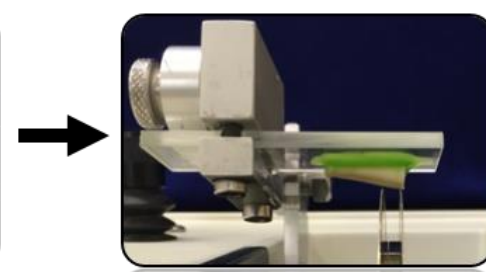

Secção da raíz na região cervical
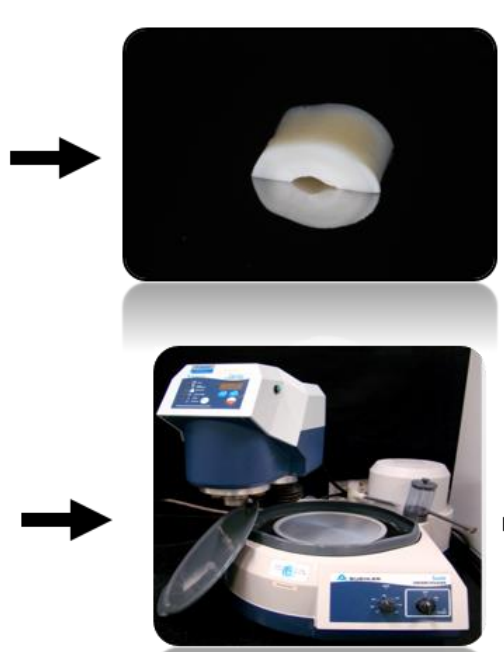

Politriz utilizada para acabamento e polimento da superfície vestibular

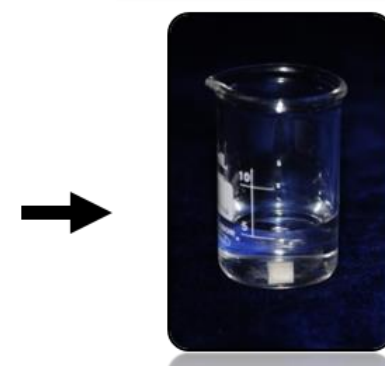

Imersão em ácido cítrico $6 \%$ (desafio erosivo inicial)

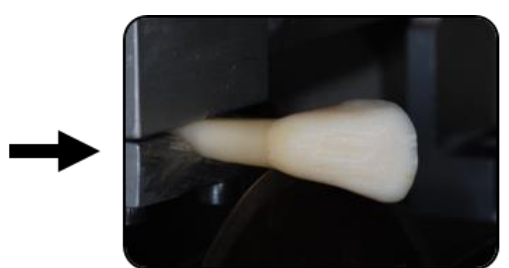

Secção do dente na junção cemento-esmalte

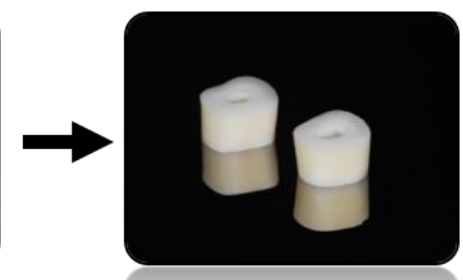

Discos de dentina obtidos (3mm de largura)

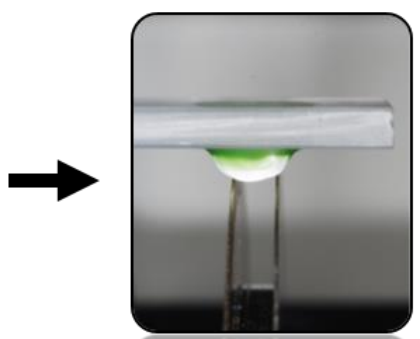

Secção longitudinal (3mm)

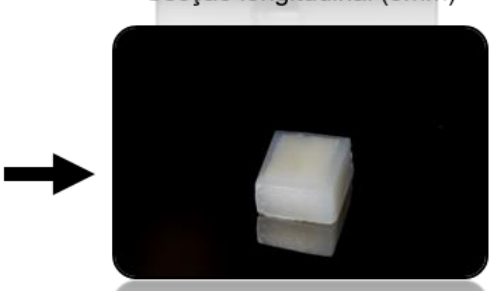

Espécime com resina circundante nivelada com a superfície vestibular

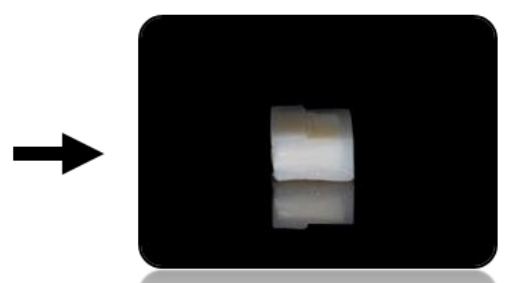

Região esquerda da superfície vestibular isolada (área controle)

Figura 1. Preparo dos espécimes e desafio erosivo inicial. 
Após o desafio inicial, os espécimes tiveram um terço de sua superfície isolada, como citado anteriormente, e foram divididos aleatoriamente em 6 grupos experimentais $(n=15)$ de acordo com o tratamento dessensibilizante que receberam (Tabela 1).

Tabela 1. Tratamentos dessensibilizantes a serem empregados nos diferentes grupos.

\begin{tabular}{|c|c|c|}
\hline DESSENSIBILIZANTES & COMPOSIÇÃO & $\begin{array}{c}\text { AGENTE } \\
\text { ATIVO }\end{array}$ \\
\hline G1 - Controle & & - \\
\hline G2 - Oxagel & Oxalato de Potássio, Carboximetil Celulose & $\begin{array}{c}\text { Oxalato de Potássio } \\
3 \%\end{array}$ \\
\hline G3 - Desensibilize Nano $P$ & $\begin{array}{c}\text { Fosfato de Cálcio nanométrico (na forma de } \\
\text { hidroxiapatita), Fluoreto de } \\
\text { Sódio, Nitrato de Potássio, Água Destilada, } \\
\text { Espessante, Tensoativo, Umectante, Aroma, Adoçante } \\
\text { e Conservante }\end{array}$ & $\begin{array}{l}\text { Fosfato de Cálcio } \\
\text { nanométrico }\end{array}$ \\
\hline G4 - Mi Paste ${ }^{\mathrm{TM}}$ & $\begin{array}{l}\text { Água Pura, Glicerol, CPP-ACP, D-sorbitol, CMC- } \\
\text { Na, Propileno-glicol, Dióxido de Silício, Dióxido de } \\
\text { Titânio, Xilitol, Ácido Fosfórico, Agentes } \\
\text { Aromatizantes, Óxido de Zinco, Sacarina de Sódio, P- } \\
\text { hidroxibenzoato de Etilo, Óxido de magnésio, Goma } \\
\text { de Guar, P-hidroxibenzoato de Propilo, P- } \\
\text { hidroxibenzoato de Butilo, Sabor Menta }\end{array}$ & $\begin{array}{c}\text { Recaldent }^{\mathrm{TM}}(\mathrm{CPP}- \\
\text { ACP): } \\
\text { fosfopeptídeo de } \\
\text { caseína - fosfato de } \\
\text { cálcio amorfo }\end{array}$ \\
\hline G5 - Agente Experimental & A base de caseína & Caseína \\
\hline G6 - Laser & Parâmetros: potência $0,7 \mathrm{~W} / 10 \mathrm{~Hz} / 25 \mathrm{~s}$ & $\begin{array}{c}\text { Laser de diodo } \\
\lambda=970 \mathrm{~nm}\end{array}$ \\
\hline
\end{tabular}

A aplicação dos tratamentos foi realizada da seguinte forma:

- Oxagel (Kota Indústria e Comércio Ltda,, São Paulo-SP, Brasil): o agente foi aplicado com auxílio de um microbrush (Aplicador Descartável KG Brush Fine, KG Sorense, Barueri-SP, Brasil), mantido com ligeiro excesso em contato com a superfície exposta durante 2 minutos e removido com jatos de água deionizada. 
- Desensibilize Nano P (FGM, Produtos Odontológicos Ltda., Joinville-SC, Brasil): a pasta foi aplicada com auxílio de um microbrush por 10 segundos, mantido com ligeiro excesso em contato com a superfície durante 5 minutos e depois removida o excesso com bolinha de algodão.

- Mi Paste (Recaldent ${ }^{\mathrm{TM}}$, GC Corporation, Tokyo, Japão): o agente foi aplicado com auxílio de um microbrush, mantido com ligeiro excesso em contato com a superfície durante 3 minutos e em seguida o excesso foi removido com gaze; o produto permaneceu na superfície por mais 2 minutos e depois foi removido com jatos de água deionizada.

- Agente Experimental: o agente foi aplicado com auxílio de um microbrush, friccionado sobre a superfície durante 20 segundos, mantido com ligeiro excesso durante 4 minutos e depois removido com jatos de água deionizada.

- Laser de diodo (Sirolaser, Sirona Dental Systems GmbH, Bensheim, Alemanha): com comprimento de onda de $970 \mathrm{~nm}+/-10 \mathrm{~nm}$, potência máxima de $7 \mathrm{~W} \mathrm{CW}$, feixe guia de $1 \mathrm{~mW}$ e fibra óptica de $320 \mu \mathrm{m}$. A irradiação foi realizada em toda área de dentina exposta no modo contato, com potência de $0,7 \mathrm{~W}$ (energia de $70 \mathrm{~mJ}$ ) e frequência de $10 \mathrm{~Hz}$ durante 25 segundos, tendo uma densidade de energia de $222,82 \mathrm{~J} / \mathrm{cm}^{2}$. O medidor de potência FieldMaxII-TOP (Coherent, Inc, USA) foi empregado previamente às aplicações e após finalizá-las.

A aplicação dos tratamentos foi realizada no início do dia. Após o procedimento os espécimes foram imersos em saliva durante 30 minutos e então submetidos à avaliação e em seguida, à ciclagem erosiva do dia. Ao todo foram 3 dias de tratamentos com intervalo de 72 horas entre eles. Durante todo experimento, os espécimes foram mantidos em saliva artificial e estufa a $37^{\circ} \mathrm{C}$. 
Para simular a erosão dentinária durante a dieta ácida, os espécimes foram imersos em ácido cítrico a $0,3 \%(\mathrm{pH}=2,45)$ por 5 minutos, sob agitação a temperatura ambiente (em torno de $25^{\circ} \mathrm{C}$ ). Em seguida, estes foram lavados com água destilada, secos cuidadosamente com papel absorvente e imersos em saliva artificial durante 2 horas em estufa. Esse ciclo foi realizado três vezes ao dia e as superfícies foram analisadas ao final do $1^{\circ}, 4^{\circ}, 7^{\circ}$ e $9^{\circ}$ dia da ciclagem erosiva/tratamentos para análise do desgaste superficial (Figura 2).

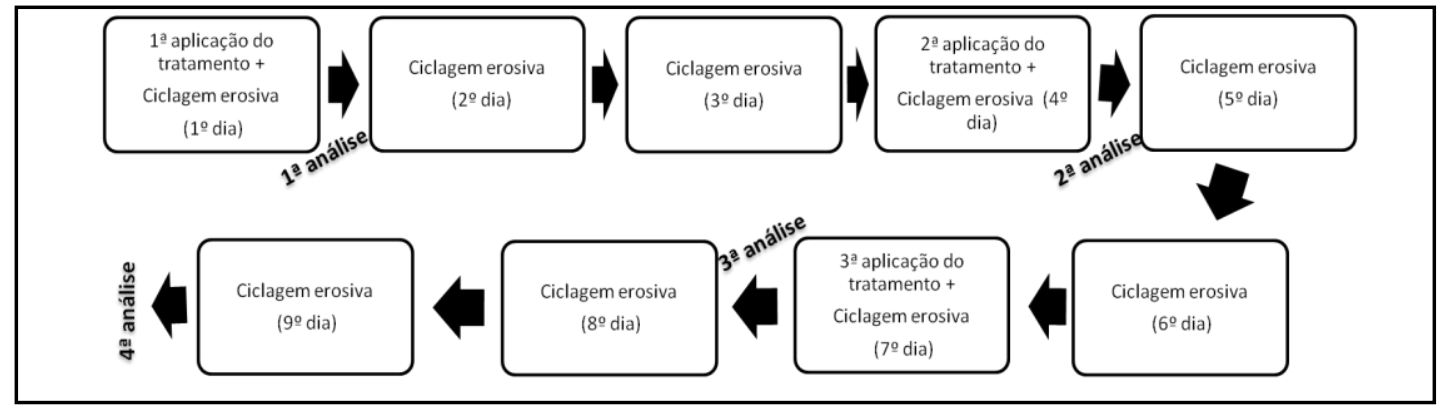

Figura 2. Sequência de análises em Microscópio Confocal a Laser 3D para análise do desgaste superficial.

\section{ANÁLISE SUPERFICIAL X TEMPO}

As análises foram realizadas por meio de um microscópio confocal a laser - MCL (Microscópio Confocal a Laser 3D OLS4000, sistema LEXT, Olympus). Para isso, os espécimes foram posicionados paralelamente à mesa do microscópio e imagens com 107x de aumento foram adquiridas.

Para a análise do perfil de desgaste, degrau e perda de volume, foi utilizada uma imagem englobando a área erodida/tratada e a área de referência (resina composta circundante) (Figura 3). O perfil de desgaste e o degrau da área erodida/tratada foram determinados a partir da área de referência (Figura 4). Para a análise de rugosidade, foram realizadas leituras somente da área 
erodida/tratada (Figura 5). Ao todo foram realizadas 10 leituras de cada espécime para cada uma das diferentes análises. O volume perdido da área erodida/tratada em relação à área referência foi analisada através da imagem tridimensional dos espécimes (Figura 6). Os dados foram fornecidos em micrometros $(\mu \mathrm{m})$ e obtidos por meio de um software específico (Olympus LEXT OLS4000®).

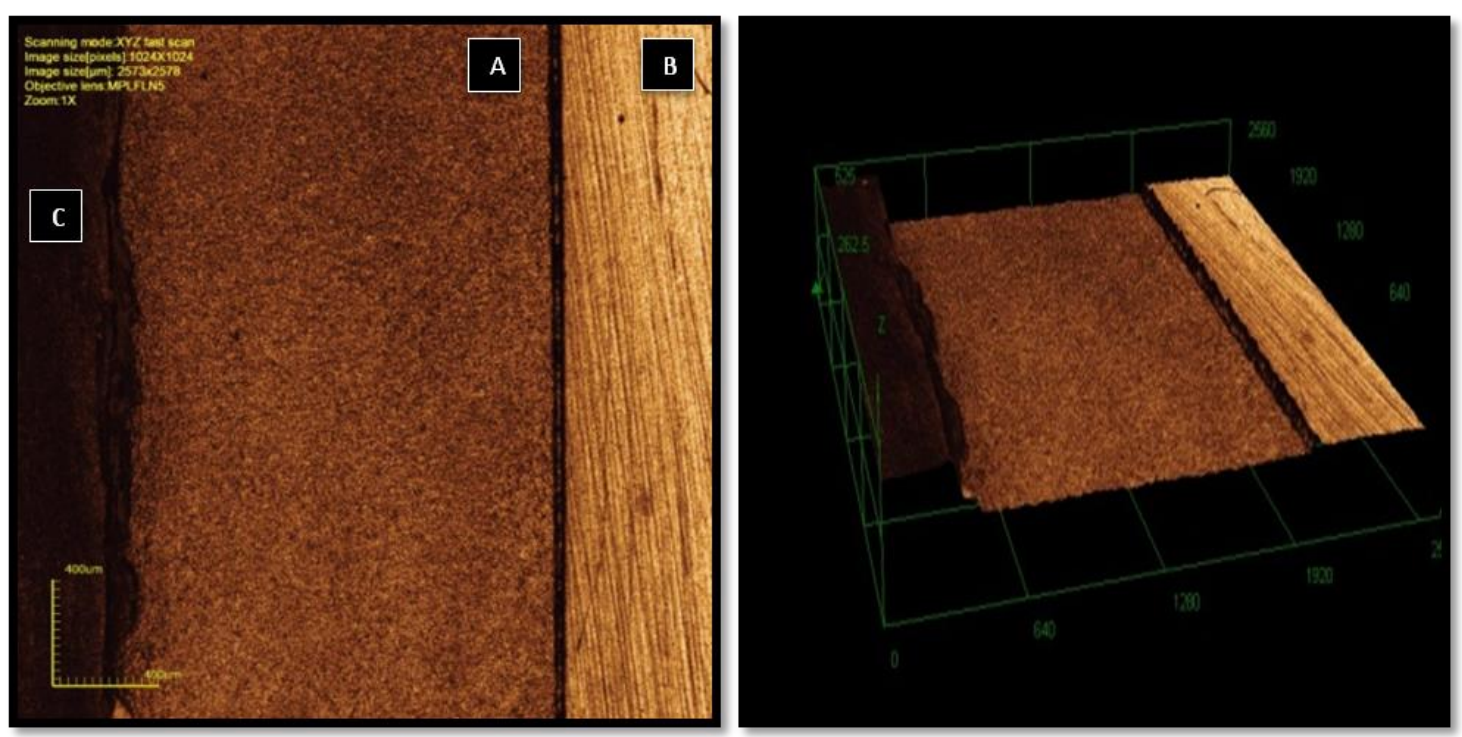

Figura 3. Imagens 2D e 3D adquiridas para análise superficial: área tratada/erodida (A), área de referência (B) e área controle protegida por resina composta (C) (107x de aumento).
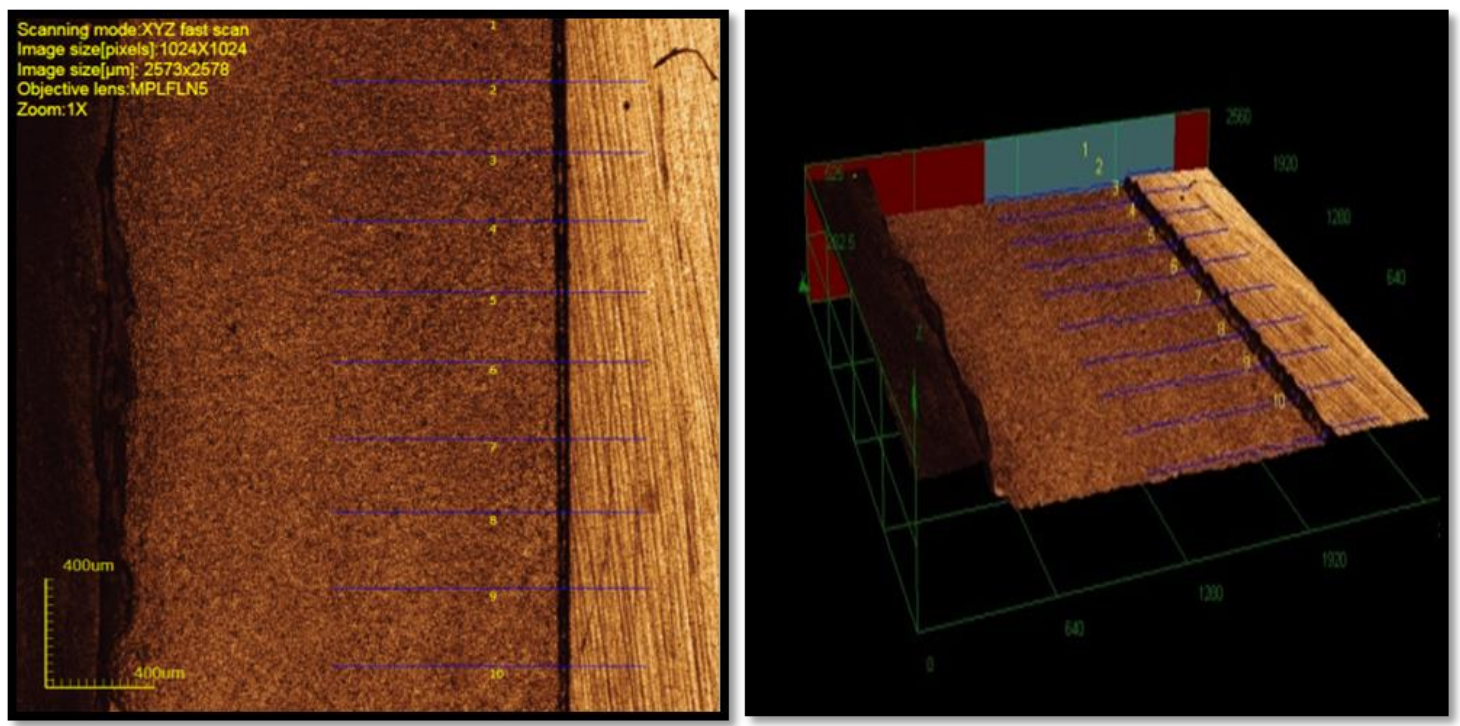

Figura 4. Mensuração do Perfil de Desgaste e Degrau $(\mu \mathrm{m})$. 


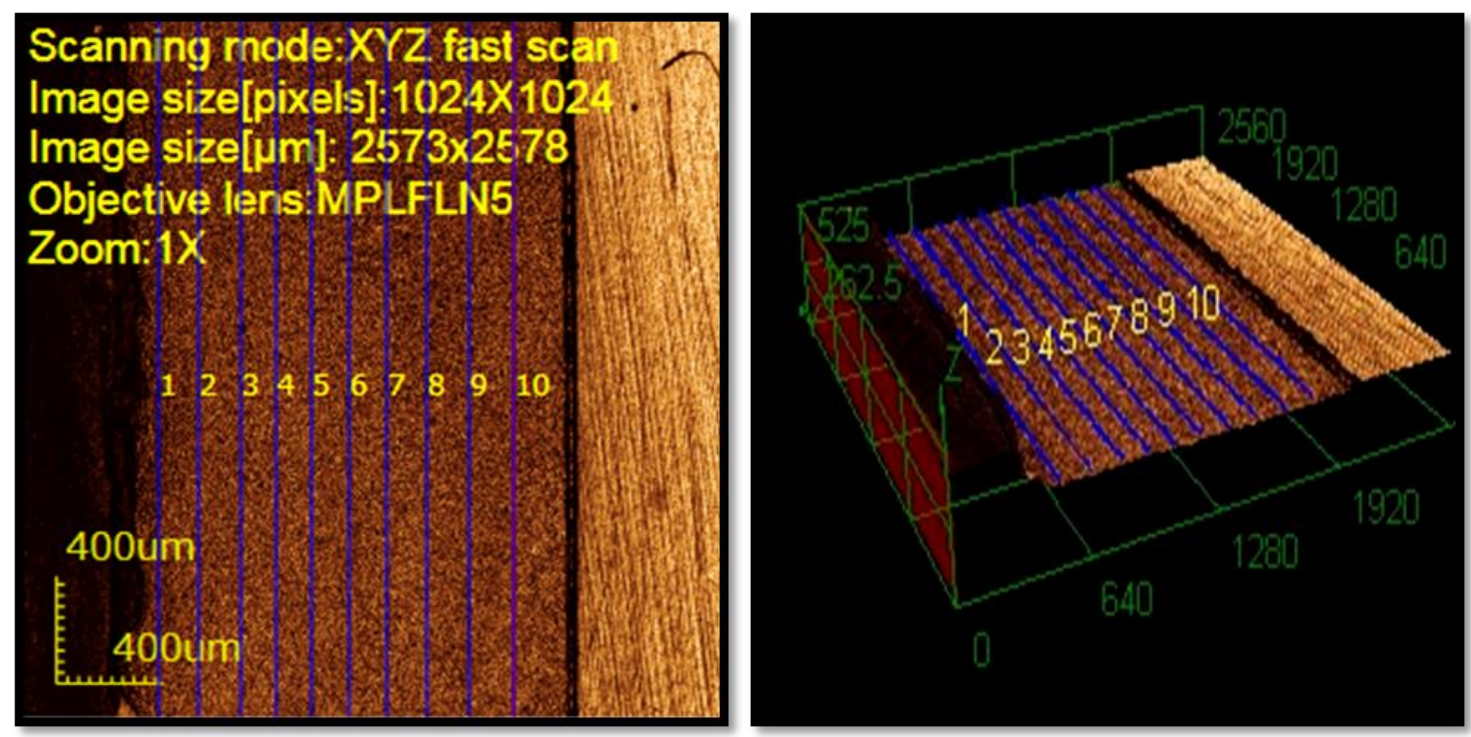

Figura 5. Mensuração da Rugosidade $(\mu \mathrm{m})$ (englobando somente da área erodida/tratada).

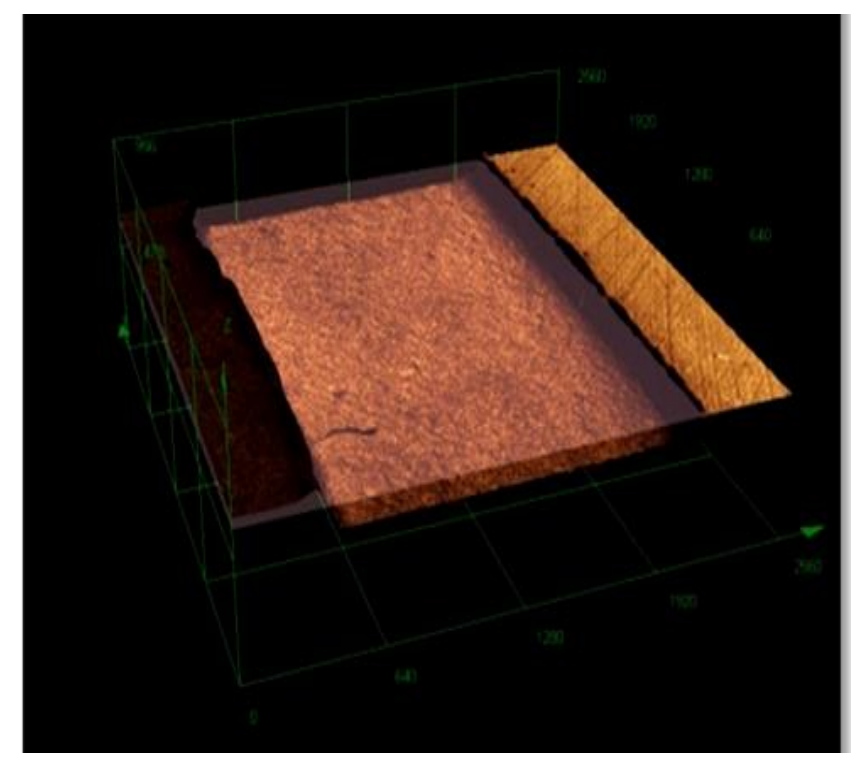

Figura 6. Imagem 3D: Mensuração da Perda de Volume: volume perdido da área erodida/tratada em relação à área referência $\left(\mu \mathrm{m}^{3}\right)$. 
Ao final da ciclagem erosiva/tratamentos, a resina composta utilizada para impermeabilizar a superfície vestibular dos espécimes foi removida delicadamente com o auxílio de uma lâmina de bisturi expondo a área controle. Outras imagens foram adquiridas em MCL englobando as áreas controle e tratada (Figura 7). O perfil de desgaste, degrau e perda de volume dos espécimes foram avaliados em relação a ambas as áreas, do mesmo modo descrito anteriormente. A rugosidade final da área erodida/tratada do grupo1 representa a rugosidade final da ciclagem erosiva, uma vez que não houve aplicação de nenhum tratamento na mesma. Diferente disso, a rugosidade da área controle do grupo 1 representou a rugosidade inicial da dentina hígida, sem o desafio inicial e a ciclagem erosiva.
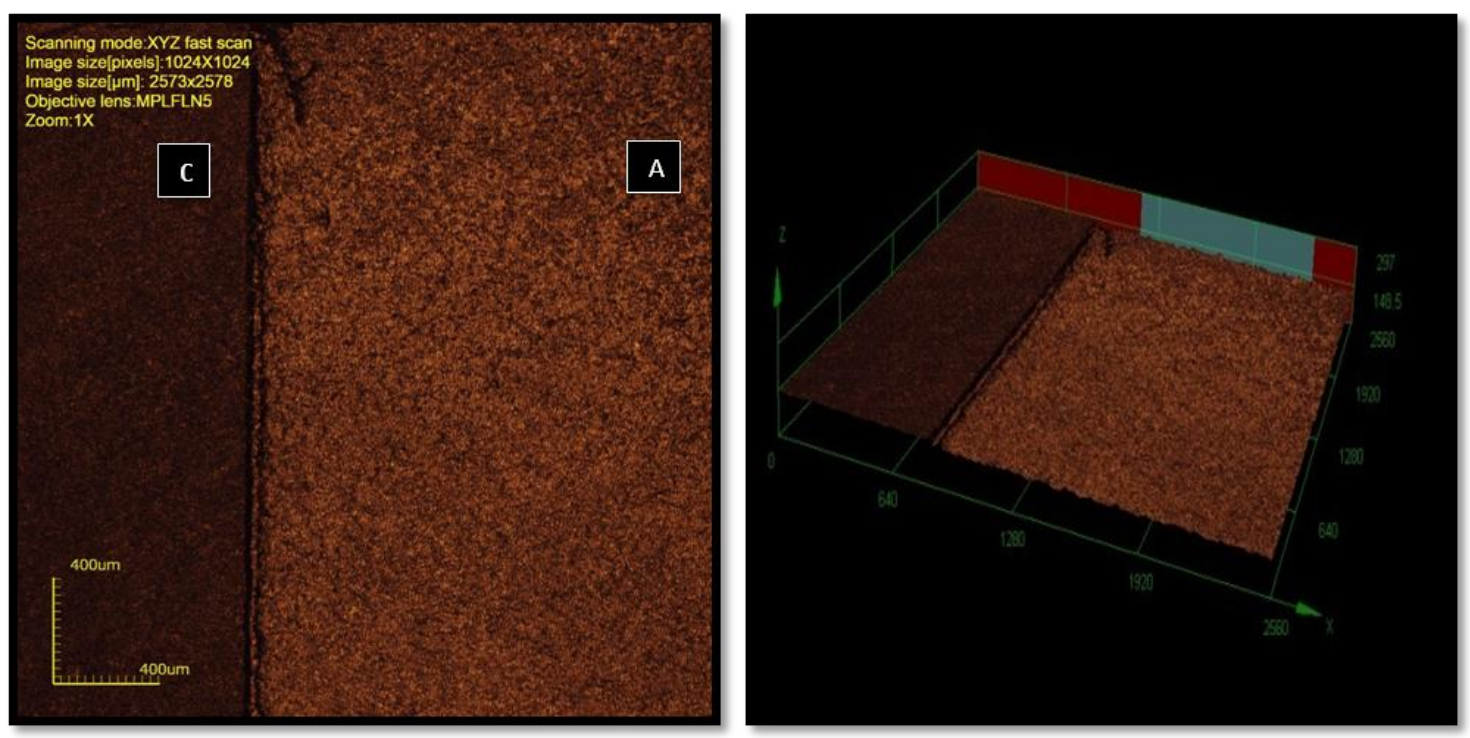

Figura 7. Imagem adquirida para análise final da superfície: área tratada/erodida (A) e área controle após remoção da resina composta (C) (107x de aumento). 
Por ser um método não destrutivo, o microscópio confocal a laser permitiu também a análise morfológica da superfície dos espécimes através de imagens 3D obtidas das áreas tratadas nos diferentes tempos. Essa análise foi realizada ao final de cada dia e imediatamente após a aplicação dos tratamentos, totalizando 13 avaliações, sendo a primeira a avaliação inicial (Av1) realizada antes do início da ciclagem (Figura 8). Utilizando como referência a resina lateral dos mesmos, imagens com 2131x de aumento (objetiva de 100x) foram obtidas da mesma região em cada espécime durante todo o período. Através das ferramentas do software foi possível identificar e avaliar o aumento/diminuição do número e da área dos túbulos dentinários expostos antes e durante tratamento/ciclagem (quantitativamente) (Figuras 9 e 10).

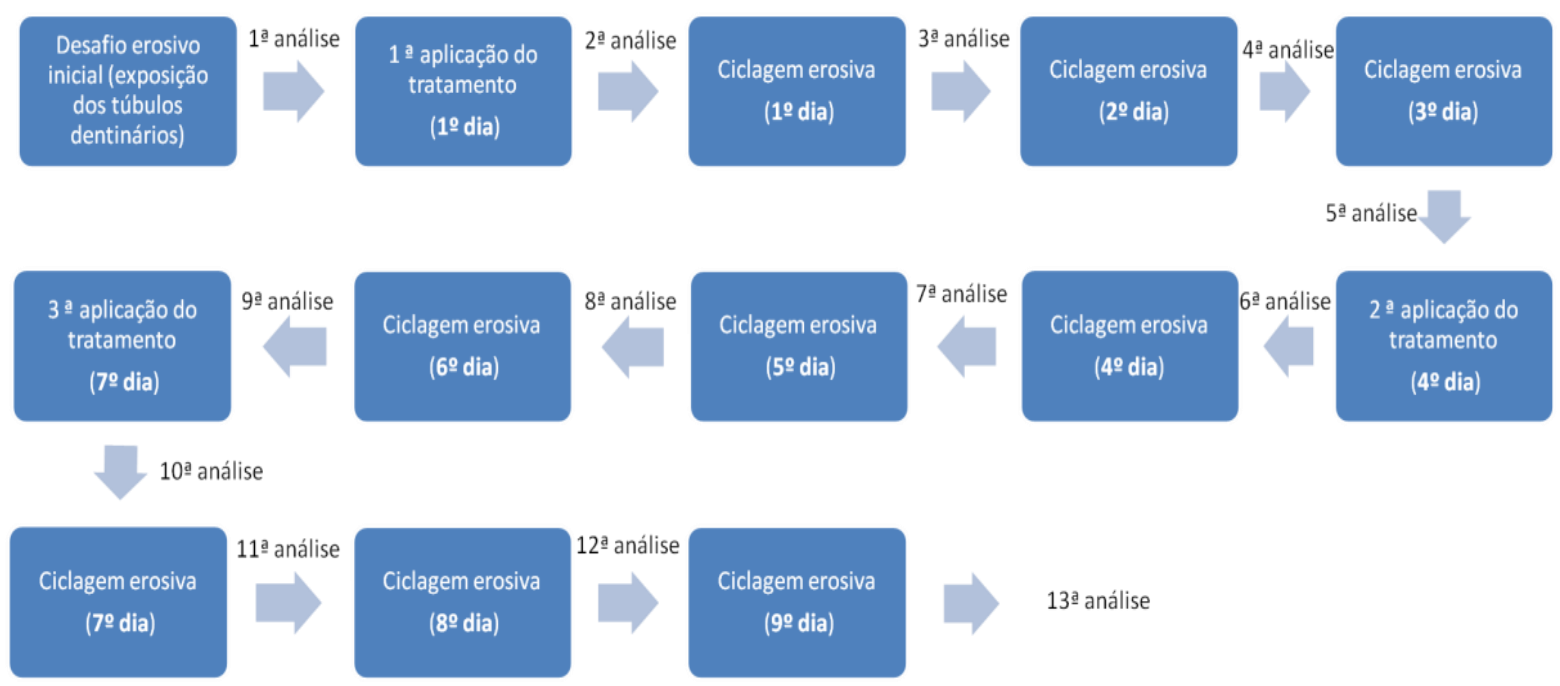

Figura 8. Sequência de análises em Microscópio Confocal a Laser. 


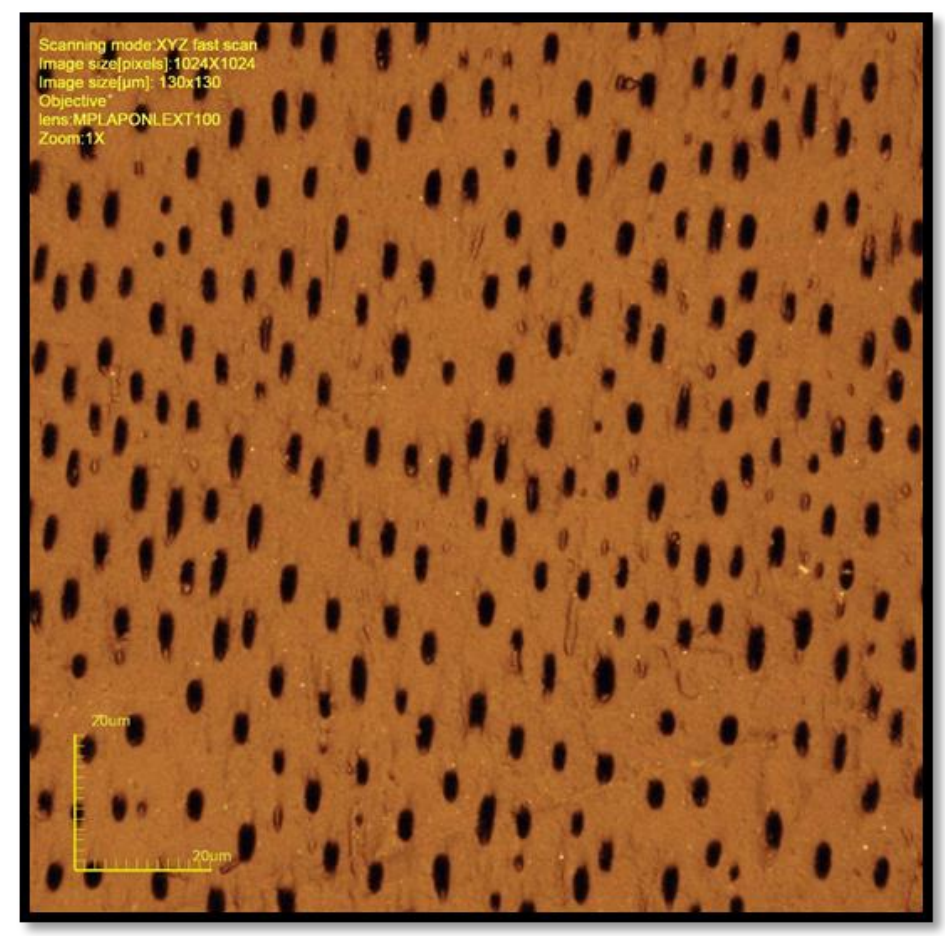

Figura 9. Análise morfológica: imagem inicial da superfície adquirida para mensuração dos túbulos dentinários expostos (aumento de 2131x).

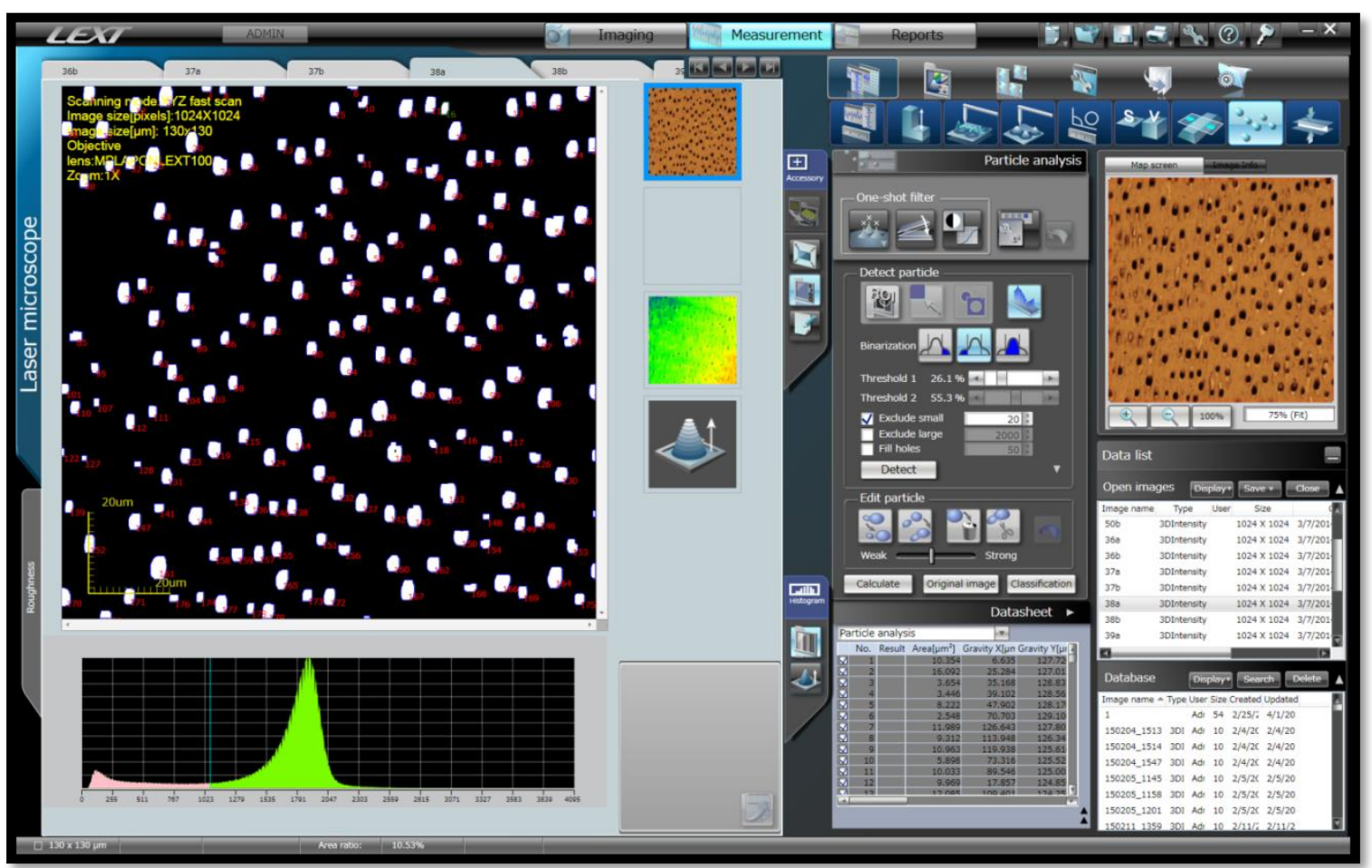

Figura 10. Área de trabalho do Software Olympus LEXT OLS4000®: detecção, contagem e dimensão dos túbulos dentinários expostos. 
Após as análises no microscópio confocal, os espécimes foram preparados para o ensaio de permeabilidade dentinária. Os espécimes foram isolados com duas camadas de esmalte cosmético (Colorama, Procosa Produtos de beleza Ltda., São Paulo - SP, Brasil) e cera para escultura (cera azul, Kota Indústria e Comérico Ltda., São Paulo-SP, Brasil) em todas as superfícies circundantes. Em seguida foram imersos em solução de sulfato de cobre $10 \%$ (Merck, Darmstadt, Alemanha) e posteriormente em ácido rubiânico 1\% (Merck, Darmstadt, Alemanha), ambos durante 30 minutos, sendo os primeiros 5 minutos de imersão realizada sob vácuo. Ao final foram submetidos ao vapor de amônia por um período de 7 dias (AMAECHI; HIGHAM; EDGAR, 1999). A reação do sulfato de cobre com a solução alcoólica de ácido rubiânico produz uma forte coloração, que vai do azul intenso até a coloração negra que é evidenciada com o vapor de amônia (PÉCORA; COSTA; MAIA CAMPOS, 1990).

Após esta etapa, os espécimes foram incluídos em blocos de resina acrílica e seccionados longitudinalmente com aproximadamente $0,5 \mathrm{~mm}$ de espessura $(2$ secções por espécime) com o auxílio de um disco montado em máquina de corte, sob refrigeração à água. As secções foram planificadas e polidas manualmente utilizando lixas d'água de granulação \#600 e \#1200, até chegar a uma espessura entre 100-150 $\mu$ m. Logo após, a limpeza e remoção de resíduos foi realizada através da imersão das secções em água deionizada sob a ação do ultrassom 3 vezes durante 5 minutos/vez.

Em seguida, os espécimes foram desidratados em álcool (Labsynth Ltda., Diadema, Brasil) nas concentrações de 70, 80, 96 e 100\%, por um período de 2 horas em cada solução e clarificados em xilol durante 6 horas (PÉCORA; COSTA; MAIA CAMPOS, 1990).

As secções foram observadas em um microscópio óptico (Axiostars Plus, Carl Zeiss, Alemanha) e, através de uma câmera fotográfica digital acoplada (Axiocam MRc, Carl Zeiss, Jena, Alemanha) as imagens das lâminas foram capturadas e digitalizadas de forma padronizada 
(objetiva de 5x). A mensuração da profundidade de penetração dos íons cobre foi realizada automaticamente através de uma ferramenta do software Axio Vision Rel. 4.8.2 (Carl Zeiss, Alemanha), previamente calibrada. A análise foi realizada com a objetiva de 5x tendo aumento final de aproximadamente 50x, sendo obtida a média de 20 leituras de profundidade da área penetrada pelo agente traçador em mm (Figura 11).

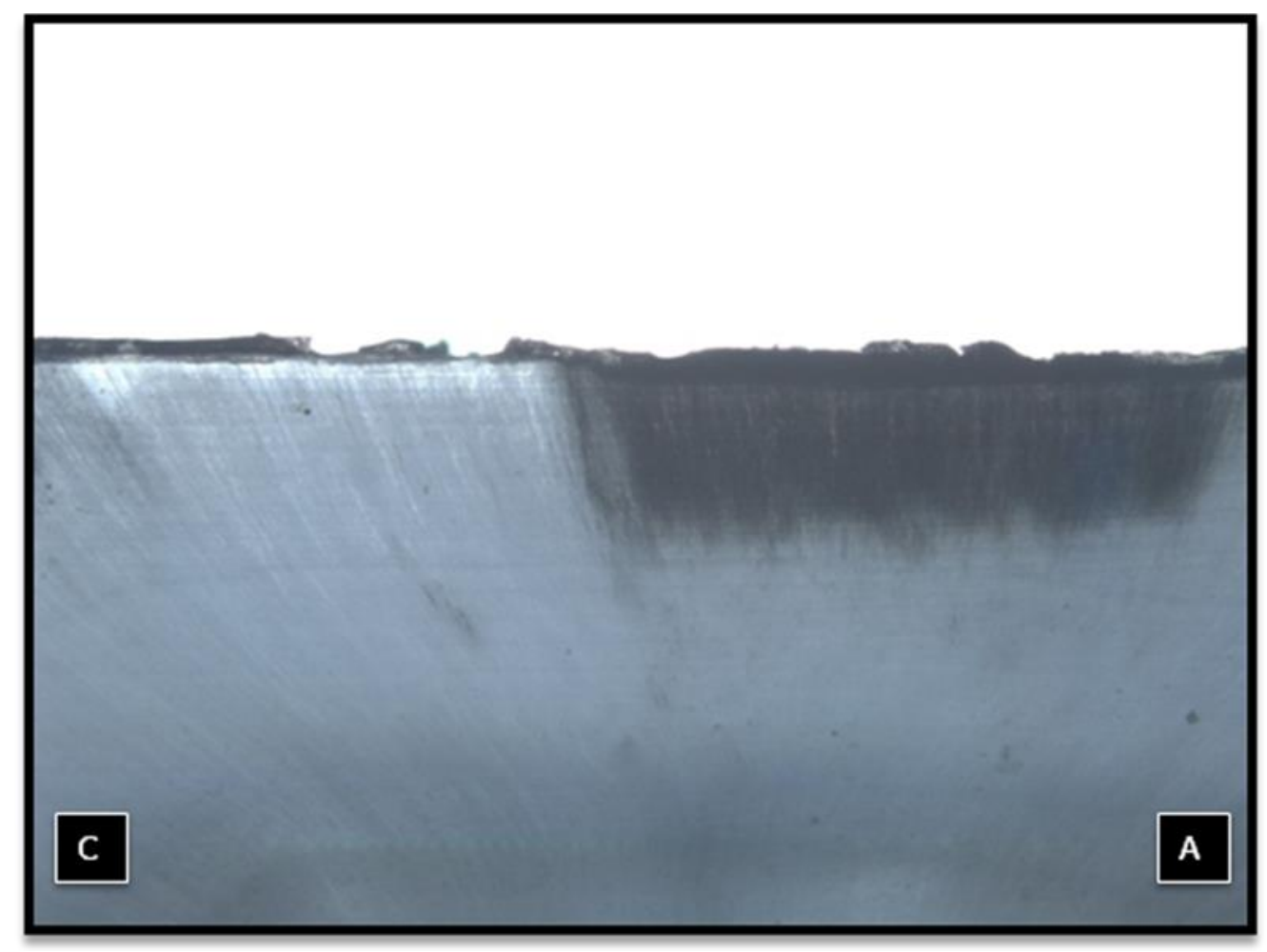

Figura 11. Secção do grupo 1: penetração dos íons de cobre. C. área controle (dentina hígida). A. área tratada (dentina erodida). 
Os dados obtidos foram analisados quanto a sua normalidade e homogeneidade e da seguinte forma: para a análise superficial, o fator de estudo tratamentos dessensibilizantes foram comparados por ANOVA a um critério e o fator tempo foi analisado internamente dentro de cada grupo pelo teste de Friedman. O teste de Tukey foi utilizado para diferenciar as médias $(\alpha=5 \%)$. Para a análise morfológica e da permeabilidade dentinária realizou-se a análise de variância e o teste de Tukey $(\alpha=5 \%)$.

\section{DELINEAMENTO EXPERIMENTAL DO ESTUDO IN VIVO}

O estudo in vivo avaliou o efeito do tratamento dessensibilizante que obteve os melhores resultados na primeira etapa do estudo (in vitro) em lesões cervicais erodidas em diferentes tempos. Nessa etapa, o fator de estudo foi o tratamento dessensibilizante em 2 níveis: sem tratamento (controle) e com tratamento. Ao todo foram selecionados 20 pacientes com lesões cervicais erodidas sendo estas divididas aleatoriamente nos dois grupos experimentais.

$\mathrm{O}$ estudo foi realizado de acordo com um delineamento em blocos completos casualizados. As variáveis de resposta para o estudo in vivo foram: desgaste superficial (quantitativa) avaliado em 7 diferentes tempos (correspondentes às sessões clínicas) e hipersensibilidade dentinária (qualitativa). A análise quantitativa foi realizada por meio da rugosidade, degrau e dimensão da lesão em microscopia confocal a laser 3D. A análise qualitativa foi avaliada através da Escala de Estimativa Numérica (Numeric Rating Scale NRS). 
Inicialmente, o protocolo de pesquisa foi submetido ao Comitê de Ética da Faculdade de Odontologia de Ribeirão (FORP-USP), Brasil, sendo aprovado (CAAE n⿳⺈ 34144014.0.0000.5419). Os pacientes foram esclarecidos verbalmente e por escrito sobre sua participação na pesquisa através do Termo de Consentimento Livre e Esclarecido que foi devidamente assinado pelos mesmos.

Ao todo foram selecionados 20 pacientes com presença de lesões cervicais não cariosas com exposição de dentina radicular e hipersensibilidade dentinária na região. Foi realizado um detalhado histórico médico e odontológico e através de um minucioso exame clínico os pacientes foram selecionados. Os critérios de exclusão foram: ausência de sensibilidade, dentes com evidência de pulpite, lesões de cárie, restaurações deficientes, contato prematuro e facetas de atrito (lesão de abfração), esmalte trincado, doença periodontal ativa ou qualquer outro fator que pode ser responsável pela sensibilidade dolorosa. Também foram excluídos pacientes em tratamento que utilizavam medicamentos diariamente, pacientes que passaram por alguma terapia de dessensibilização profissional nos últimos 3 meses, mulheres grávidas e lactantes.

Como critério de inclusão, as lesões cervicais não cariosas deveriam ser localizadas na superfície vestibular e terem característica de processos erosivos, dentina radicular exposta, podendo estar associados à abrasão e/ou recessão gengival. Os pacientes deveriam apresentar pelo menos duas lesões com sintomatologia positiva maior que o score 5 na Escala de Estimativa Numérica (Numeric Rating Scale - NRS) (FERREIRA-VALENTE; PAISRIBEIRO; JENSEN, 2011). 
O tratamento dessensibilizante foi realizado com o agente Desensibilize Nano P (FGM) que apresentou os melhores resultados para o controle das lesões no estudo in vitro. A aplicação foi realizada de acordo com as instruções do fabricante, porém sem o uso do disco de feltro a fim de evitar estimulo doloroso que poderia interferir nos resultados. $\mathrm{O}$ agente foi aplicado com auxílio de um microbrush com fricção durante 10 segundos, mantido com ligeiro excesso em contato com a superfície durante 5 minutos e depois removido com bolinha de algodão. Para o grupo controle, uma solução placebo foi manipulada e fornecida pelo fabricante FGM com a mesma composição, características quanto à apresentação e forma de aplicação do agente utilizado no grupo tratado, porém com ausência do princípio ativo predominante (nanopartículas de fosfato de cálcio).

Os tratamentos foram aplicados em 2 lesões em quadrantes diferentes, sendo assim, para um mesmo paciente, uma lesão foi selecionada para receber o tratamento dessensibilizante e outra selecionada para o grupo controle. Ao todo foram realizadas 4 sessões de tratamento com intervalo de 7 dias entre elas. O tratamento foi aplicado cegamente, ou seja, tanto o paciente como o operador não tinham conhecimento sobre quais soluções eram empregadas, sendo estas identificadas como solução A e B.

Na primeira consulta de triagem, o creme dental (Colgate Máxima Proteção Anticáries, Colgate-Pamolive Company, São Bernardo do Campo-SP, Brasil), a escova dental macia (OralB Indicator Plus, Macia 30, Procter \& Gamble do Brasil, Louveira-SP, Brasil) e o fio dental (Johnson\&Johnson Essencial, Reach, São José dos Campos, Brasil) foram fornecidos a todos os pacientes durante o período de avaliação. Dessa forma, uma semana antes do início dos tratamentos, os pacientes foram instruídos a utilizarem a escova e o dentifrício oferecidos e as lesões foram aleatoriamente distribuídas em 2 grupos (controle e tratado). 
Para análise do desgaste superficial das lesões erosivas em microscópio confocal a laser (metodologia descrita na primeira etapa), réplicas das mesmas foram confeccionadas através de moldagens realizadas no início de cada sessão clínica. Ao todo foram obtidas 7 réplicas de cada lesão em diferentes tempos correspondente às sessões clínicas. Foram realizadas 4 sessões de tratamento e 3 de avaliação pós-tratamento (1, 3 e 6 meses após).

As regiões correspondentes às lesões erosivas foram moldadas com silicona de adição (Express XT- 3M, Campinas, Brasil) para confecção de moldes de impressão de alta precisão. Foi utilizado o material leve e pesado manipulados e empregados de acordo com as instruções do fabricante. Uma vez obtido o molde, uma resina de poliéster incolor (Resina Epóxi, Arotec, Cotia - Brasil) foi utilizada para o vazamento dos moldes e confecção das réplicas. Para possibilitar a leitura no MCL, um esmalte metalizado (Colloidal Silver Liquid, Electron Microscopy Science, Hatfield-PA, EUA) foi aplicado no molde recobrindo toda a extensão da lesão e área circundante antes do vazamento do mesmo. Dessa forma, uma réplica incolor era obtida com a região da lesão metalizada e passível de ser analisada na microscopia. As réplicas foram adequadamente identificadas e imagens de 107x de aumento foram obtidas englobando a região das lesões para posterior avaliação das mesmas por meio do MCL (Figura 12). 


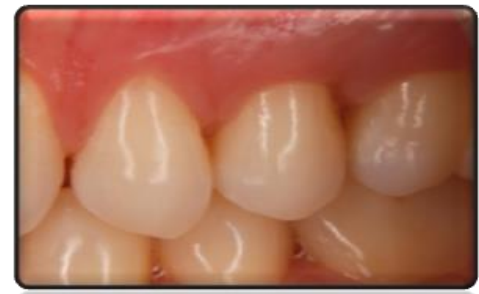

Lesão erosiva no dente 24 (cervical)

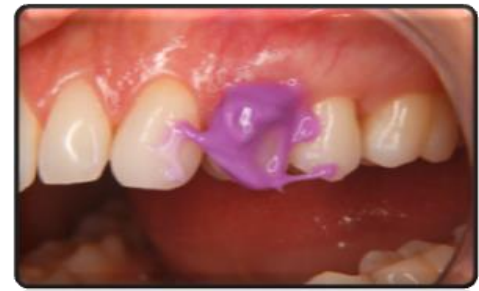

Moldagem da lesão (material leve)

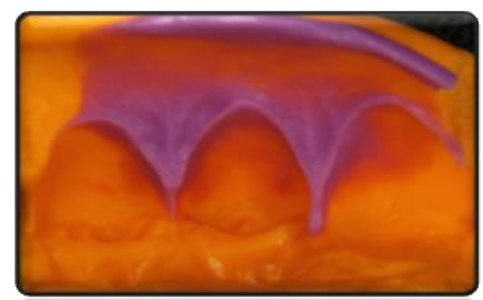

Molde obtido

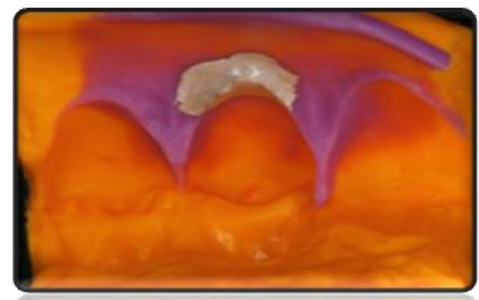

Molde pronto para vazamento da réplica

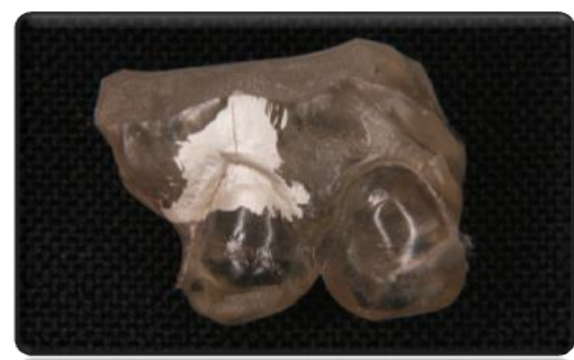

Réplica obtida para análise

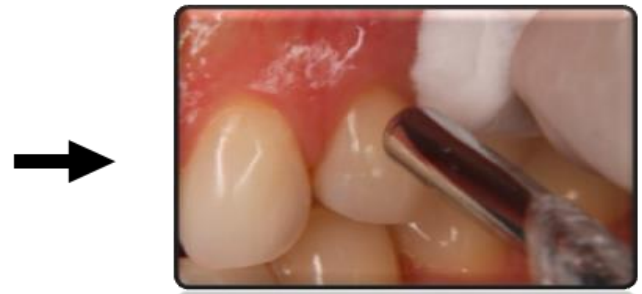

Teste de sensibilidade inicial (aplicação do jato de ar)

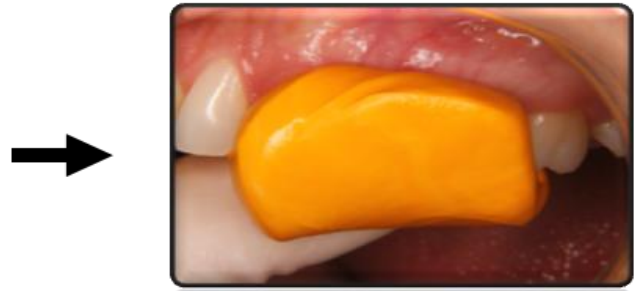

Moldagem da lesão (material pesado)

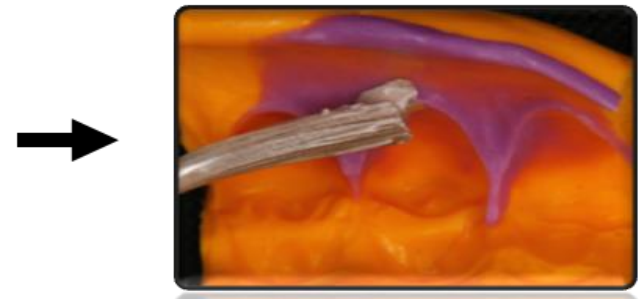

Aplicação do esmalte metálico na região da lesão

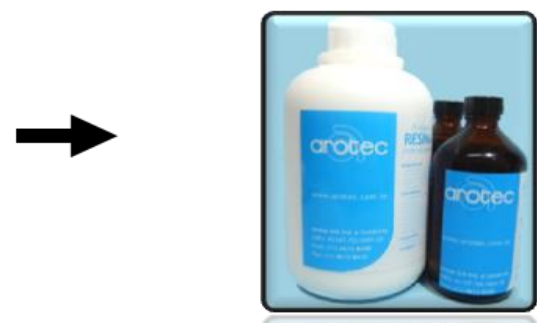

Resina epóxi utilizada para confecção das réplicas

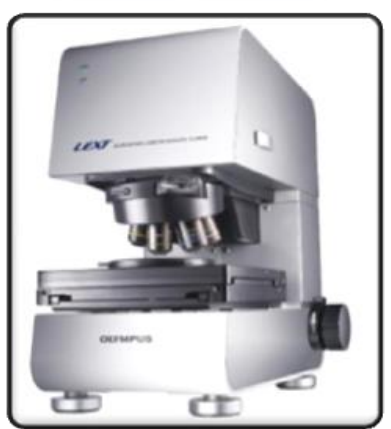

MCL utilizado para obtenção das imagens das réplicas

Figura 12. Sequência para obtenção das réplicas. 
Para a análise do desgaste superficial foi utilizada uma imagem englobando a lesão erosiva, uma porção do tecido gengival e outra do tecido dentário (Figuras 13 e 14). A obtenção das imagens de uma mesma lesão foi padronizada a fim de compará-las nos diferentes tempos.

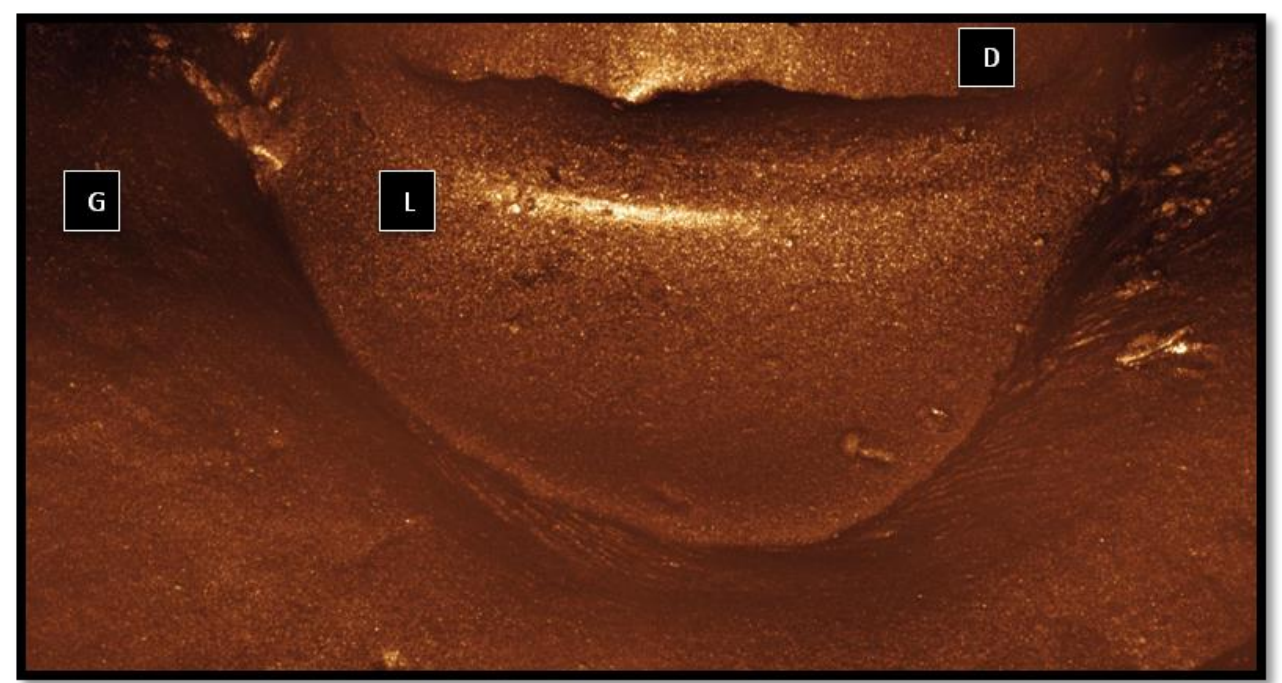

Figura 13. Imagem 2D adquirida da lesão erosiva para análise do desgaste superficial: lesão erosiva (L), tecido gengival (G) e tecido dentário (D) (107x de aumento).

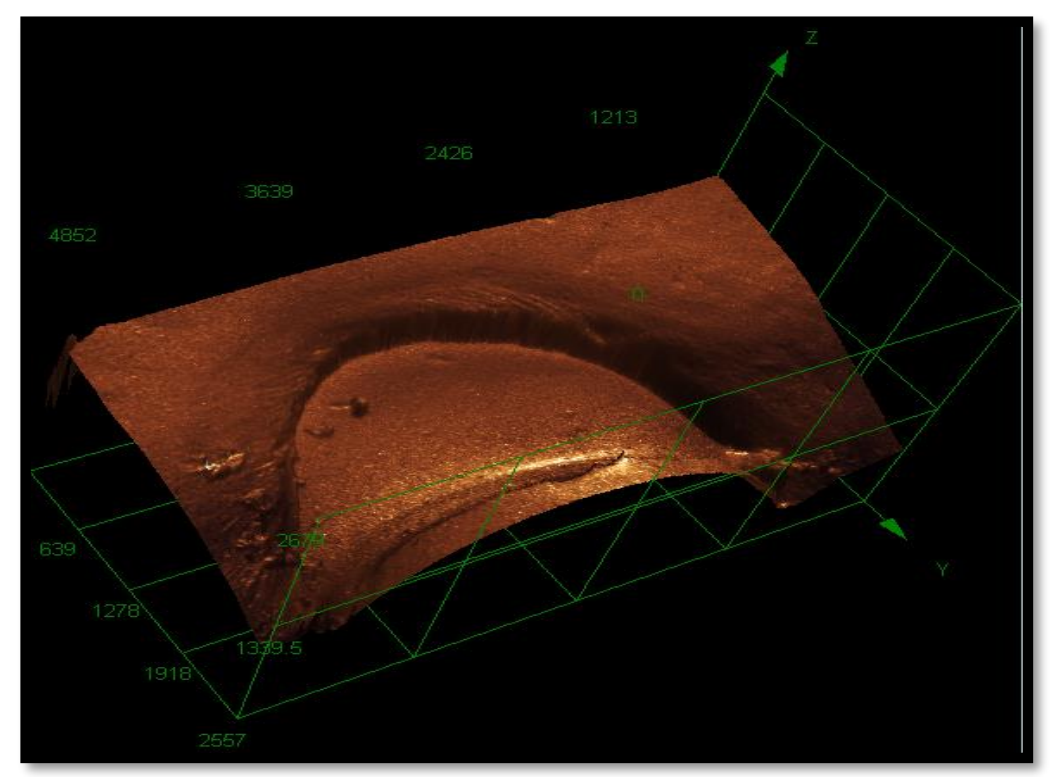

Figura 14. Imagem 3D adquirida da lesão erosiva para análise do desgaste superficial (107x de aumento). 
Para a análise do degrau, uma linha paralela à lesão foi determinada na superfície dentária como referência. A medida foi realizada através de marcações entre a linha de referência no dente e um ponto na lesão de forma que toda extensão da lesão fosse englobada (Figura 15). Para a análise da rugosidade, foram realizadas leituras somente da área correspondente à lesão (Figura 16). A avaliação da dimensão da lesão foi realizada pela mensuração da altura (medida linear entre dois pontos nos limites da lesão) e o perímetro da mesma. As marcações para mensurar a altura foram realizadas da mesma forma descrita na rugosidade. Para análise do perímetro da lesão, o mesmo foi determinado e delimitado pelo operador e mensurado pelo software (Figura 17). O número de marcações realizadas nas imagens foi determinado de acordo com o tamanho de cada lesão e com a variável de resposta em questão. Para uma mesma lesão a quantidade e posição das marcações foram padronizadas a fim de permitir a avaliação da mesma em diferentes tempos. Ao todo foram realizadas 7 avaliações para cada lesão sendo estas correspondentes às sessões clínicas. Os dados foram fornecidos em micrometros $(\mu \mathrm{m})$ e obtidos por meio de um software específico (Olympus LEXT OLS4000®).

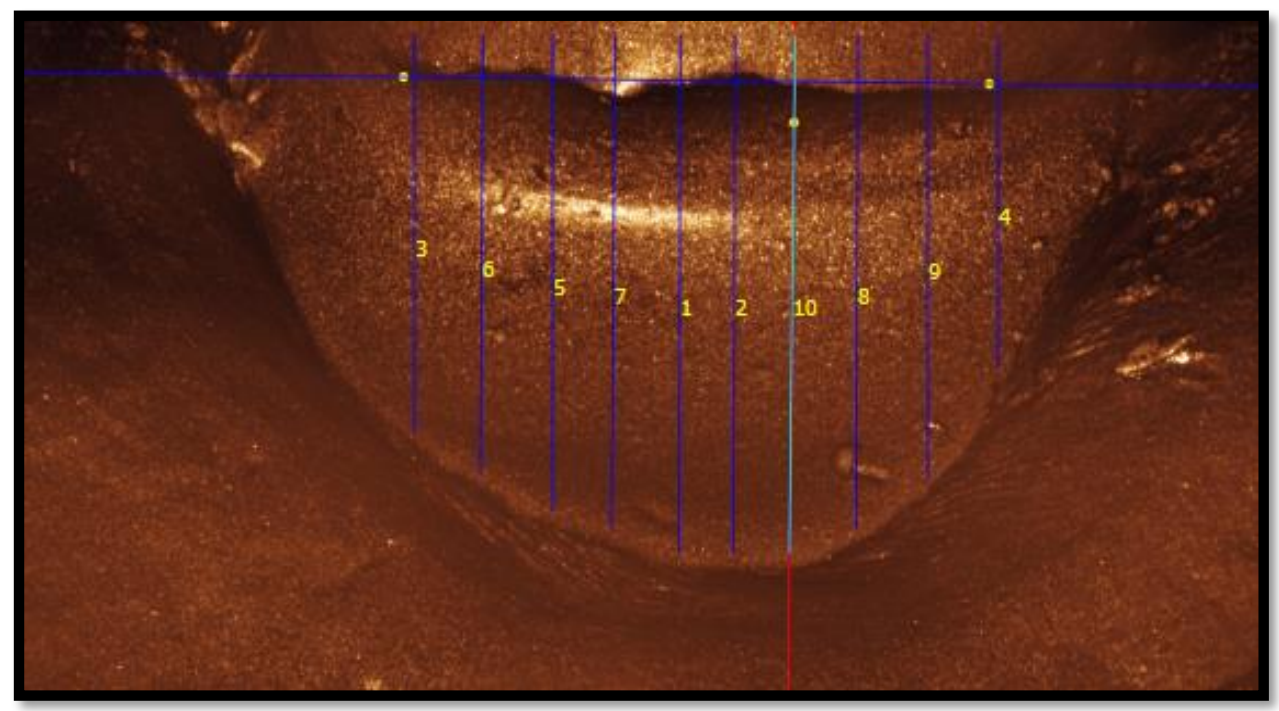

Figura 15. Mensuração do degrau da lesão. 


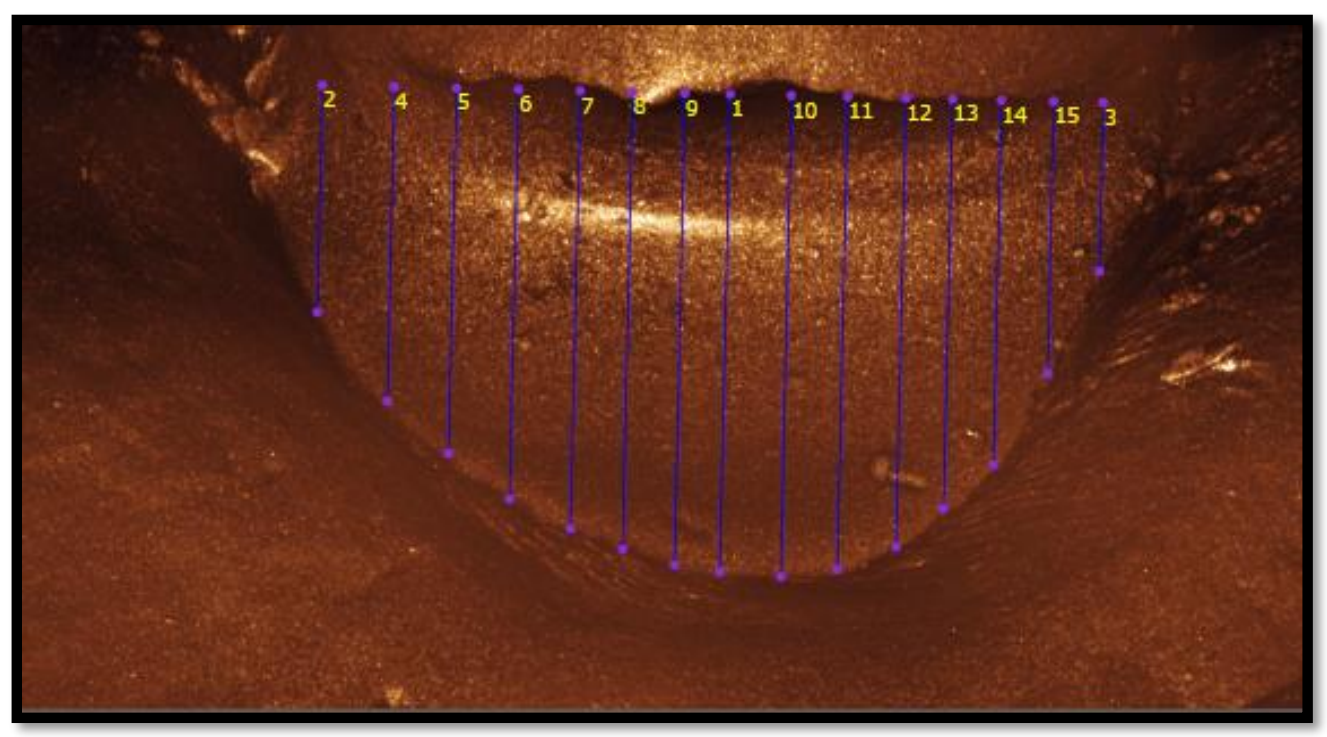

Figura 16. Mensuração da rugosidade e altura da lesão.

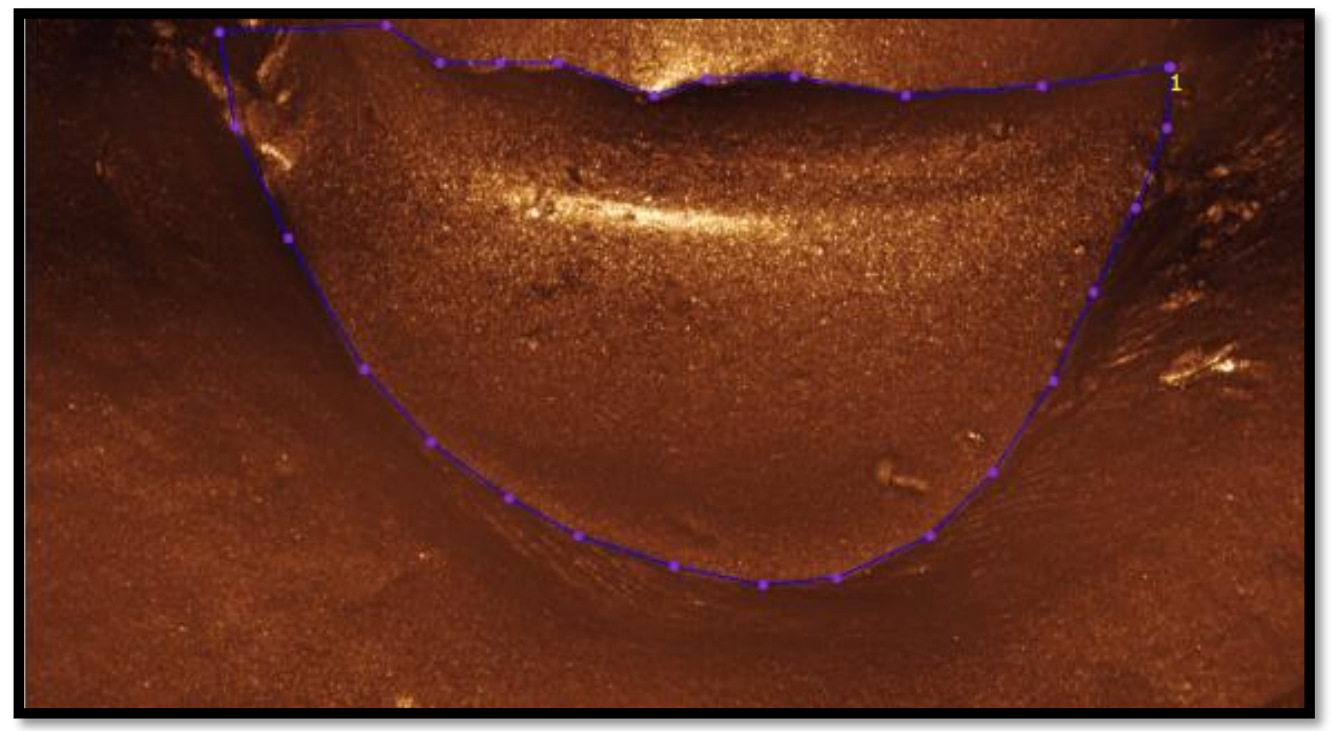

Figura 17. Mensuração do Perímetro da lesão. 
A avaliação da sensibilidade foi realizada em todas as sessões antes e após a aplicação do agente dessensibilizante através da Escala de Estimativa Numérica (Numeric Rating Scale NRS). A escala é constituída de 11 pontos (score de 0 a 10) onde " 0 " representa nenhuma dor e "10" a pior dor imaginável. Essa escala quando comparada a outras é considerada a mais sensível delas apresentando superioridade na capacidade de resposta e capacidade de detectar diferenças entre os sexos (FERREIRA-VALENTE; PAIS-RIBEIRO; JENSEN, 2011). Os voluntários foram questionados em relação à intensidade de dor após estímulo e relataram a mesma através de um número inteiro. $\mathrm{O}$ procedimento foi realizado previamente à moldagem, antes da aplicação dos agentes, e cinco minutos após a o tratamento. Já nas sessões de acompanhamento o teste foi realizado apenas uma vez no início da sessão. Para a realização do estímulo, os dentes vizinhos foram isolados com roletes de algodão e então o jato de ar foi aplicado durante 1 segundo a uma distância de $1 \mathrm{~cm}$ do dente para evitar a dessecação da superfície da dentina (CAMILOTTI et al., 2012) (Figura 18). A análise também foi realizada cegamente. 


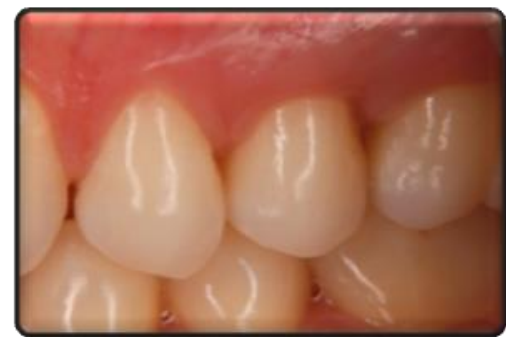

Lesão erosiva no dente 24 (cervical)

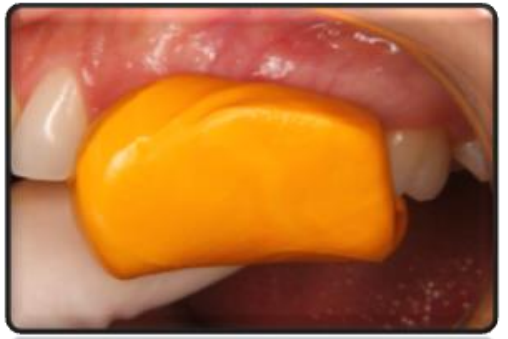

Moldagem da lesão (para obtenção da réplica)

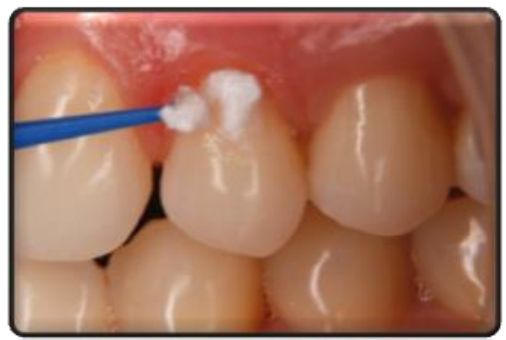

Aplicação dos tratamentos

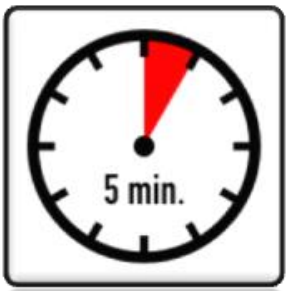

Intervalo de 5 minutos para nova avaliação

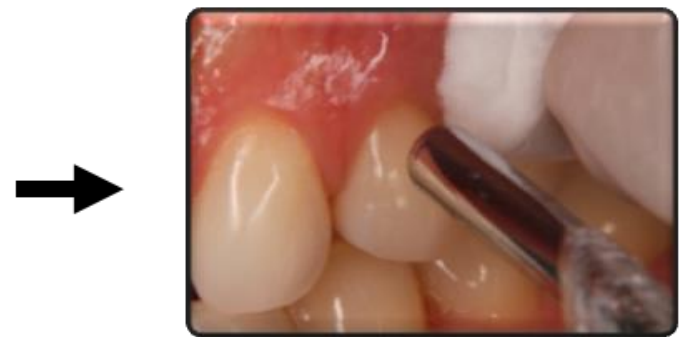

Teste de sensibilidade inicial (aplicação do jato de ar)

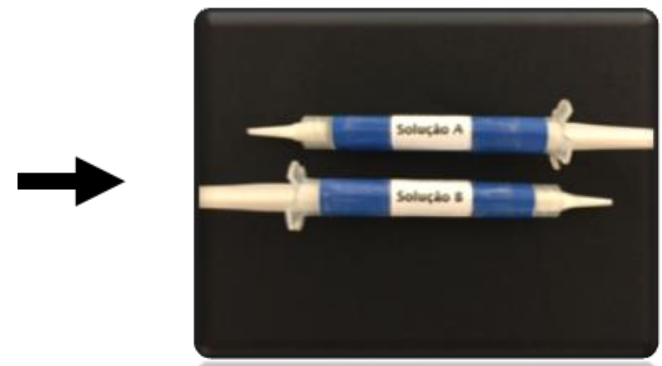

Identificação dos agentes para tratamento

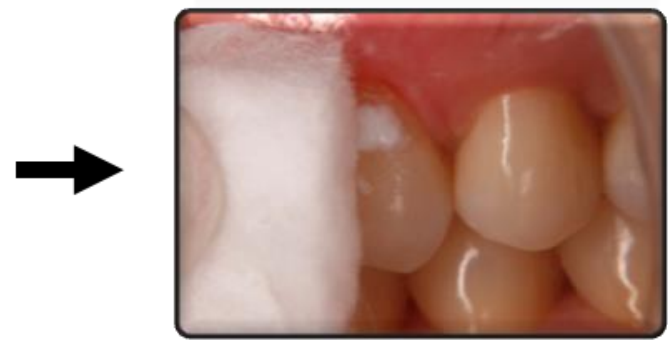

Remoção dos excessos

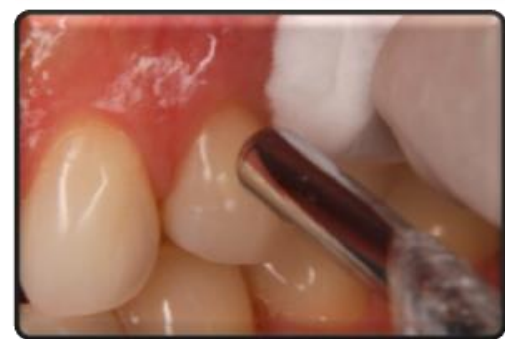

Teste de sensibilidade Final (término da sessão)

Figura 18. Sequência clínica para avaliação da sensibilidade dentinária. 
Ao final da pesquisa os voluntários receberam o devido tratamento para reduzir a hipersensibilidade dentinária, assim como o tratamento restaurador necessário. Essa informação consta no Termo de Consentimento Livre e Esclarecido aprovado pelo Comitê de Ética em Pesquisa e devidamente entregue e assinado pelos voluntários.

\section{ANÁLISE DOS DADOS}

Os dados obtidos foram analisados quanto a sua normalidade e homogeneidade. Para aqueles que foram normais realizou-se análise de variância e os que não foram normais realizou-se os testes de Friedman e Kruskall-Wallis e como complementar o teste de Tukey $(\alpha=5 \%)$. Para análise da hipersensibilidade dentinária, os dados foram submetidos ao teste nãoparamétrico Wilcoxon com significância de 5\%. 


\section{ESTUDO IN VITRO}

\section{ANÁLISE SUPERFICIAL X TEMPO}

De acordo com os dados obtidos, foram encontradas diferenças estatísticas significantes para as variáveis nos diferentes tempos $(\mathrm{p}<0,05)$ (Tabela 2).

Tabela 2. Médias e desvio padrão dos grupos nos diferentes tempos para rugosidade (Ra em $\mu \mathrm{m})$, perfil de desgaste $(\mathrm{Rv}$ em $\mu \mathrm{m})$, degrau $(\mu \mathrm{m})$ e perda de volume $\left(\mu \mathrm{m}^{3}\right)$.

\begin{tabular}{|c|c|c|c|c|c|c|c|}
\hline Variáveis & $\begin{array}{l}\text { Tempos } \\
\text { Grupos }\end{array}$ & G1 & G2 & G3 & G4 & G5 & G6 \\
\hline \multirow{5}{*}{ Rugosidade } & Inicial & $0,72 \pm 0,09 a A B$ & $0,68 \pm 0,11 \mathrm{aAB}$ & $0,63 \pm 0,05 a A$ & $0,69 \pm 0,11 \mathrm{aAB}$ & $0,71 \pm 0,13 \mathrm{aAB}$ & $0,79 \pm 0,15 a В$ \\
\hline & 10 dia & $1,06 \pm 0,19 b c B$ & $0,77 \pm 0,08 a A$ & $1,01 \pm 0,08 \mathrm{bB}$ & $1,05 \pm 0,14 c B$ & $1,07 \pm 0,14 \mathrm{bB}$ & $1,15 \pm 0,11 b B$ \\
\hline & $4^{\circ}$ dia & $1,15 \pm 0,15 \mathrm{cB}$ & $0,99 \pm 0,11 b A$ & $1,11 \pm 0,15$ bcA & $1,04 \pm 0,12 \mathrm{cAB}$ & $1,10 \pm 0,13 \mathrm{bAB}$ & $1,09 \pm 0,18 \mathrm{bAB}$ \\
\hline & 70 dia & $1,06 \pm 0,13 b c A B$ & $0,93 \pm 0,14 \mathrm{bA}$ & $1,16 \pm 0,10 \mathrm{cB}$ & $0,99 \pm 0,13 \mathbf{c A}$ & $0,98 \pm 0,11 b \mathbf{b A}$ & $1,18 \pm 0,09 b B$ \\
\hline & 9o dia & $0,96 \pm 0,18 \mathrm{bAB}$ & $1,01 \pm 0,33 \mathrm{bBCD}$ & $1,03 \pm 0,14 \mathrm{bcCD}$ & $0,84 \pm 0,14 b A$ & $0,87 \pm 0,13 \mathrm{bAB}$ & $1,14 \pm 0,09 b D$ \\
\hline \multirow{5}{*}{$\begin{array}{l}\text { Perfil de } \\
\text { Desgaste }\end{array}$} & Inicial & $1,40 \pm 0,17 \mathrm{eEF}$ & $1,32 \pm 0,24 \mathrm{eEF}$ & $1,23 \pm 0,10 \mathrm{eE}$ & $1,33 \pm 0,24 \mathrm{eEF}$ & $1,38 \pm 0,25 \mathrm{eEF}$ & $1,54 \pm 0,29 \mathrm{eF}$ \\
\hline & 10 dia & $2,06 \pm 0,40 \mathrm{fE}$ & $1,50 \pm 0,16 \mathrm{fE}$ & $1,97 \pm 0,14 \mathrm{eF}$ & $2,05 \pm 0,26 \mathrm{gE}$ & $2,09 \pm 0,26 \mathrm{gE}$ & $2,25 \pm 0,24 \mathrm{fG}$ \\
\hline & $4^{\circ}$ dia & $2,2 \pm 0,27 f F$ & $1,91 \pm 0,21 \mathrm{fE}$ & $2,13 \pm 0,30 f E F$ & $2,00 \pm 0,24 \mathrm{gEF}$ & $2,14 \pm 0,24 \mathrm{gEF}$ & $2,11 \pm 0,3 \mathrm{fEF}$ \\
\hline & $7^{\circ}$ dia & $2,018 \pm 0,24 \mathrm{fEF}$ & $1,76 \pm 0,29 \mathrm{fE}$ & $2,21 \pm 0,18 f F G$ & $1,92 \pm 0,24 \mathrm{gE}$ & $1,84 \pm 0,32 \mathrm{fgE}$ & $2,31 \pm 0,19 f G$ \\
\hline & 9o dia & $1,84 \pm 0,33 \mathrm{eF}$ & $1,82 \pm 0,28 \mathrm{fE}$ & $1,98 \pm 0,30 \mathrm{fF}$ & $1,63 \pm 0,26 \mathrm{fE}$ & $1,68 \pm 0,23 \mathrm{fE}$ & $2,24 \pm 0,34 \mathrm{fF}$ \\
\hline \multirow{4}{*}{ Degrau } & 10 dia & $21,94 \pm 9,19 \mathrm{hH}$ & $16,11 \pm 9,68 \mathrm{hH}$ & $16,04 \pm 6,48 \mathrm{hH}$ & $27,09 \pm 12,38 \mathrm{hH}$ & $19,25 \pm 9,63 \mathrm{hH}$ & $21,14 \pm 16,53 \mathrm{hH}$ \\
\hline & 4ㅇ dia & $29,68 \pm 14,68 \mathrm{hiHI}$ & $44,42 \pm 42,11 \mathrm{iHI}$ & $20,82 \pm 7,25 \mathrm{hiH}$ & $52,59 \pm 26,32 \mathrm{il}$ & $39,94 \pm 27,78 \mathrm{hiHI}$ & $32,37 \pm 20,24 \mathrm{iHI}$ \\
\hline & 70 dia & $32,81 \pm 11,66 \mathrm{hiHI}$ & $48,05 \pm 34,06 \mathrm{iHI}$ & $25,57 \pm 9,97 \mathrm{hH}$ & $56,03 \pm 30,49 \mathrm{il}$ & $44,61 \pm 25,81 \mathrm{iHI}$ & 42,22 $\pm 19,41$ jHI \\
\hline & 9o dia & $35,96 \pm 15,45 \mathrm{iHI}$ & $37,34 \pm 20,46 \mathrm{iHI}$ & $22,52 \pm 11,91 \mathrm{hiH}$ & $49,45 \pm 35,060 \mathrm{iHI}$ & $40,12 \pm 27,88 \mathrm{iHI}$ & $50,17 \pm 16,78 \mathbf{k l}$ \\
\hline \multirow{4}{*}{$\begin{array}{c}\text { Perda de } \\
\text { Volume }\end{array}$} & 10 dia & $13,73 \pm 4,71 \mathrm{IL}$ & $13,31 \pm 6,24 \mathrm{IL}$ & $9,89 \pm 4,07 \mathrm{IL}$ & $16,56 \pm 7,34 \mathrm{IL}$ & $11,45 \pm 5,34 \mathrm{IL}$ & $13,66 \pm 9,50 \mathrm{IL}$ \\
\hline & $4^{\circ}$ dia & $15,31 \pm 10,22$ IL & $20,42 \pm 7,88 \mathrm{mLM}$ & $14,64 \pm 4,47$ ILM & $26,01 \pm 6,34 \mathrm{ImM}$ & $22,04 \pm 13,99 \mathrm{mLM}$ & $19,84 \pm 12,29 \mathrm{nLM}$ \\
\hline & $7^{\circ}$ dia & $16,65 \pm 7,51$ ILM & $21,30 \pm 11,90 \mathrm{mLM}$ & $15,15 \pm 5,18 \mathrm{IL}$ & $25,21 \pm 7,52 \mathrm{mM}$ & $19,91 \pm 9,57 \mathrm{mLM}$ & $26,66 \pm 12,74 \mathrm{mLM}$ \\
\hline & 9o dia & $16,47 \pm 8,41 \mathrm{IL}$ & $19,02 \pm 11,35 \mathrm{mLM}$ & $13,32 \pm 7,51 \mathrm{IL}$ & $21,74 \pm 10,47 \mathrm{ImLM}$ & $16,13 \pm 7,94 \mathrm{~mL}$ & $31,55 \pm 11,21 \mathrm{mM}$ \\
\hline
\end{tabular}

Letras minúsculas iguais indicam semelhança estatística na mesma coluna nos diferentes tempos. Letras maiúsculas iguais indicam semelhança estatística na mesma linha para os diferentes tratamentos. 
Para a rugosidade nos diferentes tempos, o G2 apresentou aumento estatisticamente significativo a partir do $4^{\circ}$ dia $(\mathrm{p}<0,05)$. Os demais grupos foram semelhantes entre si, apresentando aumento estatisticamente significante na rugosidade a partir do $1^{\circ}$ dia $(p<0,05)$. Após este período, a rugosidade foi alterada, porém não houve diferença significante entre os tempos $(p>0,05)$ (Figura 19).

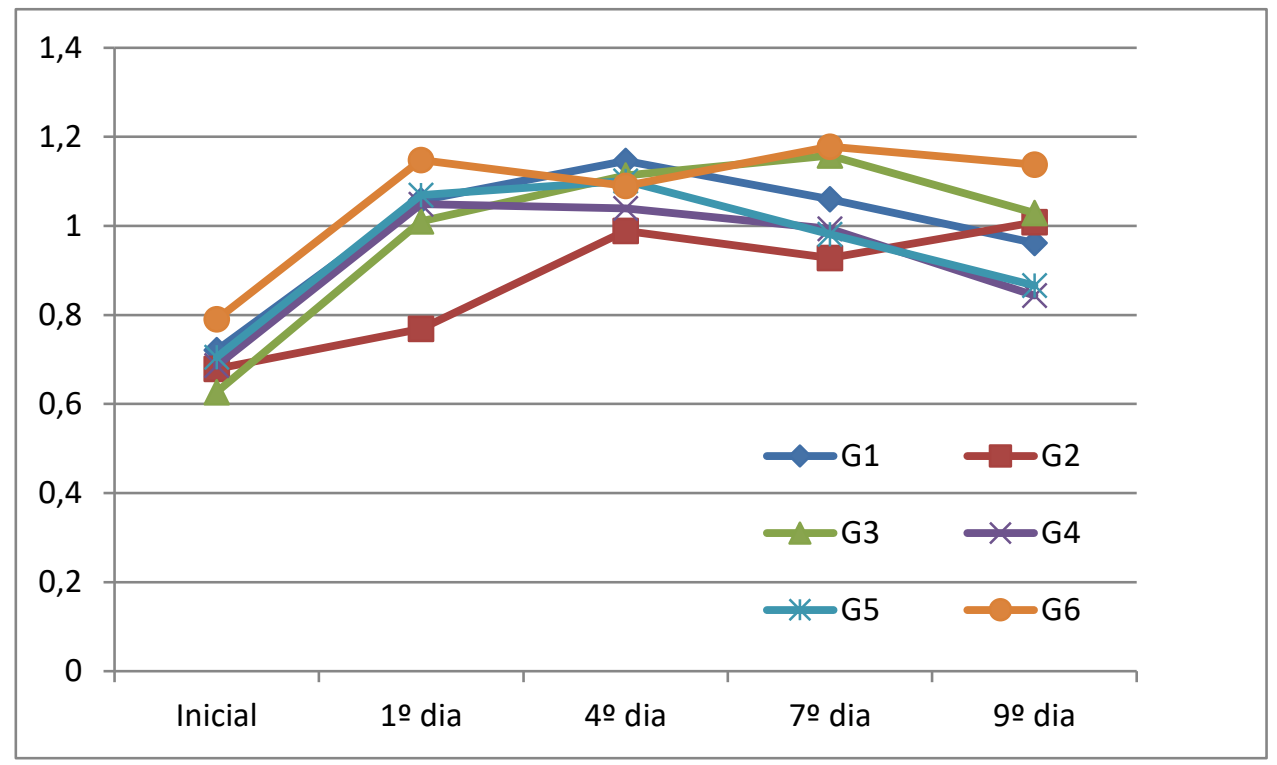

Figura 19. Rugosidade ( $\mathrm{Ra})$ nos diferentes tempos $(\mu \mathrm{m})$. 
Para o perfil de desgaste, o grupo G2 apresentou aumento estatisticamente significante a partir do $4^{\circ}$ dia $(p<0,05)$ e o grupo G4 não apresentou diferença estatística nos valores a partir do tempo inicial $(\mathrm{p}>0,05)$. Os demais grupos foram semelhantes entre si e apresentaram aumento estatisticamente significativo no perfil de desgaste no $1^{\circ}$ dia $(\mathrm{p}<0,05)$. Após esse período, houve alteração nos valores, porém sem significância estatística entre os tempos (p> 0,05) (Figura 20).

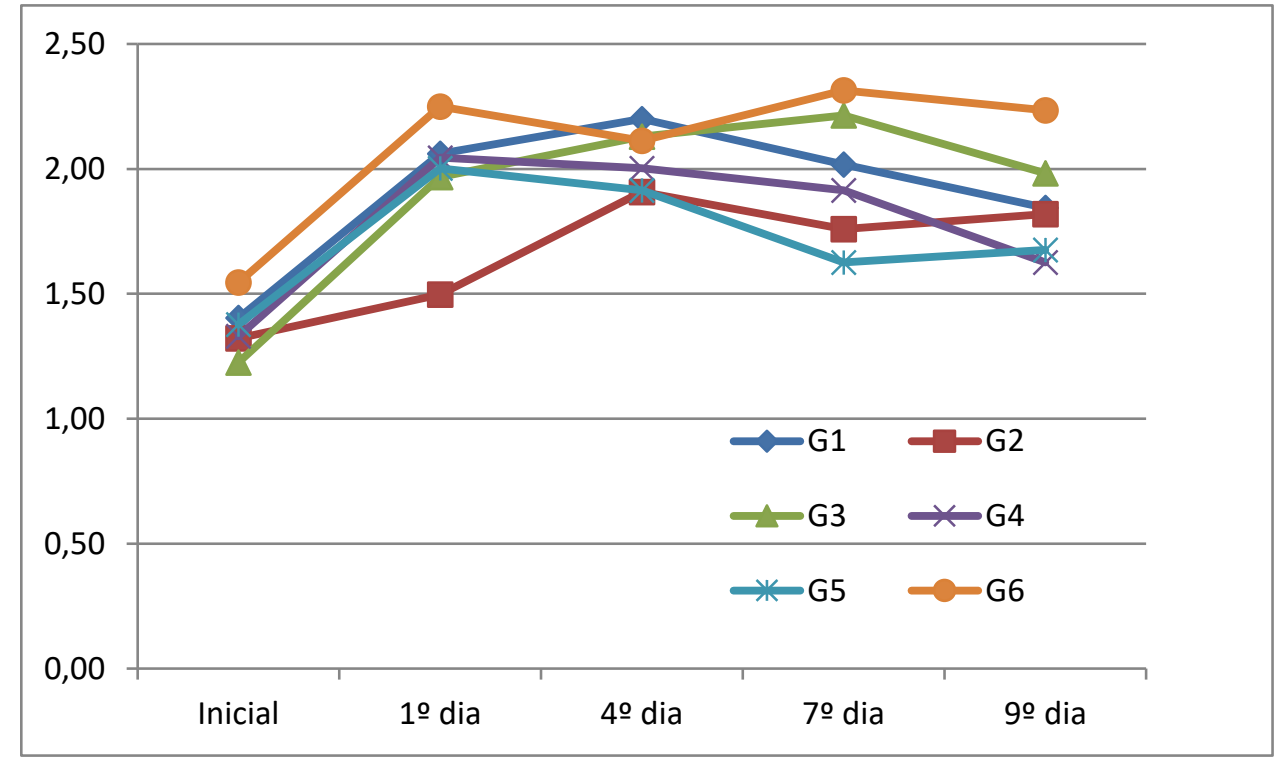

Figura 20. Perfil de Desgaste (Rv) nos diferentes tempos $(\mu \mathrm{m})$. 


\section{DEGRAU X TEMPO}

Com relação ao degrau, o grupo G1 mostrou um aumento gradual dos valores estatisticamente significativo apenas a partir do $9^{\circ}$ dia $(p<0,05)$. Nos grupos G2, G4 e G5, apenas o $4^{\circ}$ dia apresentou valores estatisticamente diferentes do $1^{\circ}$ dia $(p>0,05)$, houve um aumento gradual nos valores, porém sem significância entre os tempos ( $p>0,05)$. No G3 houve um aumento significativo do degrau apenas a partir do $7^{\circ}$ dia $(\mathrm{p}<0,05)$. O grupo G6 apresentou um aumento gradual e significativo durante todo desafio erosivo $(\mathrm{p}<0,05)$ (Figura 21).

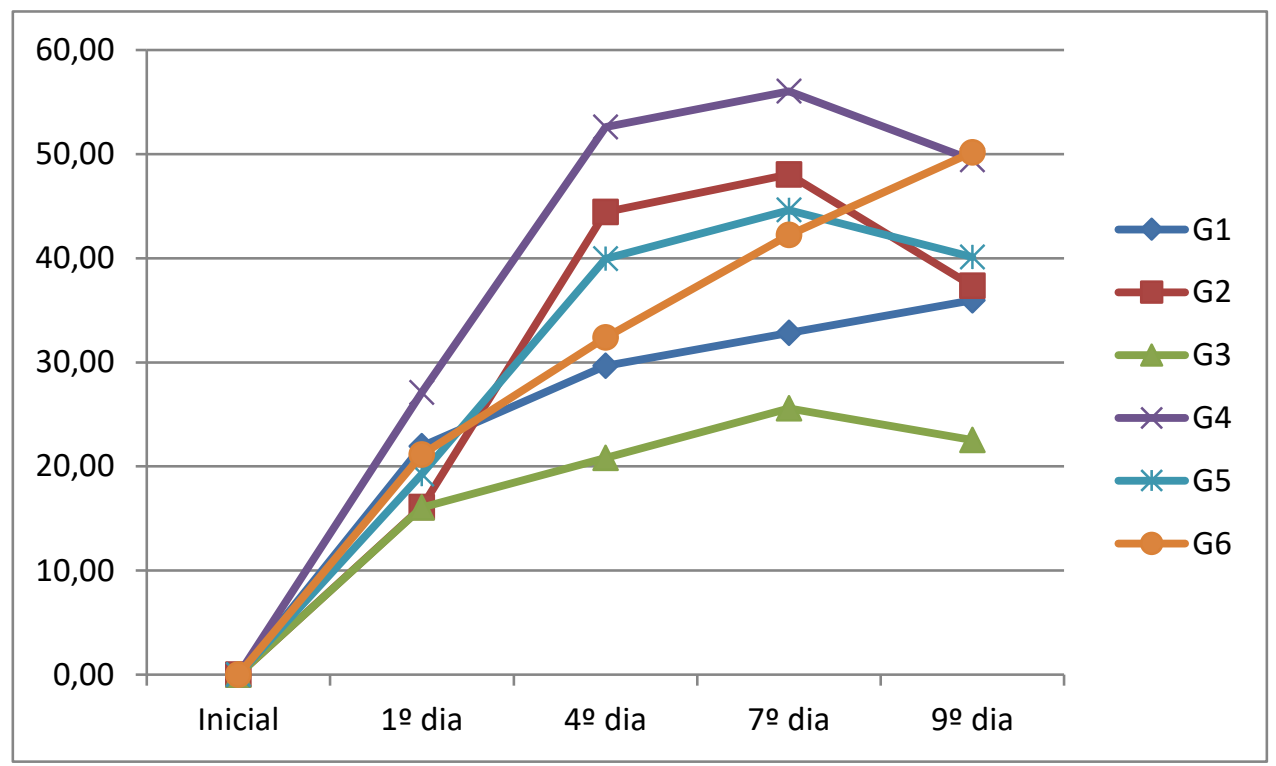

Figura 21. Degrau nos diferentes tempos $(\mu \mathrm{m})$. 
Quanto à perda de volume, os grupos G1 e G3 apresentaram aumento dos valores sem significância estatística entre os tempos (p>0,05). O G6 apresentou um aumento gradual e significativo dos valores durante toda ciclagem erosiva $(\mathrm{p}<0,05)$. Para os demais grupos, houve um aumento gradual da perda de volume, porém sem significância estatística ( $p>0,05)$, apenas os valores do $4^{\circ}$ dia foram estatisticamente diferentes do $1^{\circ}$ dia ( $\left.p>0,05\right)$ (Figura 23).

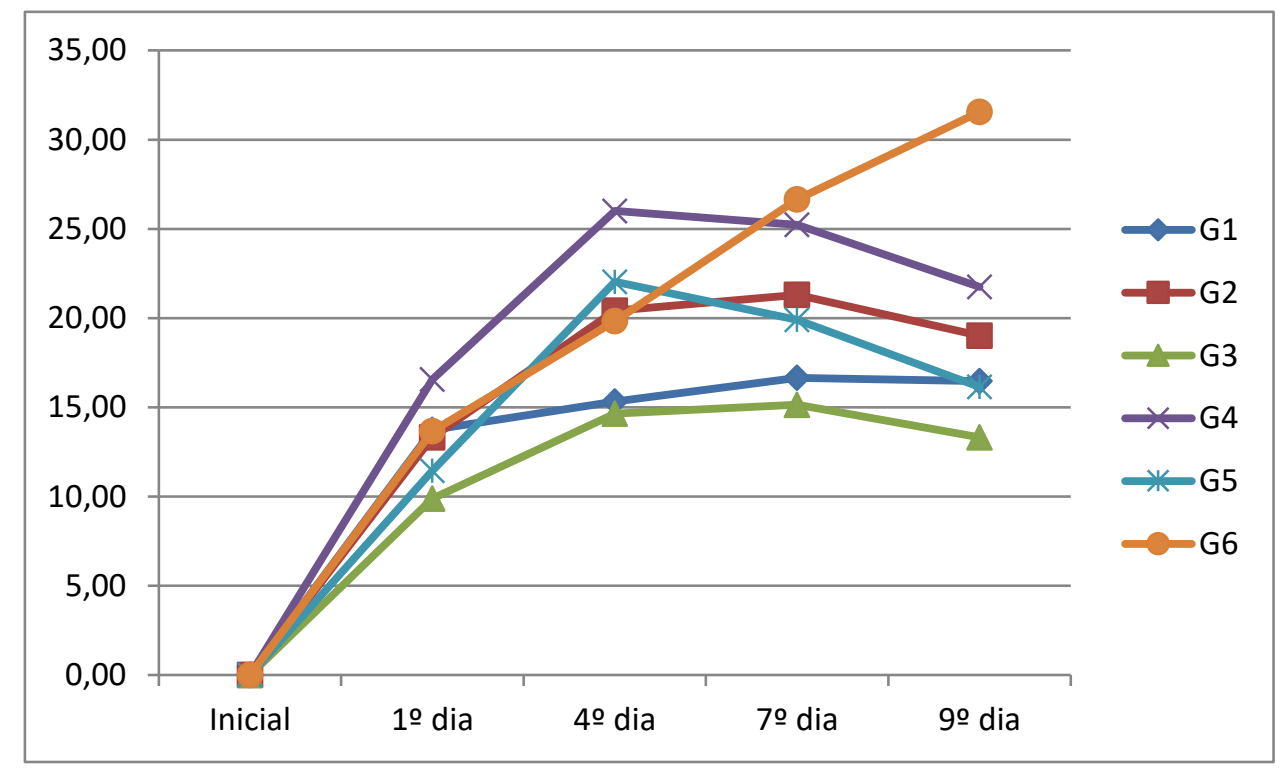

Figura 22. Perda de Volume nos diferentes tempos $\left(\mu \mathrm{m}^{3}\right)$. 
Ao final da ciclagem erosiva/tratamentos, o grupo G2 foi o que apresentou o menor valor de rugosidade sendo estatisticamente diferente dos demais $(\mathrm{p}<0,05)$. Para o perfil de desgaste, o G2 apresentou os valores mais baixos sendo semelhantes aos grupos G4 e G5 (p> 0,05). O G6 apresentou os maiores valores para rugosidade e perfil de desgaste $(\mathrm{p}<0,05)$. Para o degrau e perda de volume, o G3 apresentou os menores valores sendo estatisticamente diferentes dos demais grupos $(\mathrm{p}<0,05)$. Na tabela 3 estão descritas as médias e o desvio padrão dos grupos para as diferentes variáveis de resposta:

Tabela 3. Médias e desvio padrão dos diferentes grupos para rugosidade (Ra), perfil de desgaste $(\mathrm{Rv})$, degrau $(\mu \mathrm{m})$ e perda de volume $\left(\mu \mathrm{m}^{3}\right)$.

\begin{tabular}{ccccc} 
& Rugosidade & Perfil de Desgaste & Degrau & Perda de Volume \\
\hline G1 & $0,99 \pm 0,09 \mathrm{ab}$ & $1,91 \pm 0,17 \mathrm{~b}$ & $35,82 \pm 6,64 \mathrm{~b}$ & $17,58 \pm 4,17 \mathrm{ab}$ \\
\hline G2 & $0,88 \pm 0,11 \mathrm{c}$ & $1,66 \pm 0,22 \mathrm{c}$ & $29,03 \pm 7,10 \mathrm{~b}$ & $16,02 \pm 3,02 \mathrm{~b}$ \\
\hline G3 & $0,99 \pm 0,05 \mathrm{ab}$ & $1,90 \pm 0,99 \mathrm{~b}$ & $17,31 \pm 5,09 \mathrm{a}$ & $10,41 \pm 2,83 \mathrm{a}$ \\
\hline G4 & $0,92 \pm 0,11 \mathrm{~b}$ & $1,78 \pm 0,23 \mathrm{bc}$ & $34,59 \pm 4,68 \mathrm{~b}$ & $20,66 \pm 5,38 \mathrm{c}$ \\
\hline G5 & $0,95 \pm 0,13 \mathrm{~b}$ & $1,82 \pm 0,24 \mathrm{bc}$ & $27,69 \pm 4,36 \mathrm{~b}$ & $15,19 \pm 4,10 \mathrm{~b}$ \\
\hline G6 & $1,07 \pm 0,15 \mathrm{a}$ & $2,09 \pm 0,29 \mathrm{a}$ & $28,63 \pm 6,37 \mathrm{~b}$ & $16,07 \pm 4,08 \mathrm{ab}$ \\
\hline
\end{tabular}

Mesma letra indica semelhança estatística. 

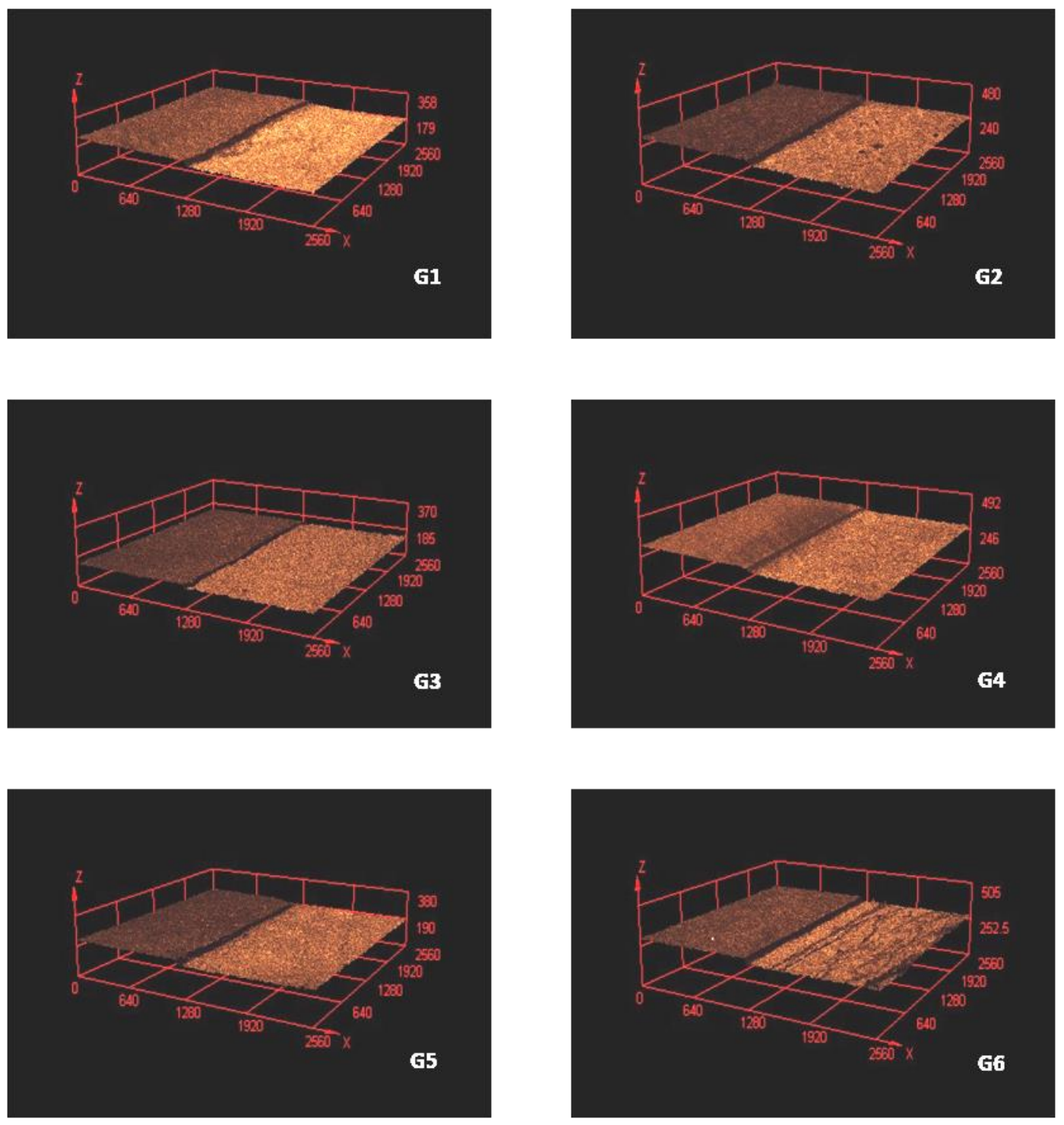

Figura 23. Imagens 3D representativas dos diferentes grupos no final da ciclagem erosiva/tratamentos com área controle (esquerda) e área tratada (direita): o degrau observado corresponde ao desgaste superficial final dos grupos. 
Para a análise morfológica, o número e área dos túbulos foram avaliados imediatamente após cada aplicação dos tratamentos e ao final de cada dia. De acordo com os dados obtidos, o grupo G5 foi o que apresentou o menor número e área de túbulos dentinários expostos durante toda ciclagem erosiva sendo estatisticamente diferente dos demais grupos $(p<0,05)$. Em contrapartida, o grupo G2 foi o que apresentou os maiores valores sendo estatisticamente diferente dos demais ( $\mathrm{p}<0,05)$. Os grupos $\mathrm{G} 1, \mathrm{G} 3$, G4 e G6 foram semelhantes entre si $(\mathrm{p}>0,05)$ (Figura 24).
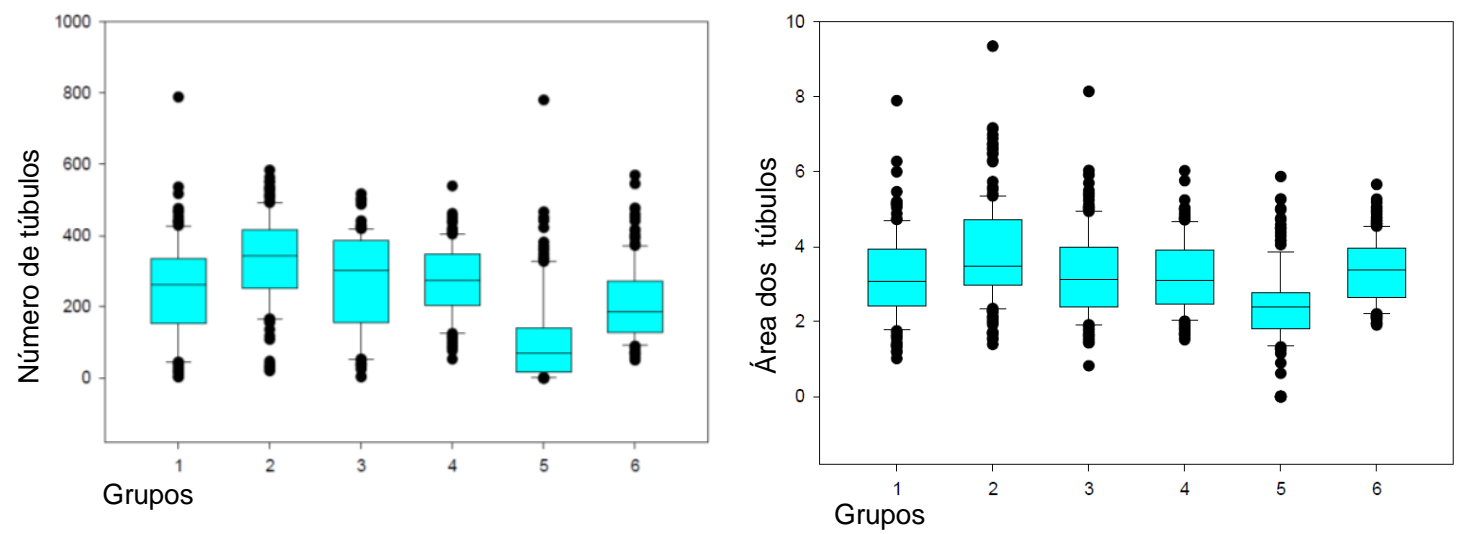

Figura 24. Gráficos representativos do número e área de túbulos dentinários abertos para os diferentes grupos.

Em relação aos diferentes tempos, os grupos apresentaram resultados semelhantes quanto ao número e área de túbulos dentinários expostos (Figura 25 e 26). No grupo G1, não houve diferença estatisticamente significante entre os diferentes tempos ( $p>0,05)$. Para os grupos G2 e G3, as primeiras aplicações dos agentes (Av2 e Av6) diminuíram o número e a área de túbulos expostos, porém nos demais tempos os valores aumentaram; o $6^{\circ}$ dia (Av9) foi o que apresentou o maior número $(\mathrm{p}<0,05)$ e os tempos finais foram semelhantes ao tempo inicial (p>0,05). Nos grupos G4 e G5, os túbulos expostos foram diminuindo a cada aplicação e progressivamente até o final da ciclagem sendo que o grupo G5 apresentou os menores valores 
sendo o tempo inicial (Av1) estatisticamente diferente de todos os demais dias $(\mathrm{p}<0,05)$. O grupo G6 apresentou diminuição na área e número dos túbulos expostos a partir da $1^{\mathrm{a}}$ e $2^{\mathrm{a}}$ aplicação do tratamento (Av2 e Av6), respectivamente, mantendo essa diminuição ao longo da ciclagem sendo essa diferente estatisticamente do tempo inicial $(\mathrm{p}<0,05)$.
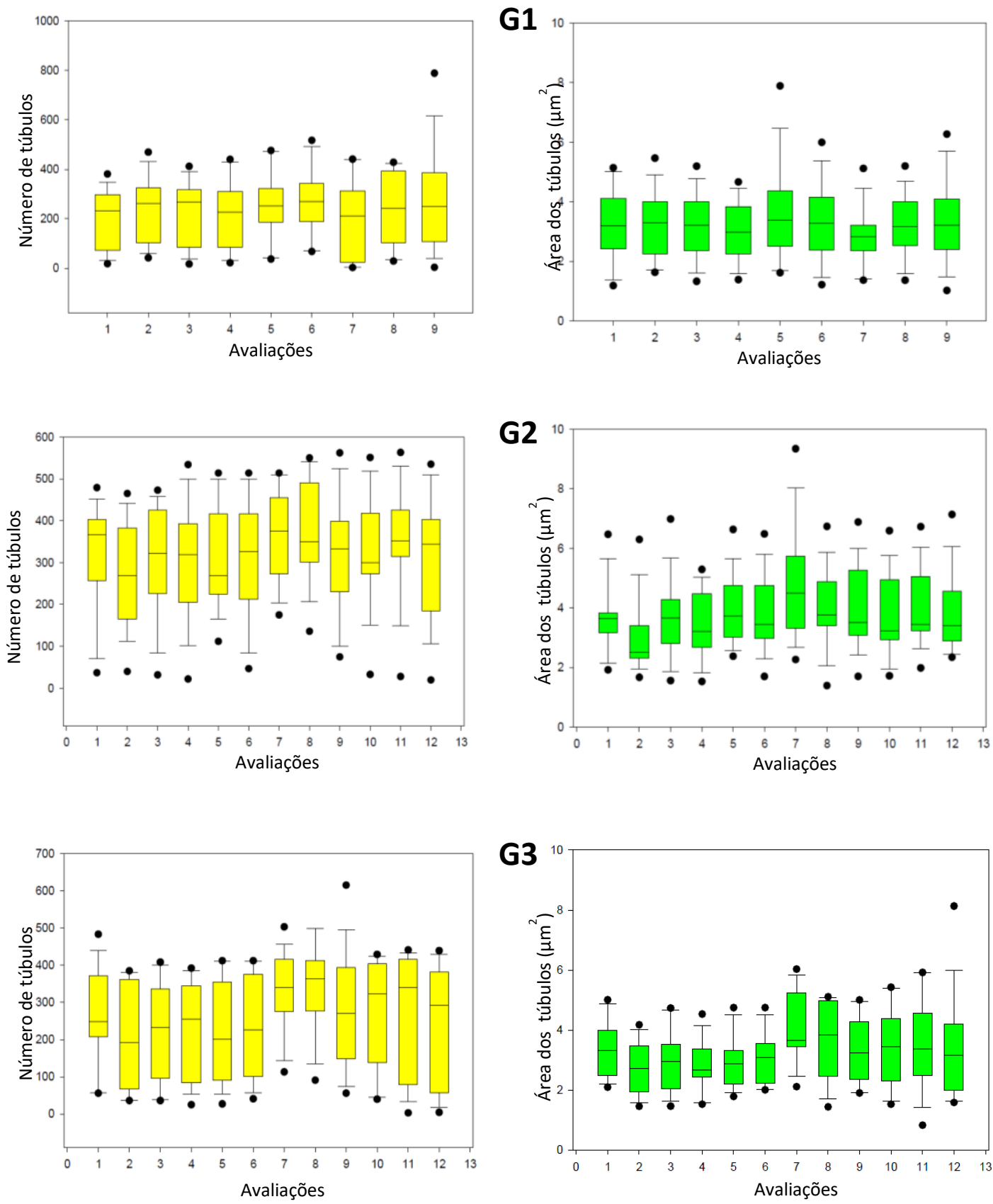

Figuras 25. Gráficos representativos do número e área de túbulos dentinários abertos dos grupos G1, G2 e G3 nos diferentes tempos. 

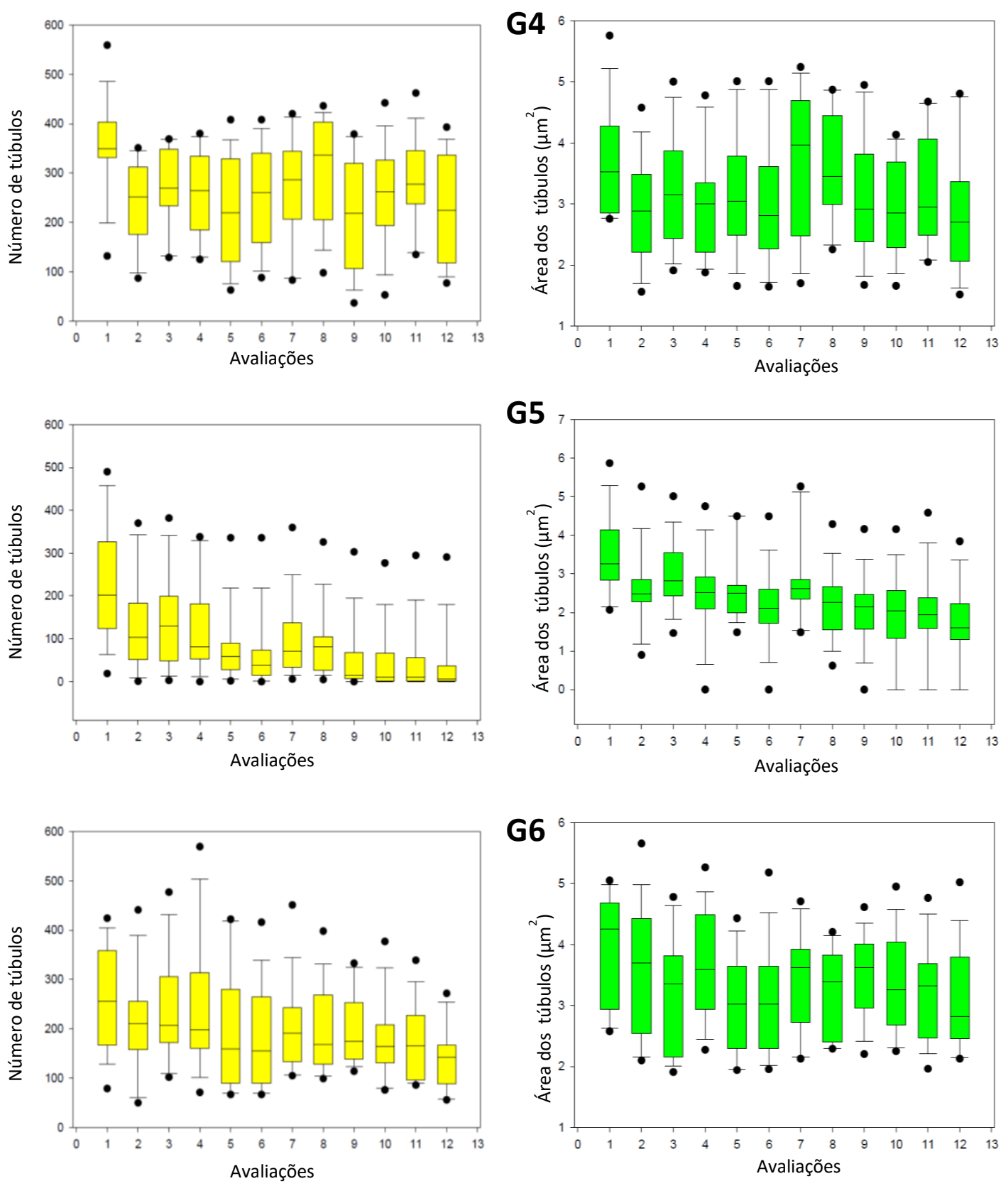

Figura 26. Gráficos representativos do número e área de túbulos dentinários abertos dos grupos G4, G5 e G6 nos diferentes tempos. 
De acordo com os dados, pode-se observar que G3 apresentou os maiores valores de permeabilidade e diferiu estatisticamente do G5 que apresentou os menores valores (ANOVA e Teste de Tukey) ( $p=0,009)$. Os demais grupos foram semelhantes entre si e ao G3 e G5 $(\mathrm{p}>0,05)$ (Tabela 4).

Tabela 4. Média e desvio padrão da permeabilidade dentinária da área tratada dos diferentes grupos experimentais (em $\mathrm{mm})$

\begin{tabular}{cc}
\hline GRUPOS & MÉDIAS \pm DP \\
\hline G1 & $234,15 \pm 129,32 \mathrm{ab}$ \\
G2 & $287,00 \pm 117,17 \mathrm{ab}$ \\
G3 & $326,78 \pm 142,84 \mathrm{a}$ \\
G4 & $292,11 \pm 120,42 \mathrm{ab}$ \\
G5 & $167,42 \pm 104,78 \mathrm{~b}$ \\
G6 & $227,48 \pm 85,35 \mathrm{ab}$ \\
\hline
\end{tabular}

Mesma letra indica semelhança estatística. 


\section{ESTUDO IN VIVO}

\section{AVALIAÇÃO DO DESGASTE SUPERFICIAL}

Para a análise do desgaste superficial das lesões nos diferentes tempos, os valores das variáveis quantitativas foram sempre comparados com os valores da sessão clínica anterior. Ao todo foram 4 sessões clínicas com aplicação dos agentes e mais 3 sessões de monitoramento pós tratamento (1, 3 e 6 meses após). Dessa forma, para os resultados foram fornecidos 6 diferentes tempos sendo o $1^{\mathrm{o}}$ tempo a diferença entre os dados obtidos na $2^{\mathrm{a}}$ e $1^{\mathrm{a}}$ sessão, o $2^{\mathrm{o}}$ tempo a diferença entre a $3^{\mathrm{a}}$ e $2^{\mathrm{a}}$ sessão e assim sucessivamente. 
De acordo com os dados obtidos, não houve diferença estatisticamente significante na rugosidade entre o grupo placebo e o grupo tratado ( $p>0,05)$ (Figura 27). Ambos os grupos também não apresentaram diferença estatística na rugosidade em relação aos diferentes tempos $(\mathrm{p}>0,05)$ (Figura 28).

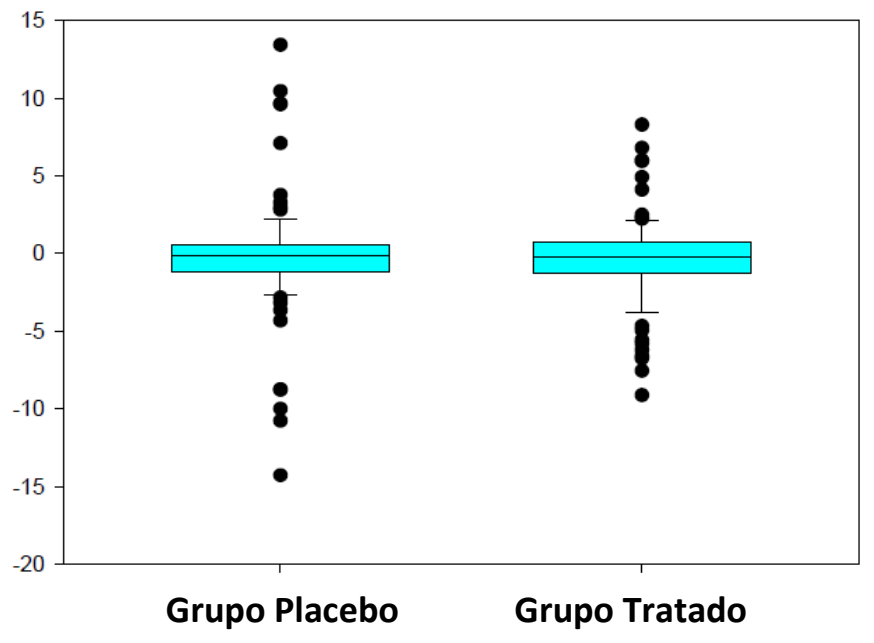

Figura 27. Rugosidade nos grupos placebo e tratado (Ra).
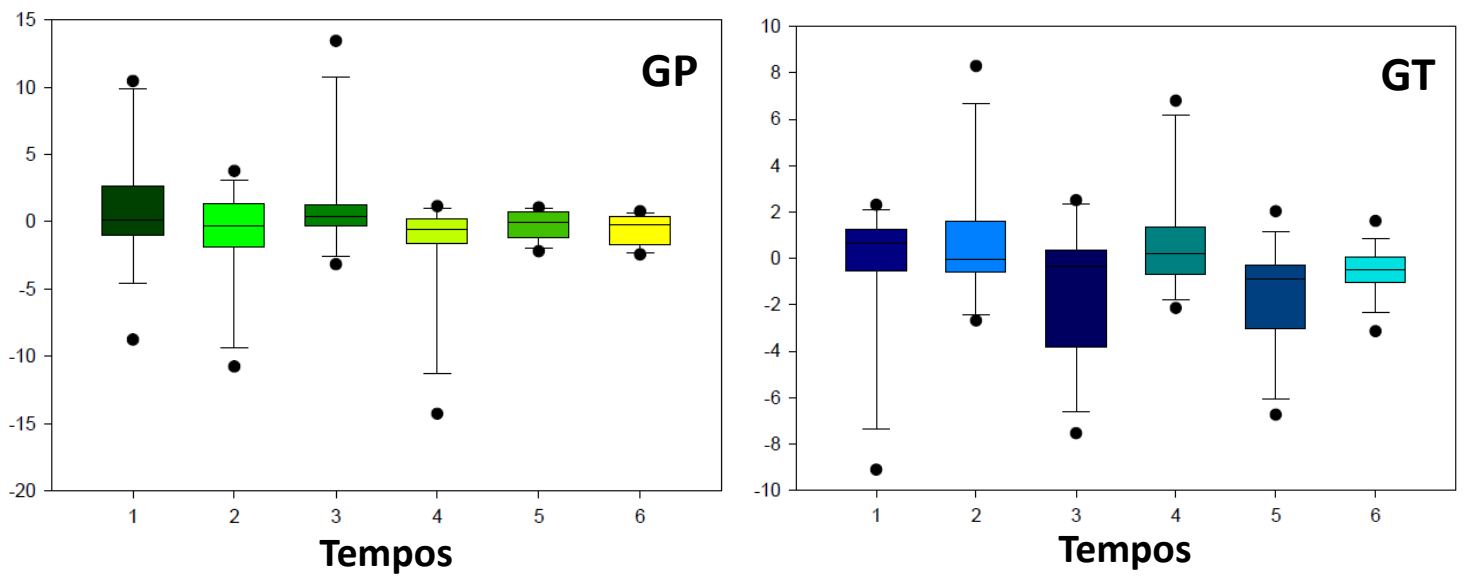

Figura 28. Rugosidade (Ra) nos grupos placebo (GP) e tratado (GT) nos diferentes tempos. 
Para o degrau de desgaste, não houve diferença estatisticamente significante entre os grupos $(p>0,05)$, porém um aumento similar ocorreu entre os valores iniciais e finais de cada um $(\mathrm{p}<0,05)$ (Tabela 5). Apesar do aumento gradual do degrau, ambos os grupos não apresentaram diferença estatística nos diferentes tempos ( $p>0,05)$ (Figura 29).

Tabela 5. Média e desvio padrão inicial e final do degrau $(\mu \mathrm{m})$ para os grupos placebo e tratado.

\begin{tabular}{ccc}
\hline Grupos & Inicial & Final \\
\hline Placebo & $407,51 \pm 161,73$ a & $520,00 \pm 162,78 \mathrm{~b}$ \\
Tratado & $450,06 \pm 226,85$ a & $607,34 \pm 275,31 \mathrm{~b}$ \\
\hline
\end{tabular}
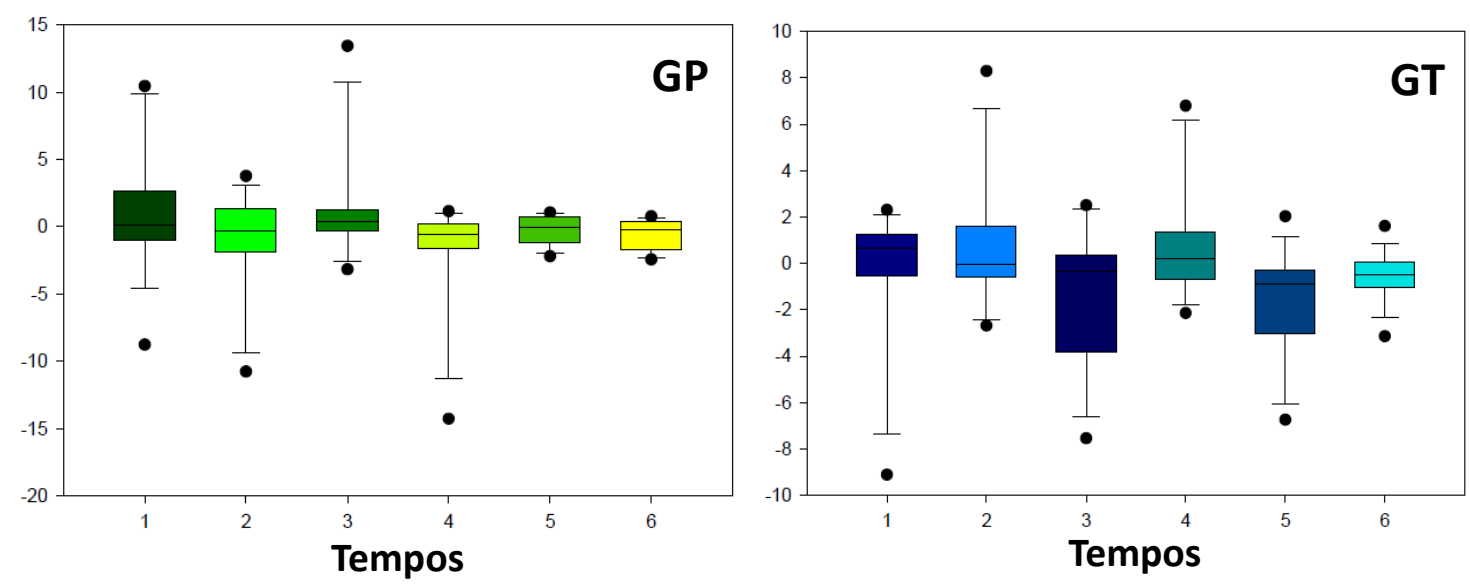

Figura 29. Degrau $(\mu \mathrm{m})$ nos grupos placebo $(\mathrm{GP})$ e tratado (GT) nos diferentes tempos. 
Com relação à dimensão da lesão, não houve diferença estatisticamente significante entre os grupos placebo e tratado tanto para a altura da lesão quanto para o perímetro ( $p>0,05)$. Comparando os valores iniciais e finais, houve um aumento similar em ambos os grupos $(\mathrm{p}<0,05)$ (Tabela 6). Para os diferentes tempos, ambos os grupos não apresentaram diferença estatística entre eles (p>0,05) (Figuras 30 e 31).

Tabela 6. Média e desvio padrão inicial e final da dimensão das lesões $(\mu \mathrm{m})$ nos grupos placebo e tratado.

\begin{tabular}{cccc}
\hline & Grupos & Inicial & Final \\
\hline \multirow{2}{*}{ Altura } & Placebo & $836,55 \pm 347,65 \mathrm{a}$ & $1050,70 \pm 358,82 \mathrm{~b}$ \\
& Tratado & $699,42 \pm 426,02 \mathrm{a}$ & $901,30 \pm 480,09 \mathrm{~b}$ \\
\hline \multirow{2}{*}{ Perímetro } & Placebo & $8635,55 \pm 1563,63 \mathrm{c}$ & $9280,55 \pm 1496,30 \mathrm{~d}$ \\
& Tratado & $7445,96 \pm 2708,23 \mathrm{c}$ & $8395,88 \pm 3183,39 \mathrm{~d}$ \\
\hline & & Mesma letra indica semelhança estatística.
\end{tabular}



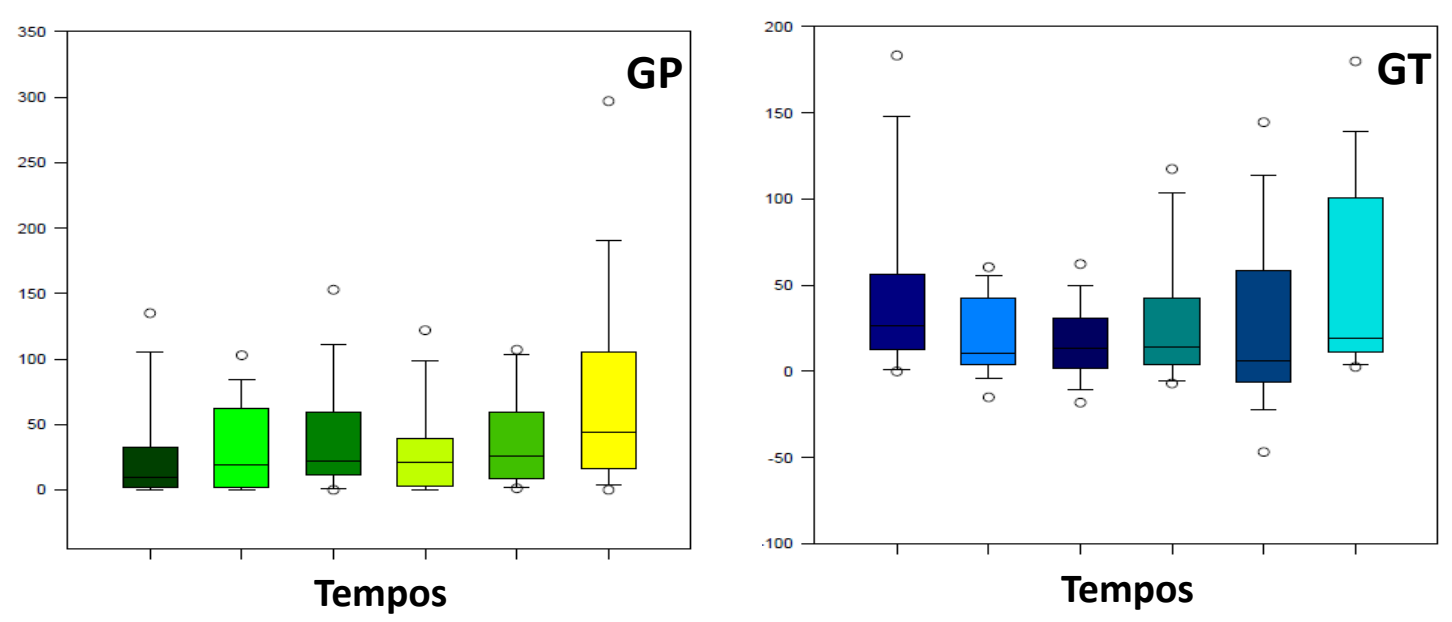

Figura 30. Altura das lesões $(\mu \mathrm{m})$ nos grupos placebo $(\mathrm{GP})$ e tratado $(\mathrm{GT})$ nos diferentes tempos.
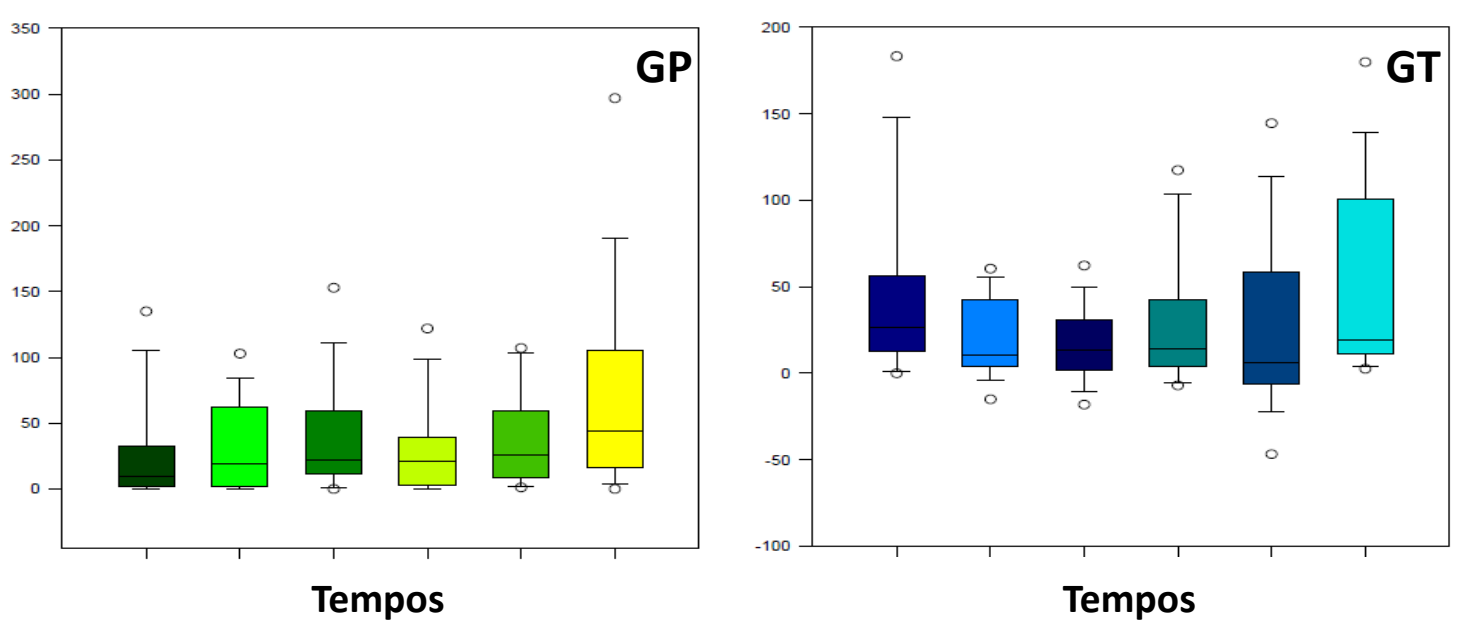

Figura 31. Perímetro das lesões $(\mu \mathrm{m})$ nos grupos placebo (GP) e tratado (GT) nos diferentes tempos. 
Em relação à sensibilidade dentinária, de acordo com os dados obtidos não houve diferença estatisticamente significante entre os grupos e nos diferentes tempos $(\mathrm{p}>0,05)($ Tabela $5)$.

Tabela 5. Mediana (25\%/75\%) dos escores (NRS) de hipersensibilidade relatados pelos pacientes para o grupo placebo e tratado nas diferentes sessões clínicas antes e após a aplicação dos agentes e pós-tratamento (PT).

\begin{tabular}{cccc}
\hline Sessões clínicas/Grupos & Placebo & Tratado \\
\hline \multirow{2}{*}{$\mathbf{1}^{\mathbf{a}}$ sessão } & Antes & $8(7 / 9)$ & $8(5,75 / 9)$ \\
& Após & $6(4 / 8)$ & $5(3 / 8)$ \\
\hline \multirow{2}{*}{$\mathbf{2}^{\mathbf{a}}$ sessão } & Antes & $7(5 / 8)$ & $7(5 / 8)$ \\
& Após & $5(1,75 / 7)$ & $3(1,75 / 6,25)$ \\
\hline \multirow{2}{*}{$\mathbf{3}^{\text {a }}$ sessão } & Antes & $4(3 / 6,25)$ & $5(3 / 7,25)$ \\
& Após & $3(1 / 5)$ & $3(1,75 / 5)$ \\
\hline \multirow{2}{*}{$\mathbf{4}^{\mathbf{a}}$ sessão } & Antes & $3(2 / 5)$ & $4(2,75 / 6)$ \\
& Após & $1(0,75 / 3)$ & $2(0,75 / 4)$ \\
\hline $\mathbf{5}^{\mathbf{a}}$ sessão (1 mês PT) & $2(0 / 3,50)$ & $2,5(1 / 7)$ \\
\hline $\mathbf{6}^{\mathbf{a}}$ sessão (3 meses PT) & $2(0 / 3,75)$ & $3(1,25 / 7)$ \\
\hline $\mathbf{7}^{\mathbf{a}}$ sessão (6 meses PT) & $2(1 / 3)$ & $2,5(1 / 7)$ \\
\hline
\end{tabular}




\section{DISCUSSÃO}

Estudos recentes têm demonstrado a dieta ácida como fator etiológico importante das lesões erosivas, sendo a faixa etária jovem a mais acometida (BARTLETT et al., 2011; BARBOUR; LUSSI, 2014; KITASAKO et al., 2015) pois tem o consumo maior de sucos e refrigerantes que possuem ácido cítrico na sua composição (WEST; HUGHES; ADDY, 2001). Uma vez presentes com frequência no meio bucal, os ácidos provenientes dos alimentos podem causar a dissolução e exposição dos túbulos dentinários, aumentando assim a sensibilidade dentinária (SHETTY; KOHAD; YELTIWAR, 2010).

Como o tecido dentinário possui menor conteúdo mineral e maior conteúdo orgânico, a perda de estrutura inicial através do processo erosivo ocorre entre a dentina peritubular e intertubular. Em estágios mais avançados, com exposição contínua à erosão, ocorre perda de superfície do tecido através da degradação enzimática ou mecânica da matriz orgânica exposta (SCHULUETER et al., 2011). Contudo, essa matriz parece resistir com sucesso ao processo erosivo produzido por ácidos fortes, sendo o inverso para ácidos fracos como é caso do ácido cítrico (CHEUNG et al., 2005). Dessa forma, esse ácido vem sendo utilizado previamente em trabalhos in vitro para exposição dos túbulos dentinários (KIM et al., 2013; HAN et al., 2013). Diante do exposto, determinar um tratamento dessensibilizante eficaz que controle a progressão das lesões erosivas seria de suma relevância para a odontologia atual. Assim, neste estudo as avaliações foram realizadas ao decorrer da ciclagem erosiva em conjunto com a aplicação dos tratamentos.

Dentre os recursos utilizados para avaliar as lesões erosivas, a microscopia confocal a laser 3D (MCL) é considerado um método quantitativo rápido e preciso para mensurar perda de superfície (HEURICH et al., 2010; SCHWENDICKE et al., 2014). Através da captura e digitalização de uma imagem, o equipamento realiza medições sem contato com a superficie 
fornecendo dados como rugosidade, perfil de desgate, degrau e perda de volume. No presente trabalho, a quantificação e tamanho dos túbulos dentinários expostos foram mensurados durante todo experimento por meio do MCL através de imagens da superfície semelhante às obtidas pela microscopia eletrônica de varredura $(\mathrm{MEV})$, com a vantagem de não ser necessário o preparo das amostras (FIELD; WATERHOUSE; GERMAN, 2010).

Pode-se observar no presente estudo que a rugosidade e o perfil de desgaste demonstraram comportamento semelhantes para os diferentes grupos apresentando um aumento dos valores a partir do $1^{\circ}$ dia da ciclagem. Isso demonstra que o processo erosivo ocorreu da mesma forma em ambos os grupos estudados. Os valores iniciais representam o desafio inicial realizado nos espécimes que resultaram na exposição dos túbulos dentinários e na remoção da camada de esfregaço observando-se uma superfície mais homogênea e plana representada por menores valores de rugosidade e o perfil de desgaste. Em seguida, realizou-se a primeira aplicação dos tratamentos e o desafio erosivo ( $1^{\circ}$ dia). A partir desse momento a erosão ocorreu progressivamente, representada pela curva ascendente e descendente da rugosidade e do perfil. Esta característica pode ser explicada pelo fato de que o processo erosivo é caracterizado pelo "amolecimento" inicial da superfície e consequente perda da estrutura amolecida (KAMOZAKI et al., 2015) que ocorreu sucessivamente durante a ciclagem de 9 dias. A similaridade do grupo controle com os demais sugere que os tratamentos não foram capazes de interferir no efeito do processo erosivo sobre a dentina.

Em relação ao desgaste erosivo, este pode ser avaliado através do degrau e perda de volume que quantificam a perda de estrutura superficial. De acordo com os achados, o grupo controle e do laser de diodo não foram capazes de diminuir a perda de estrutura em nenhum momento diferente dos demais grupos que mesmo apresentando valores maiores para degrau e perda de volume, em algum ponto da ciclagem o desgaste diminuiu. No grupo controle não houve aplicação de nenhum tratamento e apenas o efeito protetor da saliva (trocas iônicas) pode 
ter influenciado contra a erosão na superfície (CHEUNG et al., 2005) o que pode explicar o aumento pequeno do desgaste ao longo da ciclagem. Ademais, nos outros grupos a aplicação dos agentes foi realizada com fricção na superfície por meio de um microbrush o que pode ter contribuído para remoção da estrutura superficial amolecida pelo processo erosivo. No caso do laser de diodo, as alterações morfológicas causadas pela irradiação no tecido podem ter aumentado a energia de superfície o que provavelmente facilitou a ação da ciclagem erosiva representada pelos maiores valores para degrau e volume perdido apresentado pelo grupo. O Oxagel também não foi capaz de controlar a progressão da erosão na dentina principalmente no início do tratamento, entretanto houve uma diminuição na evolução do processo erosivo ao final da ciclagem. Em concordância com esses achados, Calabria et al. (2014) concluíram que o oxalato de potássio não possiu nenhum efeito contra a progessão da erosão dentinária.

No presente trabalho, os agentes dessensibilizantes à base de caseína não demonstraram resultados positivos no controle da progressão do processo erosivo sendo que a pasta MI Paste (CPP-APP) apresentou os maiores valores de degrau e perda de volume entre os grupos. A caseína possui uma longa cadeia de aminoácidos e ácidos fosfóricos quimicamente ligados a íons cálcio que favorecem as interações com os íons presentes nos cristais de hidroxiapatita do tecido resultando numa camada protetora, uniforme e persistente na superfície do mesmo (FERREIRA et al., 2015). Neste estudo, um agente experimental a base de caseína foi avaliado devido a essas propriedades, porém o tratamento também não foi capaz de proteger o desgaste erosivo na dentina, corroborando com Ferreira et al. (2015) que observaram bons resultados da caseína para o esmalte, mas não para dentina. Este fato pode ser explicado pela fraca afinidade das proteínas do leite com a superfície do dente em condições ácidas. As interações eletrostáticas entre a proteína e o tecido são reduzidas uma vez que as micelas de caseína e a superfície de hidroxiapatita são carregadas positivamente a um pH abaixo de 5,0 (WANG et al., 2011). 
No presente estudo, a caseína e o MI Paste também não foram eficazes no controle da perda de estrutura; resultados similares foram observados nas diferentes formulações da pasta CPP-ACP que não foram capazes de diminuir o desgaste tanto na dentina como no esmalte (WANG et al., 2011; WIEGAND; ATTIN, 2014). O complexo CPP-ACP proporciona concentrações supersaturadas de íons cálcio e fosfato que impedem a desmineralização e aumenta a formação de cristais de hidroxiapatita em lesões desmineralizadas (MOEZZYZADEH; MOTAMEDI, 2011). Esta formação parece não ocorrer nas regiões erodidas devido às fracas interações eletrostáticas entre a superfície e a caseína em condições ácidas o que pode ter ocorrido neste estudo. Além disso, o CPP-ACP demonstrou produzir apatita intrafibrilar e interfibrilar no colágeno da dentina fosforilada (CAO et al., 2013) e, clinicamente, tem sido eficaz no tratamento da hipersensibilidade dentinária (MAHESUTI et al., 2014).

Ainda em relação ao desgaste erosivo, o agente Desensibilize Nano $\mathrm{P}$ foi o que apresentou melhores resultados no degrau e perda de volume, porém a comparação com a literatura é difícil devido à escassez de trabalhos relacionadas à dentina. Segundo a literatura (B LOW; ALLEN; KONTOGIORGOS, 2015), os produtos com nanohidroxiapatita foram capazes de reparar microdefeitos na superfície do esmalte e dentina in vitro devido ao tamanho dos cristais. Em esmalte, observa-se que o agente pode penetrar mais profundamente no esmalte erodido através da fricção, formando um depósito "tipo reservatório" de íons de cálcio e fosfato (Medeiros et al. 2014). Esse mecanismo associado ao flúor pode manter o esmalte protegido de desafios erosivos posteriores e num estado de supersaturação mineral (HUANG et al., 2011), sendo que o nanofosfato de cálcio reduz a erosão do esmalte quando comparado a outros agentes (CARVALHO et al., 2013). Os cristais de hidroxiapatita em tamanho nanométrico são semelhantes à morfologia e estrutura da hidroxiapatita dentinária natural e têm sido utilizados em dentifrícios e enxaguantes bucais para reparar a superfície dentária desmineralizada. A 
hidroxiapatita é considerada como um dos materiais mais biocompatíveis e bioativos devido à sua semelhança com a composição inorgânica do dente facilitando sua interação com o mesmo (GOPINATH et al., 2015; WANG et al., 2016) o que poderia justificar o controle do processo erosivo na dentina neste estudo. Além disso, a penetração profunda das nanopartículas associada ao flúor presente no Desensibilize Nano P parece ser resistente à erosão devido a um imbricamento mecânico da nanohidroxiapatita dentro e/ou sobre os túbulos dentinários (WANG et al., 2016).

Os resultados mostraram que o laser de diodo não foi eficiente para intervir na evolução do processo erosivo. Um dos prováveis motivos pode ser os parâmetros empregados, visto que diferentes potências são utilizadas a fim de selar os túbulos dentinários através do aumento da energia da superfície dentinária causado pela irradiação que provoca a fusão na mesma (UMANA et al., 2013). Contudo, não existe um consenso quanto aos parâmetros a serem empregado. Estudos recentes têm demonstrado alterações na superfície dentinária utilizando potências de 0,8 a $3 \mathrm{~W}$ sendo estes efeitos mais evidentes com parâmetros maiores (FARIA et al., 2011 e 2013; VIAPIANA el al., 2012; UMANA et al, 2013). Entretanto, densidades de energia de 1,6 a $2 \mathrm{~W}$ podem causar uma importante destruição da superfície dentinária e danificam a polpa dentária (UMANA et al., 2013). Por outro lado, Liu et al. (2013) observaram que 2,0 W/CW $\left(166 \mathrm{~J} / \mathrm{cm}^{2}\right)$ parece ser eficaz no tratamento clínico da hipersensibilidade dentinária e seguro para os odontoblastos e tecidos pulpares.

Devido às divergências na literatura, a densidade de energia de $0,7 \mathrm{~W}$ foi determinada e empregada neste trabalho baseado em estudo anterior, onde a irradiação com 0,5 e $0,7 \mathrm{~W}$ mostrou uma redução parcial efetiva da permeabilidade dentinária após o desafio com ácido cítrico (RIZZANTE et al., 2016). Apesar disso, no presente estudo, o laser de diodo não foi capaz de prevenir a progressão da erosão na dentina, o que pode ser justificado pelo desafio erosivo contínuo realizado durante o experimento. As amostras irradiadas com laser de diodo 
apresentaram valores de rugosidade mais elevados devido às alterações morfológicas causadas na superfície. O desafio erosivo pode ter sido maior neste grupo porque a superfície mais irregular (rugosa) apresenta uma superfície de contato maior, aumentando a energia de superfície do tecido o que provavelmente facilitou a ação da erosão. Este fato pode explicar os resultados negativos apresentados por este grupo em relação ao desgaste superficial representado pelos maiores valores para degrau e volume perdido dentre os grupos.

A análise morfológica da superfície, assim como o teste de permabilidade dentinária, são métodos eficazes utilizados para avaliar os efeitos dos agentes dessensibilizantes na oclusão dos túbulos dentinários (THANATVARAKORN et al., 2013; GEORGE et al., 2013). Para análise morfológica, este estudo utilizou a microscopia confocal a laser que permitiu avaliar o número e área dos túbulos expostos na superfície dentinária nos diferentes tempos. Para análise da permeabilidade dentinária foi utilizado o método histoquímico proposto por Pécora et al. (1990) por se tratar de um método reprodutível que utiliza moléculas de íons cobre que são insolúveis permitindo assim a mensuração da sua profundidade de penetração que representa a permeabilidade.

Em relação aos efeitos oclusivos dos agentes testados, a pasta experimental à base de caseína apresentou o menor número e área de túbulos dentinários expostos, já o Oxagel foi o agente que apresentou os maiores valores. De acordo com Miglani, Aggarwal e Ahuja (2010), o efeito de oxalatos na hipersensibilidade dentinária diminui ao longo do tempo devido à remoção dos cristais de oxalato de cálcio através da escovação ou ácidos alimentares, o que esclarece os resultados do presente estudo. Analisando os tempos da ciclagem, o Oxagel foi capaz de diminuir os túbulos expostos nas avaliações logo após a primeira e segunda aplicação do tratamento, porém nos demais dias os túbulos aumentaram sendo os valores finais semelhantes aos valores do início da ciclagem. Sendo assim, o agente não foi capaz de manter a oclusão dos túbulos dentinários resultante das aplicações ao longo do processo erosivo e de 
diminuir a permeabilidade dentinária. Resultados divergentes demonstraram 94\% dos túbulos dentinários ocluídos com oxalato de potássio monohidratado a 3\% (Oxagel), porém após exposição única ao ácido cítrico (SAURO; WATSON; THOMPSON, 2010). Segundo estudo (CALABRIA et al., 2014), o oxalato de potássio é eficiente para reduzir a permeabilidade da dentina devido à formação de cristais de oxalato de cálcio que precipitam e penetram ocluindo os túbulos dentinários. Atualmente, tem-se sugerido sua aplicação antes do sistema adesivo, especialmente em cavidades profundas, a fim de reduzir ou eliminar o desconforto associado com procedimentos adesivos devido à diminuição da circulação de fluidos dentro dos túbulos dentinários (DE MORAES PORTO et al., 2012; SILVA et al., 2012). A aplicação de um agente dessensibilizante à base de oxalato antes das restaurações de lesões cervicais não cariosas também foi sugerida a fim de reduzir a hipersensibilidade dentinária (CORRAL et al., 2016). Nestes casos, o efeito positivo a longo prazo do oxalato pode ser explicado pela situação onde o agente é aplicado antes do tratamento restaurador o qual o protege das condições ácidas do meio bucal, diferente da situação do presente estudo, onde foi feita a avaliação do agente frente ao desafio erosivo.

Quanto ao grupo controle, não houve diferença significativa no número e área dos túbulos dentinários expostos ao longo da ciclagem erosiva. Em relação à permeabilidade dentinária, o grupo não apresentou os maiores valores entre os demais. Estes achados reforçam a teoria de que o efeito protetor da saliva (trocas iônicas) pode ter influenciado contra a erosão da superfície assim como foi observado na avaliação do desgaste erosivo. Mesmo com a ação da erosão na superfície, a estrutura superficial amolecida pelo processo não pode ser removida uma vez que os espécimes não passaram por nenhum desafio mecânico como a fricção realizada nos outros grupos durante a aplicação dos agentes.

Apesar dos resultados positivos no controle da evolução do processo erosivo, o Desensibilize Nano P não apresentou bons resultados na oclusão dos túbulos dentinários e no 
teste de permeabilidade dentinária. Durante a ciclagem erosiva/tratamentos, os túbulos diminuíram logo após a primeira e segunda aplicação do agente, porém nos outros tempos os valores aumentaram equiparando aos valores iniciais. Comparando esses achados com os resultados positivos apresentados para o desgaste superficial, pode-se considerar que o efeito oclusivo do Desensibilize Nano $\mathrm{P}$ ocorreu dentro dos túbulos dentinários devido à maior profundidade de penetração das nanopartículas presentes no agente (KUNAM et al., 2016). Dessa forma, a análise morfológica superficial dos túbulos desse trabalho pode não ter sido capaz de mensurar o efeito oclusivo nesse grupo. Na literatura, diferentes trabalhos in vitro observaram a deposição de partículas sobre a superfície dentinária após tratamento com nanohidroxiapatita por meio de outros métodos como microscopia eletrônica de varredura e microrradiografias (TSCHOPPE et al., 2011; PINTADO-PALOMINO; TIRAPELLI, 2015; KULAL et al, 2016). Porém, o método utilizado neste estudo avaliou o efeito das partículas nos túbulos dentinários e não na superfície como um todo. Em relação à permeabilidade dentinária, o Desensibilize Nano P foi o grupo que apresentou os maiores valores de penetração dos íons de cobre. Da mesma forma, avaliando a permeabilidade através da condutância hidráulica de discos de dentina tratados com diferentes agentes dessensibilizantes, o agente conseguiu reduzir a condutância comparada à máxima (ácido fosfórico 37\%), porém após o desafio erosivo com ácido cítrico $6 \%$ pós-tratamento, a mesma foi semelhante à permeabilidade inicial. O resultado negativo na condutância após o desafio erosivo pode ser devido às características das nanopartículas de formato regular que facilita o deslocamento de fluidos dentro dos túbulos (DANTAS, 2011). Possivelmente o mesmo ocorreu com as nanoparticulas após o ensaio de penetração das partículas de cobre nos túbulos dentinários.

O grupo que apresentou os melhores resultados com relação aos túbulos dentinários foi o da pasta experimental à base de caseína. Embora os resultados desfavoráveis no controle da lesão erosiva, o grupo apresentou os menores valores quanto à permeabilidade dentinária e 
número de túbulos expostos. Ao longo da ciclagem, os túbulos expostos foram diminuindo a cada aplicação do agente e progressivamente até o final da ciclagem. De acordo com os autores (TANG; MILLAR, 2010), o bloqueio dos túbulos dentinários ocorre através da deposição do componente proteico e da ligação dos íons cálcio e fosfato no interior dos mesmos.

Diferente disso, a pasta MI Paste não conseguiu ocluir os túbulos dentinários. Após as aplicações do agente houve uma diminuição no número e área dos túbulos, porém esta não foi suficiente para se manter durante a ciclagem erosiva. Ademais, o grupo apresentou um dos maiores valores para a permeabilidade dentinária. Segundo Banomyong, Kanchanasantikul e Wong (2013), poucas precipitações foram detectadas na superfície da dentina tratada com CPPACP. O agente remineralizante não conseguiu induzir uma camada protetora e reduzir a permeabilidade da dentina após 5 minutos de aplicação. Também corroborando com os resultados deste estudo, Pei et al. (2013) avaliaram o condicionamento da superfície dentinária com diferentes ácidos e observaram túbulos expostos mesmo após a aplicação a longo prazo da pasta CPP-ACP o que indica a baixa resistência do complexo aos desafios ácidos. Os autores também demonstraram que não foi possível observar oclusão dos túbulos dentinários após a aplicação do Tooth Mousse (agente à base de CPP-ACP), apenas uma camada fina tipo membrana foi observada sobre a superfície da dentina. Comparando com o fluoreto de sódio (5000 ppm) a pasta MI Paste plus (associada ao flúor) demonstrou uma fraca capacidade de ocluir os túbulos expostos (PRABHAKAR; JAISWAL MANOJKUMAR; BASAPPA, 2013).

O grupo do laser de diodo apresentou uma diminuição nos túbulos dentinários expostos após as primeiras irradiações mantendo o número alcançado ao longo da ciclagem. Apesar do resultado desfavorável no desgaste superficial, o grupo também apresentou uma diminuição no teste de permeabilidade. Corroborando com este achado, estudo demonstrou uma redução parcial efetiva da permeabilidade dentinária com os mesmos parâmetros utilizados no presente trabalho através da condutância hidráulica (RIZZANTE et al., 2016). De acordo com Alfredo 
et al. (2009), nas bandas de comprimento de onda de 980nm, parte da energia irradiada é absorvida pelo conteúdo mineral da dentina, como por exemplo carbonato e fosfato, resultando num derretimento e recristalização da superfície ('melting') podendo assim ocluir ou reduzir os túbulos dentinários expostos. Segundo autores Liu et al. (2013), o grau de fusão da superfície dentinária é maior quanto maior os parâmetros de potência utilizados, porém densidades de energia mais elevadas (1,6-2 W) produzem uma importante destruição na superfície da dentina e podem danificar o tecido pulpar (UMANA et al., 2013).

Diante dos resultados apresentados no estudo in vitro, a pesquisa e compreensão do mecanismo de ação da pasta experimental no substrato dentinário pode ser de grande valia para o tratamento da hipersensibilidade presente nas lesões erosivas e devem ser estudados em trabalhos futuros. Em virtude dos resultados favoráveis do Desensibilize Nano P de intervir na progressão do processo erosivo, este fato deve ser avaliado clinicamente para assegurar o controle da evolução e tratamento das lesões erosivas. Sendo assim, na segunda fase deste trabalho (estudo in vivo), o agente Desensibilize Nano P foi selecionado para a avaliação clínica.

No estudo in vivo, a seleção dos pacientes foi uma etapa de difícil execução devido à complexidade dos fatores etiológicos envolvidos nas lesões cervicais não-cariosas. Um único fator etiológico não pode ser responsável pela lesão e sim uma combinação variável de fatores potenciais (erosão, abrasão e abfração) atuando em níveis diferentes (SARODE; SARODE, 2013). Dentre os fatores, a erosão e a abrasão estão intimamente relacionadas. A abrasão (desgaste mecânico dos tecidos duros) está comumente associada à escovação e dentifrícios abrasivos (GRIPPO; SIMRING; COLEMAN, 2012); a erosão por sua vez, assim como já mencionado, é caracterizado pelo "amolecimento" inicial da superfície e consequente perda da estrutura amolecida (KAMOZAKI et al., 2015) que pode ser potencializada pela ação mecânica da escovação, principalmente a escovação traumática. Esta inclui o uso de força excessiva durante os movimentos de escovação que aumenta o atrito entre as cerdas da escova e a estrutura 
dentária causando um maior desgaste do tecido (WALTER et al., 2014). De acordo com Heasman et al. (2014), os fatores da escovação dentária que têm sido associados ao desenvolvimento de lesões cervicais não cariosas são: frequência, método de escovação e dureza das cerdas.

Nos casos onde foi identificado o fator erosão como predominante, os pacientes relataram uma rotina de consumo frequente de alimentos e bebidas ácidas, como por exemplo, ingestão de água com limão, suco de laranja, limão e vinagre como tempero para saladas, etc. As lesões cervicais predominantemente erosivas são caracterizadas por achatamento/aplainamento da superfície com borda intacta ao longo da margem gengival podendo ocorrer concavidades que normalmente são mais largas e menos profundas, com ou sem envolvimento da dentina (CARVALHO et al., 2016). De acordo com Grippo, Simring, Coleman (2012), o termo "erosão" seria adequadamente sucedido por "biocorrosão" uma vez que este representa melhor o processo de degradação química, bioquímica e eletroquímica da estrutura dental causada por ácidos. Porém, essa opção parece não ter sido amplamente adotada, pois na literatura atual o termo "erosão" é o mais consagrado, visto que o termo biocorrosão ainda não está bem estabelecido.

Outro fator etiológico considerável está relacionado à oclusão (abfração), mais especificamente a contatos prematuros e hábitos parafuncionais (FEMINIANO et al., 2015). A lesão na qual o fator principal é o esforço occlusal, caracteriza-se pela presença de facetas de desgaste no mesmo elemento dental e, se este for o fator etiológico primário, evidências clínicas sugerem lesões em forma de cunha (FEMINIANO et al., 2015) devido à ação de forças biomecânicas exercidas sobre o dente que se concentram na junção cemento-esmalte, causando flexão e perda de estrutura na região (NASCIMENTO et al., 2016). De acordo com autores, a progressão das lesões cervicais não cariosas foi mais correlacionada às forças oclusais do que com dieta ácida e escovação (SAWLANI et al., 2016). 
Para determinar o fator etiológico predominante na lesão, deve-se realizar uma anamnese com histórico clínico médico e odontológico abrangente, exame oclusal minucioso, investigação sobre a dieta, hábitos alimentares e higiene bucal do paciente (GRIPPO; SIMRING; COLEMAN, 2012). Dessa forma, os pacientes que apresentaram histórico, sinais e sintomas de contato prematuro/parafunção não foram incluídos na seleção da amostra. No mesmo sentido, aqueles que apresentavam histórico de dieta ácida foram incluídos uma vez que clinicamente foi fator principal a ser avaliado.

A literatura demonstra que a obtenção de réplicas é eficaz para avaliar a superfície de lesões cervicais não-cariosas e seu desgate (GRENNESS; TYAS; OSBORN, 2009; SAWLANI et al., 2016). No presente estudo as réplicas foram avaliadas por meio do MCL que permitiu analisar a rugosidade, degrau e dimensões das lesões (altura e perímetro), não dispondo na literatura trabalhos previos em que se empregou tal metodologia. A forma de análise foi semelhante à empregada no estudo in vitro.

Nas análises das réplicas observou-se um comportamento semelhante entre o grupo placebo e tratado sendo que a comparação com a literatura não foi possível devido à falta de trabalhos com essas análises. Em relação aos diferentes tempos, pode-se observar que a primeira sessão clínica (antes do tratamento) foi diferente da sessão de acopanhamento após 6 meses de tratamento. O comportamento semelhante da progressão do desgate nos diferentes grupos indica que a divisão aleatória da amostra foi efetiva. Observou-se que a aplicação do agente Desensibilize Nano P não foi capaz de evitar a progressão das lesões e, assim como no estudo in vitro, a rugosidade foi semelhante em ambos os grupo, ou seja, o desgaste erosivo atuou da mesma maneira na estrutura dentinária sem interferência do tratamento.

Neste estudo houve uma relação direta entre o aumento do tamanho das lesões e a predominância do fator abrasão. A presença de recessão gengival está intimamente associada à escovação traumática (HEASMAN et al., 2014) que ao longo do tempo aumentou a migração 
apical da margem gengival e, consequentemente, os limites da lesão. Assim como observado no estudo, algumas destas lesões apresentaram estrias de diferentes profundidades, ranhuras longitudinais e transversais decorrentes das cerdas da escova dental estando associadas à recessão gengival (LEVRINI; DI BENEDETTO; RASPANTI, 2014).

As lesões cervicais não cariosas são multifatoriais e determinar certamente qual fator está presente ou não é incerto, pois apesar da seleção rigorosa, outros fatores podem estar interagindo para a evolução da lesão. Este fato poderia explicar os resultados desfavoráveis do Desensibilize Nano P no controle da progressão das lesões, pois o agente parece ser eficaz somente no controle do fator erosão avaliado isoladamente no estudo in vitro.

Com relação à avaliação clínica da hipersensibilidade dentinária (HD), não houve diferença entre o grupo tratado com o Desensibilize Nano P e o grupo placebo no qual também houve uma redução na HD. Resultados clínicos positivos também foram descritos com a aplicação do Desensibilize Nano P clinicamente (WANG et al., 2016), porém a literatura é escassa em relação à avaliação in vivo do agente. Um dos fatores que poderia explicar o efeito positivo em ambos os grupos é o efeito placebo que, por ser mediado por mecanismos que envolvem expectativas conscientes e não cognitivas, sua administração causa expectativa de um certo efeito, o que resulta em uma menor resposta à dor (ERDEMIR et al., 2010; ANTONIAZZI et al., 2014). Ademais, o agente placebo utilizado neste estudo foi fornecido pelo fabricante do Desensibilize Nano P (FGM) que excluiu apenas seu principal agente ativo, ou seja, as nanoparticulas de hidroxiapatita, mantendo o nitrato de potássio e o flúor em sua formulação o que também contribuiu nos resultados da HD no grupo placebo. O nitrato de potássio possui uma ação neural na qual atua por difusão nas terminações nervosas (odontoblastos) ao longo dos túbulos dentinários expostos despolarizando as mesmas e diminuindo assim a transmissão dos estímulos excitatórios (CUMMINS, 2010). Dessa forma, a ação dessensibilizante avaliada no estudo clínico foi aquela relacionada apenas a ação 
oclusiva das nanopartículas de hidroxiapatita, pois ambos os grupos receberam a dessensibilização neural do nitrato de potássio. Sendo assim, pode-se observar que a nanohidroxiapatita não promoveu nenhum efeito aditivo ao nitrato no tratamento da hipersensibilidade dentinária.

Ainda em relação à avaliação da hipersensibilidade, por estar relacionada a estudos de dor, deve-se considerar que a mesma está associada a efeitos psicológicos e emocionais que podem afetar a resposta dolorosa dos pacientes (MEHTA et al., 2014). Um ponto positivo neste trabalho foi a utilização de um modelo de estudo ‘split-mouth' que parece ser mais adequado para este tipo de situação, pois os pacientes agem como seu próprio controle (ADDY et al., 2007). Em contrapartida, por ser uma experiência individual, a dor e o perfil psicológico dos participantes é um fator limitante (FREITAS SDA et al., 2015), assim como o comparecimento do paciente para realização do tratamento e o cumprimento das recomendações profissionais durante o mesmo. Dessa forma, os pacientes que tiveram dificuldade em seguir as orientações e interpretar o desconforto sentido durante o teste de hipersensibilidade foram excluídos da amostra.

No presente estudo o estímulo osmótico foi o adotado para a avaliação da hipersensibilidade dentinária através de um jato de ar aplicado sobre a lesão durante 1 segundo e a uma distância de $1 \mathrm{~cm}$ do dente para evitar a dessecação da superfície da dentina (CAMILOTTI et al., 2012). A desidratação associada com o movimento do ar sobre a superfície exposta da dentina causa alterações no fluxo dos fluídos dentro dos túbulos, induzindo estimulação do nervo e sensações dolorosas. O estímulo osmótico parece ser o mais indicado devido sua maior percepção dolorosa em relação aos outros estímulos (ANTONIAZZI et al., 2014). Essa pode ser a explicação para a melhora na hipersensibilidade no dia-a-dia dos pacientes; a grande maioria relatou que com o teste com jato de ar sentia sensibilidade, porém 
nas atividades do cotidiano como escovação, tomar água gelada ou comer frutas geladas, não havia mais sensibilidade.

As recomendações e orientações sobre dieta, escovação e hábitos parafuncionais também contribuiu para a melhoria dos sintomas dolorosos. Os pacientes foram esclarecidos e instruídos quanto aos alimentos e bebidas ácidas que ingeriam em grande quantidade ou frequência. Sendo identificado algum em especial, o mesmo foi orientado a evitar/diminuir seu consumo e realizar a escovação pelo menos 1 hora após as refeições (OLLEY; MOAZZEZ; BARTLETT, 2015). Quanto à escovação, a técnica foi revisada para identificar e eliminar possíveis efeitos nocivos no tecido gengival; a utilização de escova com cerdas macias e de tamanho pequeno e o tipo de dentifrício sem adição de agentes abrasivos também foram recomendados. A mudança nos fatores de risco favoreceu a redução da $\mathrm{HD}$ em ambos os grupos e a manutenção da mesma durante o acompanhamento dos pacientes após a terapia dessensibilizante. De acordo com autores (FREITAS SDA et al., 2015), os fatores de risco devem ser diagnosticados durante a anamnese e modificados durante a terapia. Ademais, os ácidos oriundos de alimentos e bebidas ácidas podem diminuir a eficiência do agente dessensibilizante (BANOMYONG; KANCHANASANTIKUL; WONG, 2013).

Diante do exposto, pode-se observar que para evitar a progressão das lesões cervicais não cariosas é necessária a intervenção nos fatores etiológicos envolvidos. Essa abordagem torna-se bastante difícil uma vez que envolve a cooperação do paciente no controle de seus hábitos diários. O Desensibilize Nano $\mathrm{P}$ foi capaz de controlar o processo erosivo no estudo in vitro, porém o controle da erosão clinicamente não foi suficiente para evitar a progressão das lesões avaliadas.

No presente trabalho a hipersensibilidade dentinária respondeu bem aos tratamentos dessensibilizantes, pois os pacientes relataram melhora significativa em sua rotina. Porém a 
ação neural (nitrato de potássio) parece ser a responsável pelo resultado positivo, devido à semelhança de comportamento entre o grupo placebo e o grupo tratado com o agente Desensibilize Nano P. 
De acordo com as limitações do presente trabalho pode concluir que:

In vitro, o Desensibilize Nano P (FGM) foi eficaz no controle do processo erosivo na dentina radicular e a pasta experimental à base de caseína apresentou os melhores resultados na oclusão dos túbulos dentinários e na permeabilidade dentinária;

In vivo, o Desensibilize Nano P não foi capaz de controlar a progressão das lesões erosivas. Para o tratamento da hipersensibilidade dentinária presente nas lesões o agente apresentou resultados positivos na diminuição da sensibilidade, porém o seu comportamento foi semelhante ao grupo placebo. 
ADDY, M. et al. Dentine hypersensitivity: is there both stimulus and placebo responses in clinical trials? International Journal of Dental Hygiene, Oxford, v. 5, n. 1, p. 53-59, 2007.

ALFREDO, E. et al. Morphological alterations of radicular dentine pretreated with different irrigating solutions andirradiated with 980-nm diode laser.

Microscopy

Research and Technique, New York, v. 72, n .1, p. 22-27, 2009.

AMAECHI, B. T.; HIGHAM, S. M., EDGAR, W. M. Techniques for the production of dental eroded lesions in vitro. Journal of Oral Rehabilitation, Oxford, v. 26, n. 2, p. 97 $102,1999$.

ANTONIAZZI, R. P. et al. Effectiveness of a desensitizing agent for topical and home use for dentin hypersensitivity: a randomized clinical trial. American Journal of Dentistry, San Antonio, v. 27, n. 5, p. 251-257, 2014.

ARANHA, A. C.; PIMENTA, L. A.; MARCHI, G. M. Clinical evaluation of desensitizing treatments for cervical dentin hypersensitivity. Brazilian Oral Research, São Paulo, v. 23, n. 3, p. 333-339, 2009.

AZARPAZHOOH, A.; LIMEBACK, H. Clinical efficacy of casein derivatives: a systematic review of the literature. The Journal of the American Dental Association, Chicago, v. 139, n. 7, p. 915-924, 2008.

B LOW, S.; ALLEN, E. P.; KONTOGIORGOS, E. D. Reduction in dental hypersensitivity with nano-hydroxyapatite, potassium nitrate, sodium monoflurophosphate and antioxidants. The Open Dentistry Journal, Netherlands, v. 27, n. 9, p. 92-97, 2015.

BANOMYONG, D.; KANCHANASANTIKUL, P.; WONG, R. H. Effects of casein phosphopeptide-amorphous calcium phosphate remineralizing paste and $8 \%$ arginine desensitizing paste on dentin permeability. Journal of Investigative and Clinical Dentistry, Richmond, v. 4, n. 3, p. 200-206, 2013.

BARBOUR, M. E.; LUSSI, A. Erosion in relation to nutrition and the environment. Monography in Oral Science, New York, v. 25, p. 143-154, 2014.

BARTLETT et al. The association of tooth wear, diet and dietary habits in adults aged 1830 years old. Journal of Dentistry, Bistrol, v. 39, n. 8, p.811-816, 2011.

BRÄNNSTRÖM, M. The hydrodynamic theory of dentinal pain: sensation in preparations, caries, and the dentinal crack syndrome. Journal of Endodontics, Chicago, v.12, n. 10, p. 453-457, 1986.

CALABRIA, M. et al. Comparative in vitro effect of TiF4 to NaF and potassium oxalate on reduction of dentin hydraulic conductance. Operative Dentistry, Seattle, v. 34, n. 4, p. 427 $432,2014$. 
CAMILOTTI, V. et al. Desensitizing treatments for dentin hypersensitivity: a randomized, split-mouth clinical trial. Brazilian Oral Research, São Paulo, v. 26, n. 3, p. 263-268, 2012.

CAO, Y. et al. Biomimetic mineralisation of phosphorylated dentine by CPP-ACP. Journal of Dentistry, Bistrol, v. 41, p. 818-825, 2013.

CARVALHO, F. G. et al. Protecive effect of calcium nanophosphate and CPP-ACP agents on enamel erosion. Brazilian Oral Research, São Paulo, v. 27. N. 6, p.463-470, 2013.

CARVALHO, T. S. et al. Consensus Report of the European Federation of Conservative Dentistry: erosive tooth wear - diagnosis and management. Swiss Dental Journal, Bern, v. 126, n. 4, p. 342-346, 2016.

CHERMONT, A. B. et al. Effect or prior use of desensitizing agents on bond strength of adhesive systems to human dentin. Pinnacle Medicine; Medical Sciences, Effurun, v. 2, n. 3, p. 559-566, 2015.

CHEUNG, A. et al. The potential for dental plaque to protect against erosion using an in vivo-in vitro model - A pilot study. Australian Dental Journal, Sydney, v. 50, n. 4, p. 228$234,2005$.

CHI, A. C. et al. Oral manifestations of systemic disease. American Family Physician, v. 82, n. 11, p. 1381-1388, 2010.

CHRYSANTHAKOPOULOS, N. A. Prevalence of dentine hypersensitivity in a general dental practice in Greece. Journal of Clinical and Experimental Dentistry, v.3, n.5, p.445-451, 2011.

COMAR, L. P. et al. Impact of experimental nano-HAP pastes on bovine enamel and dentin submitted to a ph cycling model. Brazilian Dental Journal, Ribeirão Preto, v. 24, n. 3, p. 273-278, 2013.

CORRAL, C. et al. Effect of oxalic acid-based desensitizing agent on cervical restorations on hypersensitive teeth: a triple-blind randomized controlled clinical Trial. Journal of Oral \& Facial Pain \& Headache, Hanover Park, v. 30, n. 4, p. 330-337, 2016.

CUMMINS, D. Recent advances in dentin hypersensitivity: clinically proven treatments for instant and lasting sensitivity relief. American Journal of Dentistry, San Antonio, v. 23, p. 3-13, 2010.

DANTAS, L. M. Análise quantitativa e qualitativa da condutância hidráulica da dentina após tratamento com diferentes agentes dessensibilizantes. Estudo in vitro. 2011. 117p. Dissertação (Mestrado). Universidade de São Paulo, Bauru, 2011.

DE MORAES PORTO, I. C. et al. Effect of dentin pretreatment with potassium oxalate: analysis of microtensile bond strengths and morphologic aspects. Microscopy Research and Technique, New York, v. 75, n. 2, p. 239-244, 2012. 
DE-MELO, M. A. et al. The effect of diode laser irradiation on dentin as a preventive measure against dental erosion: an in vitro study. Lasers in Medical Science, London, v. 26, n. 5, p. 615-621, 2011.

DILSIZ, A.; AYDIN, T.; GUNGORMUS, M. Clinical Evaluation of Er:YAG, Nd:YAG, and Diode Laser Therapy for Desensitization of Teeth with Gingival Recession. Photomedicine and Laser Surgery, Larchmont, v. 28, p. S11-S17, 2010. Supplement 2.

ERDEMIR, U. et al. The efficacy of three desensitizing agents used to treat dentin hypersensitivity. Journal of American Dental Association, Chicago, v. 141, n. 3, p. 285 296, 2010.

FAHL, N. Jr. Direct-indirect class V restorations: a novel approach for treating noncarious cervical lesions. Journal of Esthetic and Restorative Dentistry, London, v. 27, n. 5, p. 267-284, 2015.

FEMIANO, F. et al. Effectiveness on oral pain of 808-nm laser used prior to composite restoration for symptomatic non-carious cervical lesions unresponsive to desensitizing agents. Laser in Medical Science, London, online, 2016.

FERREIRA, S. et al. Supplementation of orange juice with dietary proteins to prevent enamel and dentin erosion. Brazilian Dental Journal, Ribeirão Preto, v. 26, n. 3, p. 263 267, 2015.

FERREIRA-VALENTE, M. A., PAIS-RIBEIRO, J. L., JENSEN, M. P. Validity of four intensity rating scales. Pain, Amsterdam, v. 152, n. 10, p. 2399-2404, 2011.

FIELD, J.; WATERHOUSE, P.; GERMAN, M. Quantifying and qualifying surface changes on dental hard tissues in vitro. Journal of Dentistry, Bistrol, v. 38, n. 3, p. 182$190,2010$.

FREITAS SDA, S. et al. Dentin hypersensitivity treatment of non-carious cervical lesions - a single-blind, split-mouth study. Brazilian Oral Research, São Paulo, v. 29, n. 1, p. 16, 2015.

GEORGE, E. et al. Interactions of dentine desensitisers with human dentine: morphology and composition. Journal of Dentistry, Bristol, v. 41, p. 28-39, 2013. Supplement 4.

GOPINATH, N. M. et al. Evaluation of dentifrice containing nano-hydroxyapatite for dentinal hypersensitivity: a randomized controlled trial. Journal of International Oral Health, Ahmedabad, v. 7, n. 8, p. 118-122, 2015.

GRIPPO, J. O.; SIMRING, M.; COLEMAN, T. A. Abfraction, abrasion, biocorrosion, and the enigma of noncarious cervical lesions: a 20-years perspective. Journal of Restorative Dentistry, Londo, v. 24, n. 1, p. 10-23, 2012.

HAN, S. Y. et al. Combined Effects of Er:YAG Laser and Nano-Carbonate Apatite Dentifrice on Dentinal Tubule Occlusion: In Vitro Study. Photomedicine and Laser Surgery, Larchmont, v. 31, n. 7, p. 342-348, 2013. 
HEASMAN, p. a. et al. Evidence for the occurrence of gingival recession and non-carious cervical lesions as a consequence of traumatic tooth brushing. Journal of Clinical Periodontology, Malden, v. 42, p. 237-255, 2015. Supplement 16.

HEURICH, E. et al. Quantification of dental erosion-A comparison of stylus profilometry and confocal laser scanning microscopy (CLSM). Dental Materials, Oxford, v. 26, n. 4, p. 326-336, 2010.

HUANG, S. et al. Remineralization potential of nano-hydroxyapatite on initial enamel lesions: an in vitro study. Caries Research, New York, v. 45, n. 5, p. 460-468, 2011.

KAMOZAKI, M. B. et al. The effect of CPP-ACP and Nd:AG laser on the bond strength of softened dentin. Brazilian Oral Research, São Paulo, v. 29, n. 1, p. 1-7, 2015.

KIM, J. S. et al. Synergistic Effect of dentinal tubule occlusion by nano-carbonate apatite and CO2 laser in vitro. Photomedicine and Laser Surgery, Larchmont, v. 31, n. 8, p. 392397, 2013.

KITASAKO, Y. et al. Age-specific prevalence of erosive tooth wear by acidic diet and gastroesophageal reflux in Japan. Journal of Dentistry, Bistrol, v.43, n. 4, p. 418-423, 2015.

KULAL, R. et al. Na in-vitro comparasion of nano Hydrohyapatite, Novamin and Proargin Desensitizing toothpaste - a SEM study. Journal of Clinical and Diagnostic Research, India, v. 10, n. 10, p. 51-54, 2016.

KUNAM, D. et al. Evaluation of dentinal tubule occlusion and depth of penetration of nanohydroxyapatite derived from chicken eggshell powder with and without addition of sodium fluoride: an in vitro study. Journal of Conservative Dentistry, Amritsar, v. 19, n. 3, p. 239-244, 2016.

KUROIWA, M. et al. Dentin hypersensitivity. Occlusion of dentinal tubules by brushing with and without an abrasive dentifrice. Journal of Periodontology, Chicago, v. 65, n.4, p.291-296, 1994.

LAWSON, N. C. et al. Two-year clinical trial of a universal adhesive in total-etch and selfetch model in non-carious cervical lesions. Journal of Dentistry, Bristol, v. 43, n. 10, p. 1229-1234, 2015.

LEVRINI, L.; DI BENEDETTO, G.; RASPANTI, M. Dental wear: a scanning electron microscope study. BioMed Research International, New York, v. 2014, p. 1-7, 2014.

LIU, Y. et al. In vitro study of dentin hypersensitivity treated by $980-\mathrm{nm}$ diode laser. Journal of Lasers in Medical Science, Tehran, v. n. 3, p.111-119, 2013.

LOPES, A. O.; ARANHA, A. C. C. Comparative evaluation of the effects of Nd:YAG laser and a desensitizer agent on the treatment of dentin hypersensitivity: a clinical study. Photomedicine and Laser Surgery, Larchmont, v. 31, n. 8, p. 392-397, 2013. 
MAHESUTI, A. et al. Short-term efficacy of agents containing $\mathrm{KNO}_{3}$ or CPP-ACP in treatment of dentin hypersensitivity. The Chinese Journal of Dental Research, New Malden, v. 17, n. 1, p. 43-47, 2014.

MEDEIROS, I. C. et al. In vitro effect of calcium nanophosphate and high-concentrated fluoride agents on enamel erosion: an AFM study. International Journal of Paediatric Dentistry, Oxford, v. 24, n. 3, p. 168-174, 2014.

MEHTA, D. et al. Randomized controlled clinical trial on the efficacy of dentin desensitizing agents. Acta Odontologica Scandinavica, Stockholm, v. 72, n. 8, p. 936-941, 2014.

MEIER, M. et al. Nanostructured calcium phosphate (Nano P) technology: innovation on dental desensitisation and remineralization. Journal of Dental Research, Thousand Oaks, v.89 (Spec Iss B): resumo número 4584 (www.dentalresearch.org), 2010.

MIGLANI, S.; AGGARWAL, V.; AHUJA, B. Dentin hypersensitivity: Recent trends in management. Journal of Conservative Dentistry, Amritsar, v. 13, n. 4, p. 218-224, 2010.

MOEZZYZADEH, M.; ALIMI, A. The effect of casein phosphopeptide-amorphous calcium phosphate paste and sodium fluoride mouthwash on the prevention of dentine erosion: An in vitro study. Journal of Conservative Dentistry, Amritsar, v. 17, n. 3, p. 244-249, 2014.

MOEZZYZADEH, M.; MOTAMEDI, S. H. In-vitro evaluation of the effect of CPP-ACP paste on the bond strength of glass ionomer to the tooth structure. Journal of dental School, Tehran, v. 29, p. 260-267, 2011.

NASCIMENTO, M. M. et al. Abfraction lesions: etiology, diagnosis and treatment options. Clinical, Cosmetic and Investigational dentistry, Auckland, v. 3, n. 8, p. 79-87, 2016.

NGUYEN, C et al. A qualitative assessment of non-carious cervical lesions in extracted human teeth. Australian Dental Journal, Sydney, v. 53, n. 1, p. 46-51, 2008.

NONGONIERMA, A. B.; FITZGERALD, R. J. Biofunctional properties of caseinophosphopeptides in the oral cavity. Caries Research, Basel, v. 46, n. 3, 234-267, 2012.

ODEBRECHT, C. M.; LOGUERCIO, A. D.; BOTTAN, E. Clinical Performance of a new nanotechnology-based dental desensitizinhg Professional paste. Journal of Dental Research, Thousand Oaks, v.89 (Spec Iss B): resumo número 1427 (www.dentalresearch.org), 2010.

OLLEY, R. C.; MOAZZEZ, R.; BARTLETT, D. The relationship between incisal/occlusal wear, dentine hypersensitivity and time after the last acid exposure in vivo. Journal of Dentistry, Bristol, v. 43, n. 2, p. 248-252, 2015.

OSHIRO, M. et al. Effect of CPP-ACP paste on tooth mineralization: an FE-SEM study. Journal of Oral Science, Tokyo, v. 49, n. 2, p. 115-120, 2007. 
PÉCORA, J. D.; COSTA, W. F.; MAIA CAMPOS, G. Study of the dentinal permeability of the pulp chamber floor of human lower molars with separate roots. Brazilian Dental Journal, Ribeirão Preto, v. 1, n. 1, p. 17-24, 1990.

PEI, D. et al. Effect of pretreatment with calcium containing desensitizer on the dentine bonding of mild self-etch adhesives. European Journal of Oral Sciences, Copenhagen, v. 121, n. 3, p. 204-210, 2013.

PINNA, R. et al. Clinical evaluation of the efficacy of the one self-adhesive composite in dental hypersensitivity. Clinical Oral Investigation, Berlin, v. 19, n. 7, p. 1663-1672, 2015.

PINTADO-PALOMINO, K.; TIRAPELLI, C. The effect of home-use and in-office bleaching treatments combined with experimental desensitizing agents on enamel and dentin. European Journal of Dentistry, Ankara, v. 9, n. 1, p. 66-73, 2015.

POGGIO, C. et al. Analysis of dentin/enamel remineralization by a CPP-ACP paste: AFM and SEM study. Scanning, New York, v. 35, n. 6, p. 366-374, 2013.

PONDURI, S.; MACDONALD, E.; ADDY, M. A study in vitro of the combined effects of soft drinks and tooth brushing with fluoride toothpaste on the wear of dentine. International Journal of Dental Hygiene, Oxford, v. 3, n. 1, p. 7-12, 2005.

PORTO, I. C.; ANDRADE, A. K.; MONTES, M. A. Diagnosis and treatment of dentinal hypersensitivity. Journal of Oral Science, Tokyo, v. 51, n. 3, p. 323-332, 2009.

PRABHAKAR, A. R.; JAISWAL MANOJKUMAR, A.; BASAPPA, N. In vitro remineralization of enamel subsurface lesions and assessment of dentine tubule occlusion from $\mathrm{NaF}$ dentifrices with and without calcium. Journal of Indian Society of Pedodontics and Prevntive Dentistry, Chandigarh, v. 31, n. 1, p. 29-35, 2013.

RAHIOTIS, C.; VOUGIOUKLAKIS, G. Effect of a CPP-ACP agent on the demineralization and remineralization of dentine in vitro. Journal of Dentistry, Bristol, v. 35, n. 8, p. 695-698, 2007.

RANJITKAR, S. et al. An in vitro assessment of the effect of load and $\mathrm{pH}$ on wear between opposing enamel and dentine surfaces. Archives of Oral Biology, Oxford, v. 53, n. 11, p. 1011-1016, 2008.

RIZZANTE, F. et al. In vitro evaluation of dentin hydraulic conductance after 980nm diode laser irradiation. Journal of Periodontology, Chicago, v. 87, n. 3, p. 320-326, 2016.

SARODE, G. S., SARODE, S. C. Abfraction: a review. Journal of Oral and Maxillofacial Pathology, Chennai, v. 17, n. 12, p. 222-227, 2013.

SAURO, S; WATSON, T. F.; THOMPSON, I. Dentine desensitization induced by prophylactic and air-polishing procedures: an in vitro dentine permeability and confocal microscopy study. Journal of Dentistry, Bristol, v. 38, n. 5, p.411-422, 2010. 
Sawlani, K. et al. Factors influencing the progression of noncarious cervical lesions: a 5year prospective clinical evaluation. The Journal of Prosthetic Dentistry, St. Louis, v. 115 , n. 5 , p. $571-577,2016$.

SCHLUETER, N.; JAEGGI, T.; LUSSI, A. Is dental erosion really a problem? Advances in Dental Research, Washington, v. 24, n. 2, p. 68-71, 2012.

SCHULUETER, N. et al. Methods for the Measurement and Characterization of Erosion in Enamel and Dentine. Caries Research, New York, v. 45, p. 13-23, 2011. Supplement 1.

SCHWENDICKE, F., et al. Comparasion of four methods to assess erosive substance loss of dentin. PloS One, San Francisco, v. 17, n. 9, e. 108064, 2014.

SHARMA, D.; HONG, C. X.; HEIPP, P. S. A novel potassium oxalate-containing toothdesensitising mouthrinse: A comparative in vitro study. Journal of Dentistry, Bristol, v. 41, p. S18-27, 2013. Supplement 4.

SHETTY, S.; KOHAD, R.; YELTIWAR, R. Hydroxyapatite as an in-Office agent for tooth hypersensitivity: A clinical and scanning electron microscopic study. Journal of Periodontology, Chicago, v. 81, n. 12, p. 1781-1789, 2010.

SHIAU, H. J. Dentin Hypersensitivity. The Journal of Evidence-based Dental Practice, St. Louis, v. 12, p. 220-228, 2012. Supplement 3.

SILVA, S. M. et al. Effects of potassium oxalate on knoop hardness of etch-and- rinse adhesives. Operative Dentistry, Seattle, v. 37, n. 4, p. 356-362, 2012.

SOARES, L. E. et al. Erosion effects on chemical composition and morphology of dental materials and root dentin. Microscopy Research and Technique, New York, v. 75, n. 6, p. 703-710, 2012.

STEINER-OLIVEIRA, C et al. Effect of a pulsed CO2 laser and fluoride on the prevention of enamel and dentine erosion. Archives of Oral Biology, Oxford, v. 55, n. 2, p. 127-33, 2010 .

SURI, I. et al. a comparative evaluation to assess the efficacy of 5\% sodium fluoride varnidh and diode laser and their combined application in the treatment of dentin hypersensitivity. Journal of Indian Society of Periodontology, Mumbai, v. 20, n. 3, p. 307-314, 2016.

TANG, B.; MILLAR, B. J. Effect of chewing gum on tooth sensitivity following whitening. British Dental Journal, London, v. 208, n. 12, p. 571-577, 2010.

THANATVARAKORN, O. et al. In vitro evaluation of dentinal hydraulic conductance and tubule sealing by a novel calcium-phosphate desensitizer. Journal of Biomedical Materials Research, Hoboken, v. 101, n. 2, p. 303-309, 2013.

TRUSHKOWSKY, R. D.; OQUENDO, A. Treatment of dentin hypersensitivity. Dental Clinics of North American, Philadelphia, v. 55, n. 3, p. 599-608, 2011. 
TSCHOPPE, P. et al. Enamel and dentineremineralization by nano-hydroxyapatite toothpastes. Journal of Dentistry, Bistrol v. 39, n. 6, p. 430-437, 2011.

UMANA, M. et al. Dentinal tubules sealing by means of diode lasers (810 and $980 \mathrm{~nm})$ : a preliminary in vitro study. Photomedicine and Laser Surgery, Larchmont, v. 31, n. 7, p. 307-314, 2013.

WALKER, G. D. et al. Consumption of milk with added casein phosphopeptideamorphous calcium phosphate remineralizes enamel subsurface lesions in situ. Australian Dental Journal, Sydney, v. 54, n .3, p. 245-249, 2009.

WALTER, c. et al. The anatomy of non-carious cervical lesions. Clinical Oral Investigations, Berlin, v. 18, n.1, p. 139-146, 2014.

WANG, L. et al. Treatment of dentin hypersensitivity using nano-hydroxyapatite pastes: a randomized three-month clinical trial. Operative Dentistry, Seattle v. 41, n. 4, p. 93-101, 2016.

WANG, X. et al. Preventing erosion with novel agents. Journal of Dentistry, Bristol, v. 39, n.2, p. 163-170, 2011.

WEST, N. X.; HUGHES, J. A.; ADDY, M. The effect of $\mathrm{pH}$ on the erosion of dentine and enamel by dietary acids in vitro. Journal of Oral Rahabilitation, Oxford, v. 28, n.9, p. 860-864, 2001.

WIEGAND, A.; ATTIN, T. Randomised in situ trial on the effect of milk and CPP-ACP on dental erosion. Journal of Dentistry, Bristol, v. 42, n.9, p. 1210-1215, 2014.

WOOD, I. et al. Non-carious cervical tooth surface loss: a literature review. Journal of Dentistry, Bristol, v. 36, n. 10, p. 759-766, 2008.

YE, W.; FENG, X. P.; LI, R. The prevalence of dentine hypersensitivity in Chinese adults. Journal of Oral Rehabilitation, Oxford, v. 39, n. 3, p. 182-187, 2012

YILMAZ, H. G. et al. Clinical evaluation of Er,Cr:YSGG and GaAlAs laser therapy for treating dentine hypersensitivity: A randomized controlled clinical trial. Journal of Dentistry, Bristol, v. 39, n. 3, p. 249-254, 2011.

YILMAZ, H. G.; KURTULMUS-YILMAZ, S.; CENGIZ, E. Long-term effect of diode laser irradiation compared to sodium fluoride varnish in the treatment of dentine hypersensitivity in periodontal maintenance patients: a randomized controlled clinical study. Photomedicine and Laser Surgery, Larchmont, v. 29, n. 11, p. 721-725, 2011. 


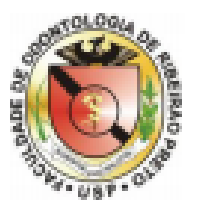

\author{
UNIVERSIDADE DE SÃO PAULO \\ FACULDADE DE ODONTOLOGIA DE RIEEIRÃO PRETO \\ TERMO dE CONSENTIMENTO LIVRE E ESCLARECIDO
}

(Resolução 466/2012 - Conselho Nacional de Saúde)

Eu, Júlia Olien Sanches, portadora do CPF 357.235.898-14, pós-graduanda e pesquisadora responsável pelo projeto de pesquisa intitulado "Efeito dos tratamentos dessensibilizantes no desenvolvimento de lesōes erosivas dentinárias" convido o (a) Sr (a) a participar do referido projeto que será realizado na Faculdade de Odontologia de Ribeirăo Preto sob orientaçăo da Prof" Dra Regina Guenka Palma-Dibb e colaboração da pesquisadora $\mathrm{Dr}^{\mathrm{a}}$. Juliana Jendiroba Faraoni-Romano.

Este trabalho tem como objetivo avaliar clinicamente os efeitos dos tratamentos dessensibilizantes na sensibilidade do dente e na evolução de cavidades que se formam no dente perto da gengiva. O tratamento de suas cavidades será feita com a aplicação de produtos que diminuem a sensibilidade ou com o uso do Laser (uma luz que sai de um aparelho, sem lhe proporcionar nenhum risco).

Você será acompanhado por 7 meses, devendo retornar a Clínica Odontológica da Faculdade para os tratamentos e avaliaç̋̄es. Ao todo serão 7 sessōes sendo as 4 primeiras com intervalo de 7 dias entre elas e as demais 1,3 e 6 meses após o final do tratamento. Os tratamentos serão aplicados em dentes localizados em lados diferentes da boca. Após isso um jato de ar frio será aplicado pelo examinador durante 1 segundo sobre os dentes e o participante irá classificar sua dor de acordo com uma escala. Essa avaliaçăo será realizada em todas as sessões antes e depois da aplicação dos tratamentos. Ao final de cada sessão,as regiōes dos dentes serão moldadas onde será colocada uma massinha dentro da sua boca copiando os dentes para que depois o examinador possa avaliar as cavidades no microscópio.

Você está sendo esclarecido que este tratamento proporciona riscos mínimos, já que não machuca, nåo causa dor, sendo assim não causa riscos para a sua saúde, nem danos aos seus dentes já que năo é uma terapia invasiva. Haverá somente o desconforto da moldagem e durante a avaliação da sensibilidade.

Como benefício, você receberá gratuitamente o devido tratamento para a sensibilidade e os resultados encontrados deste estudo poderåo também ajudar outras pessoas. Não será oferecido nenhum tipo de pagamento pela sua participação na pesquisa, caso necessário será pago o transporte de ônibus municipal e sua alimentação para o seu comparecimento à FORP, todo seu atendimento será gratuito. Sua identidade e seus dados seråo mantidos em segredo, mas participando desta pesquisa, você autoriza que os resultados obtidos sejam divulgados e publicados em revistas cientificas e terá, por parte dos pesquisadores, a garantia do sigilo (segredo) que garantem a sua privacidade.

Você terá total liberdade para pedir maiores esdarecimentos antes e durante o desenvolvimento đa pesquisa. Se tiver qualquer dúvida, você poderá ligar para a pesquisadora responsável para pedir qualquer informação sobre a pesquisa (PG. Júlia Olien Sanches - Avenida do Café, $\mathrm{S} / \mathrm{N}$ - Departamento de Odontologia Restauradora, Dentística Faculdade de Odontologia de Ribeirăo Preto - Tel: 16 3315-4016 ou 16 99202-6404). Suas redamaçōes e/ou insatisfaçőes relacionadas à sua participação na pesquisa poderåo ser comunicadas por escrito à Secretaria do CEP/FORP/USP, devendo conter seu nome que será mantido em sigilo.

A sua participaçå̃o não é obrigatória, e você poderá desistir a qualquer momento, retirando o seu consentimento (autorização). A nåo autorizaçăo deste trabalho não trará 
nenhum prejuizo em sua relação com a pesquisadora ou com a Faculdade de Odontologia de Ribeirão Preto - USP.

Este Termo será confeccionado em duas vias de igual teor, sendo uma mantida com a pesquisadora responsável e a outra deverá ser entregue a você. Todas as páginas do TCLE devem ser rubricadas, com exceçăo da última, que deve ser assinada por todos.

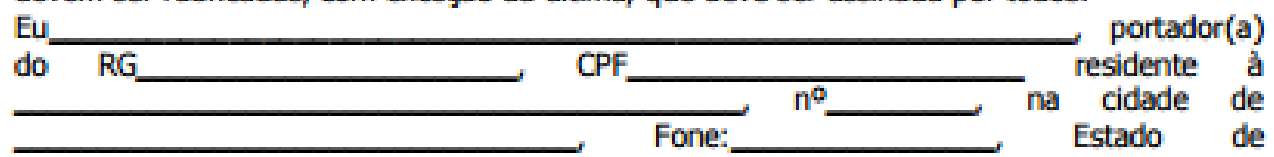

Declaro que li, compreendi e concordo com o presente Termo, por isso assino este documento de livre e espontânea vontade.

Ribeirăo Preto, de de 201

Assinatura do participante

\begin{tabular}{c}
\hline Júlia Olien Sanches \\
CPF 357.235.898-14 \\
Pesquisadora responsável \\
\\
\hline Dr" Juliana Jendiroba Faraoni-Romano \\
CPF 214308568-07 \\
Pesquisadora participante
\end{tabular}

Prof Dra Regina Guenka Palma
Dibb
CPF $145831718-89$
Pesquisadora participante

Pesquisadora participante

Secretária do Comitê de Ética em Pesquisa da FORP

Marcela Scatolin Calache - telefone (16) 3315-0493; e-mail: cep@forp.usp.br

Horário de atendimento da Secretaria: de $2^{\mathrm{a}}$ a $6^{\mathrm{a}}$ feira, das 8 as $12 \mathrm{~h}$

Júlia Olien Sanches (pesquisadora responsável)

Avenida do Café, s/n - Monte Alegre, Ribeirăo Preto - SP - Brasil - CEP: 14040-904

Telefones: (16) 3315-4016, (16) 99202-6404; e-mail: ju-olien@usp.br 